\title{
X-Ray Fluorescence Applications in Mudrock Characterization: Investigations into Middle Devonian Stratigraphy, Appalachian Basin, USA
}

\author{
Keithan Garrett Martin \\ West Virginia University, kgm0002@mix.wvu.edu
}

Follow this and additional works at: https://researchrepository.wvu.edu/etd

Part of the Geology Commons

\footnotetext{
Recommended Citation

Martin, Keithan Garrett, "X-Ray Fluorescence Applications in Mudrock Characterization: Investigations into Middle Devonian Stratigraphy, Appalachian Basin, USA" (2019). Graduate Theses, Dissertations, and Problem Reports. 7462.

https://researchrepository.wvu.edu/etd/7462

This Dissertation is protected by copyright and/or related rights. It has been brought to you by the The Research Repository @ WVU with permission from the rights-holder(s). You are free to use this Dissertation in any way that is permitted by the copyright and related rights legislation that applies to your use. For other uses you must obtain permission from the rights-holder(s) directly, unless additional rights are indicated by a Creative Commons license in the record and/ or on the work itself. This Dissertation has been accepted for inclusion in WVU Graduate Theses, Dissertations, and Problem Reports collection by an authorized administrator of The Research Repository @ WVU. For more information, please contact researchrepository@mail.wvu.edu.
} 
X-Ray Fluorescence Applications in Mudrock Characterization: Investigations into Middle Devonian Stratigraphy, Appalachian Basin, USA

Keithan G. Martin

\author{
Dissertation submitted \\ to the Eberly College of Arts and Sciences \\ at West Virginia University \\ in partial fulfillment of the requirements for the degree of \\ Doctor of Philosophy in \\ Geology
}

Timothy Carr, Ph.D., Chair

Dustin Crandall, Ph.D.

Dengliang Gao, Ph.D.

Shikha Sharma, Ph.D.

Amy Weislogel, Ph.D.

Department of Geology and Geography

Morgantown, West Virginia

2019

Keywords: Geology, Mudrock, Shale, X-Ray Fluorescence, Natural Fractures, Organic Carbon, Trace Metals

Copyright 2019 Keithan Martin 


\section{Abstract \\ X-Ray Fluorescence Applications in Mudrock Characterization: Investigations into Middle Devonian Stratigraphy, Appalachian Basin, USA}

\section{Keithan G. Martin}

Mudrocks are characterized by nanometer-scale pore sizes and nano-darcy permeability, which plays a significant role in hydrocarbon flow during production. Resulting from these characteristics, mudrocks were exclusively considered a source rock, which charged overlying, more porous mediums. Hydraulic fracturing, a technology used to create artificial fractures to liberate hydrocarbons from the reservoir, enabled natural gas to be produced from mudrock reservoirs economically. Over the last fifteen years, this technology motivated research efforts to understand reservoir characteristics of mudrock. These investigations significantly improved our knowledge of mudrock systems, but have also highlighted key areas that are undeveloped and/or where conflicting hypotheses exist. Utilizing wave-dispersive X-ray fluorescence (XRF) and highresolution handheld energy-dispersive X-ray fluorescence (hhEDXRF) datasets collected from seven middle Devonian core throughout the Appalachian basin, this dissertation focuses on three areas of mudrock research: (1) development of mudrock calibrations to increase the analytical quality of hhEDXRF datasets, (2) investigation into the relationship between chemical composition of the host rock and natural fracture presence, and (3) assessment of the relationship between paleo-depositional conditions and organic carbon enrichment. This research indicates that lithology-specific calibrations significantly increase the analytical quality of hhEDXRF datasets, natural fractures preferential concentrate in zones of similar composition in a predictable manner, and an interplay of limited dilution and a robust anoxia-productivity feedback mechanism controlled organic carbon enrichment within middle Devonian mudrock of the Appalachian basin. 


\section{Acknowledgements}

This research was supported by West Virginia University (WVU) Department of Geology and Geography, National Energy Technology Laboratory (NETL), West Virginia Geological Survey (WVGS), Triana Energy, and Eclipse Resources. Funding sources included the U.S. Department of Energy - NETL (as a part of their Marcellus Shale Energy and Environmental Laboratory (MSEEL) project (DOE Award No.: DE-FE0024297) and WVU Department of Geology and Geography.

I would like to thank my advisor and mentor, Dr. Timothy Carr, for accepting me into his research group, providing me with a research assistantship, and for giving me creative liberty within my research. I would also like to thank the following past graduate students at WVU for their friendship and support; Liaosha Song, Payam Kavousi, and Thomas Paronish.

My family has encouraged and supported me throughout my graduate studies at WVU, and I thank them very much for this support. Finally, I would like to thank my wife, Kaiti, for supporting me over the last three years and for taking care of our son, Harvey, during the final semester of my $\mathrm{PhD}$. 


\section{Preface - A note on organization}

This manuscript is comprised of three stand-alone papers/chapters (chapters 2-4). Chapter 2, titled "Developing a quantitative regression-based mudrock calibration for a handheld energy dispersive X-ray fluorescence spectrometer", is under review with a peer-reviewed journal and will be referred to as "Martin and Carr (under review)" when referenced in following chapters. Chapter 3, titled "Relationships between Lineal Fracture Intensity and Chemical Composition in the Marcellus Shale, Appalachian Basin," was accepted for publication by Interpretation, a peerreviewed journal co-published by Society of Exploration Geophysicists (SEG) and American Association of Petroleum Geologists (AAPG), and was published November 2019. To fit the style of this manuscript, table and figure numberings have been altered, but no substantive changes have been made to the publication. Chapter 4, titled "Controls on Organic Matter Accumulation and Preservation: An Investigation into the Marcellus Shale, Appalachian Basin, USA", is in preparation for submission to a peer-reviewed journal. 


\section{Data Availability}

All supporting data for this dissertation are located at http://mseel.org/research. 


\section{Table of Contents}

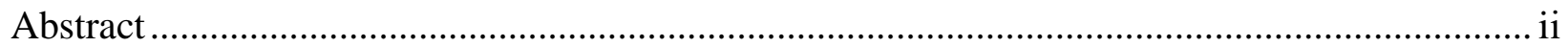

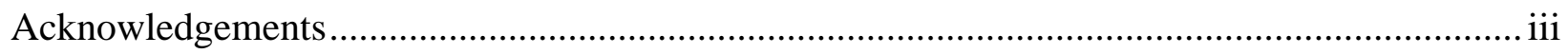

Preface - A note on organization .................................................................................... iv

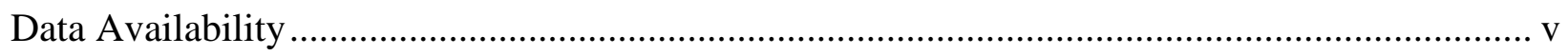

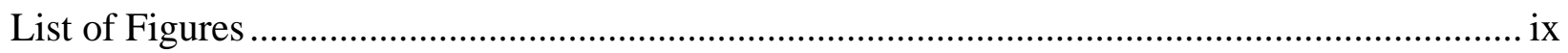

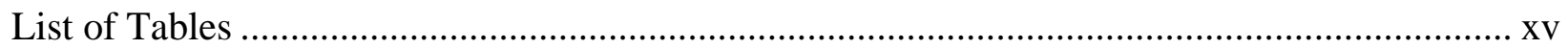

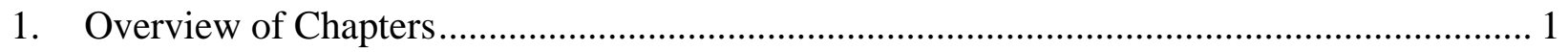

2. Developing a quantitative regression-based mudrock calibration for a handheld energy dispersive X-ray fluorescence spectrometer ................................................................ 3

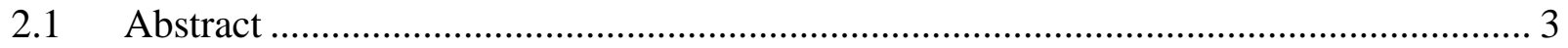

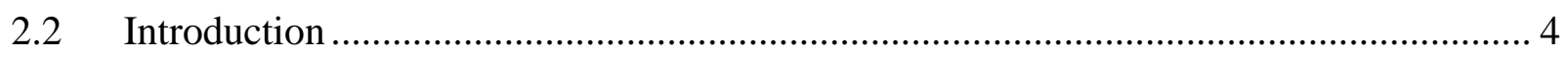

2.2.1 Handheld EDXRF technology in geological sciences ..................................... 4

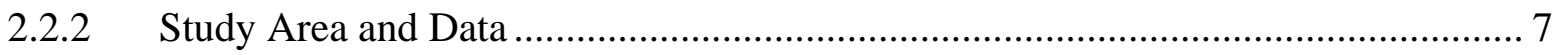

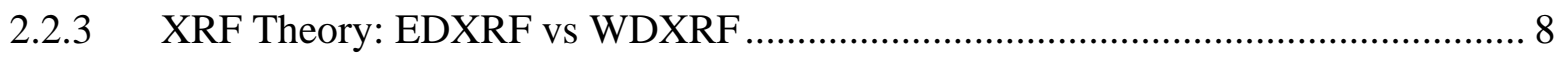

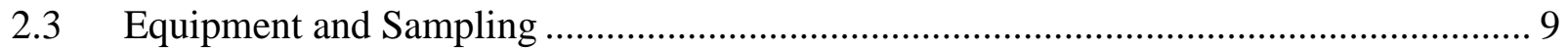

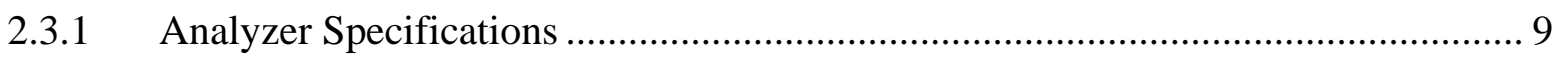

2.3.2 WDXRF Specifications and Sample Preparation ............................................ 11

2.3.3 Defining clusters via Hierarchical Cluster Analysis ...................................... 13

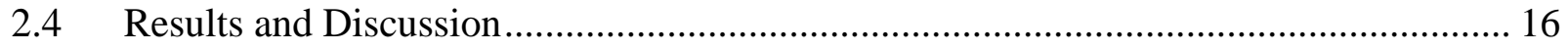

2.4.1 Mudrock Calibration - hhEDXRF vs. WDXRF........................................... 16

2.4.2 Analyzer Drift and Precision ............................................................. 21

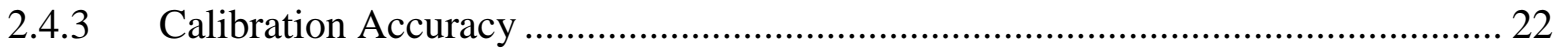




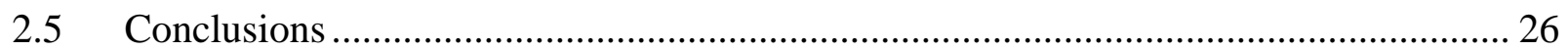

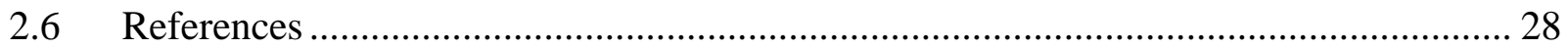

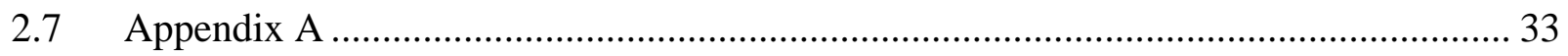

3. Relationships between Lineal Fracture Intensity and Chemical Composition in the Marcellus

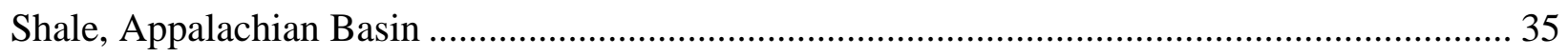

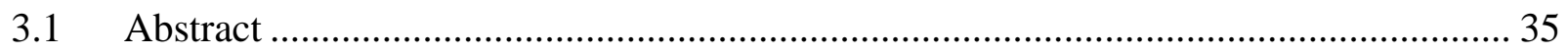

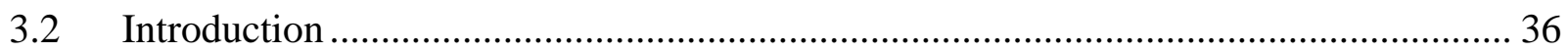

3.2.1 Middle Devonian Stratigraphy of the Appalachian Basin ...................................... 39

3.2.2 Study Area and General Character of Core ......................................................... 40

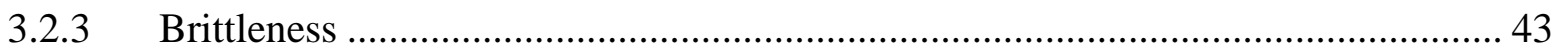

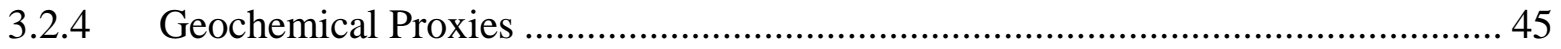

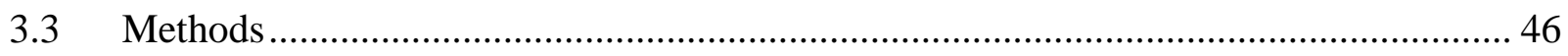

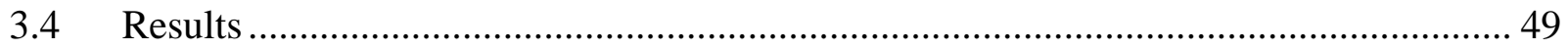

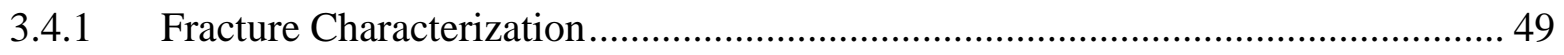

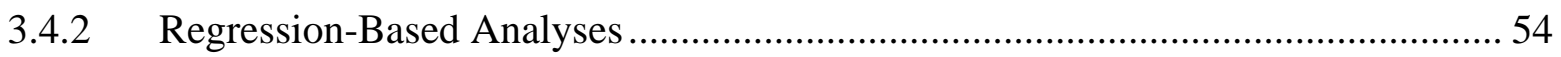

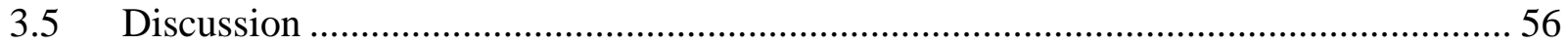

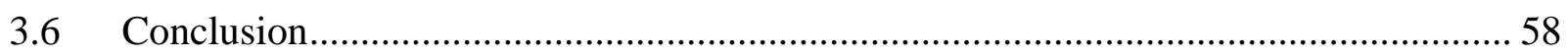

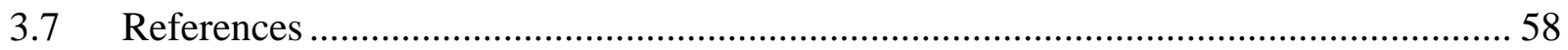

4. Controls on Organic Matter Accumulation and Preservation: An Investigation into the

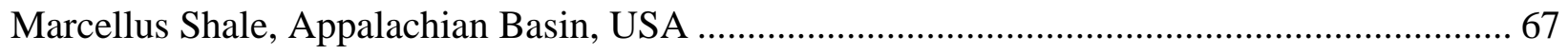

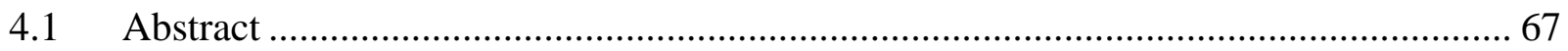

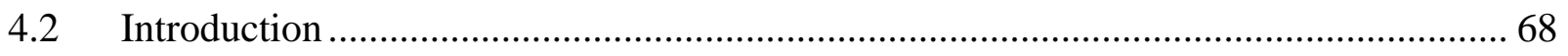

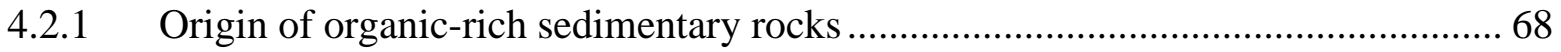


4.2.2 Stratigraphic Nomenclature .................................................................. 74

4.2.3 Rock Classification and Characterization ...................................................... 76

4.3 Overview of Elemental Geochemical Proxies .................................................. 83

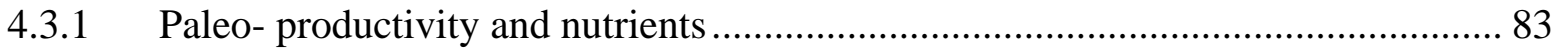

4.3.2 Anoxia and Euxinia............................................................................... 84

4.3.3 Dilution - Detrital Influx and Carbonate Enrichment .................................... 87

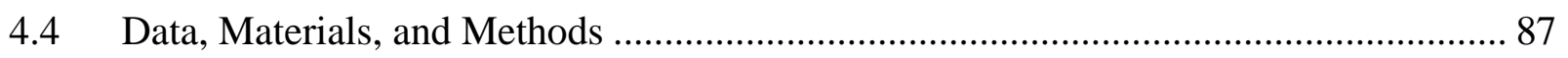

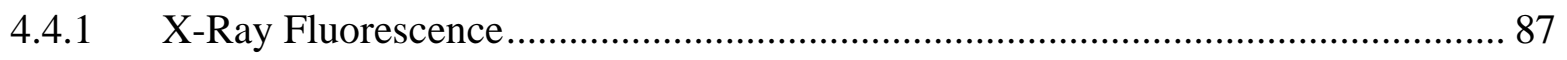

4.4.2 C/H/N/S Elemental Analysis ............................................................ 88

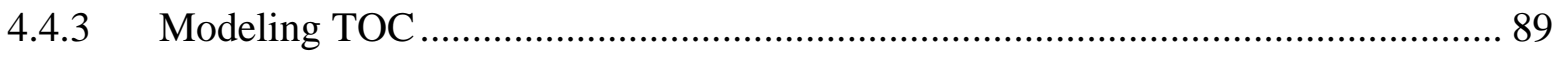

4.4.4 Hierarchical Cluster Analysis ............................................................... 90

4.4.5 Defining Enrichment/Depletion............................................................ 91

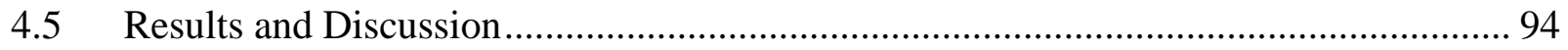

4.5.1 Establishment of Proxy Elements and Elemental Groups ................................. 94

4.5.2 Paleo-depositional Conditions ................................................................ 95

4.5.3 Covariation of Elements and Elemental Proxy Groups with TOC ..................... 103

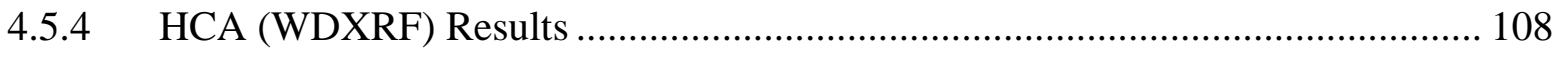

4.5.5 Control on Organic Carbon Enrichment/Depletion ....................................... 117

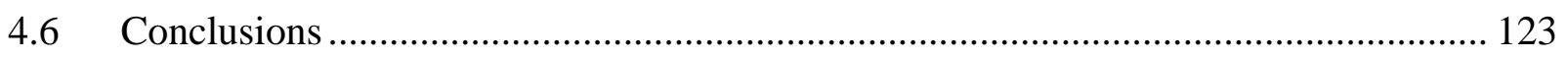

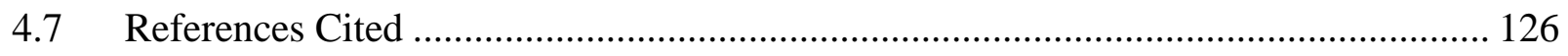

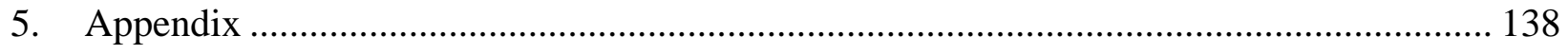

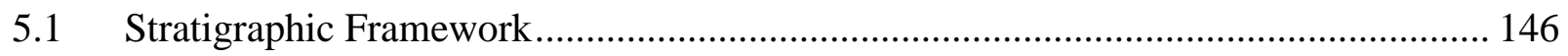




\section{List of Figures}

Figure 2-1. The area of study, referenced by the rectangle, is shown in an expanded view, highlighting the four cored wells, represented by black dots, used in this study. The area of study is located in the central Appalachian Basin (AB). The AB is illustrated as dashed lines and the

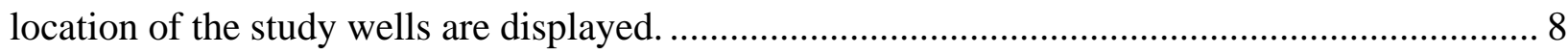

Figure 2-2. Bar graph of number of samples collected from each formation within each well. .... 8

Figure 2-3a, b. a) An X-Y plot showing distance relative to number of clusters. The black rectangle highlights where the cluster cut off was drawn based on distances between points. b) Constellation plot illustrating the relative distance (degree of dissimilarity) between clusters and the samples that are within each of the nine clusters.

Figure 2-4 (A-O). X-Y scatter with line of best fit and corresponding r2, slope, Y-intercept, and root mean square error (RMSE) values displayed for each element. The X-axis and Y-axis represents elemental values collected from the hhEDXRF and WDXRF, respectively.

Figure 2-5 (A-O). Well Name and corresponding depths (X-axis) and elemental concentrations (wt.\% and ppm) from the calibrated hhEDXRF and the WDXRF (Y-axis). The log view shows the change in elemental concentrations relative to depth and highlights the strong correlation between measured concentrations from the calibrated hhEDXRF and the WDXRF. 21

Figure 2-6. Plot of Ca versus percent difference demonstrating the concentration effect and the reliable detection limit (RDL). The RDL is defined at the concentration level of Ca where all following values are $<20 \%$ difference. 25 
Figure 2-7. Plot of $\mathrm{Al}$ versus percent difference demonstrating the non-existence of the concentration effect as a result of not approach the RDL for this specific element in the measured samples. The absence of relationship between the concentration of $\mathrm{Al}$ and the percent difference is demonstrated. 25

Figure 3-1. (a) United States map displaying the location of Study Well No. 1 within the Appalachian basin. The Appalachian basin, "AB", is represented by the dashed polygon. The skewed rectangle represents the study area for this research; (b) an expanded view of the study area, highlighting the location of Well No. 1 in West Virginia. The dashed lines represent the margins of the Appalachian basin. 41

Figure 3-2. Composite of general characteristics of core from Study Well No. 1 and 2 displaying the formations, lithology, texture profile and gamma ray signature. 42

Figure 3-3A, B, and C. A, B, and C) Crossplot of elemental data ( $\mathrm{Si}, \mathrm{Ca}$, and $\mathrm{Al}$ ) collected from WDXRF and HHXRF with R-square values on display. D) Crossplot of TOC and uranium with the R-square value on display. 48

Figure 3-4. Display of the variety of natural and open fractures defined in this study. All mineralized fractures are infilled with calcite. A - Semi-compacted vertical mineralized fracture; B and C - Vertical to sub-vertical open fracture; D - Sub-vertical to bedding parallel open fractures; E - Vertical mineralized fractures; F - Sub-vertical mineralized fractures; G - Bedding parallel mineralized and open fractures. 50

Figure 3-5. Starting on the left, fracture intensity of open, mineralized, and natural (total) fractures are displayed relative to depth. The color gradient indicates intervals that have higher frequency 
of fractures within a half-foot window, with white representing low to no fractures and increasing intensity becoming progressively darker. $\mathrm{Si}, \mathrm{Al}$, and $\mathrm{Ca}$ are displayed as individual data points and a smoothed curve to highlight gross trends. Formations (Fm) are located on the far right, with "Ch. V.” abbreviating Cherry Valley. 52

Figure 3-6A, B, and C. Display of three core intervals, including core photos, core CT scans, and normalized elemental concentrations (unitless). 53

Figure 3-7. Cross plot displaying P10 predicted from the least partial square analysis on the y-axis and P10, which represents natural fracture intensity derived from core evaluation, on the x-axis.

Figure 3-8. Log view showing the correlation between P10 predicted from plot the least partial square analysis in light gray and P10, which represents natural fracture intensity derived from core evaluation, in black. 55

Figure 4-1. United States map displaying the location of the Marcellus Shale within the Appalachian basin across the states of Pennsylvania, West Virginia, and Ohio, represented by the dashed polygon. The expanded view of the study area shows the location of the seven study wells.

Figure 4-2. TST $=$ transgressive systems tract, $\mathrm{RST}=$ regressive systems tract, $\mathrm{T}-\mathrm{R}=$ transgressive - regressive, $\mathrm{MRS}=$ maximum regressive surfaces, $\mathrm{MFS}=$ maximum flooding surfaces. Sequence stratigraphic framework modified from Lash and Engelder (2011). 75

Figure 4-3. A) hhEDXRF, and B) WDXRF data points determined for this study populating the ternary defined by $\mathrm{Si}, \mathrm{Ca}$ and $\mathrm{Al}$ was modified from Gamero et al. (2012). 78 
Figure 4-4. Distribution of ternary-derived facies within the study intervals 82

Figure 4-5A, B. Mechanistic illustration of trace metal and organic carbon accumulation in both an (a) oxic and (b) anoxic setting. 85

Figure 4-6. Graphic displaying the three more significant contributors to organic matter deposition and preservation. Also the elements used to approximate dilution, primary productivity, and redox state, along with numerous references from literature on the veracity of use of each element for specific depositional conditions (dilution, primary production, and decomposition summary recreated from Sageman (2003)). 86

Figure 4-7. A) Graph of TOC (EA) versus modeled TOC. B) Graph of residuals versus modeled TOC. C) Variable importance, the absolute value of each component's t-statistic, as determined from the coefficients calculated in the regression model 90

Figure 4-8. Variable clustering displaying column variables (elements) clustering. Dashed line represents pruning line 95

Figure 4-9 (A-D). Cross plot of Mo/Al, U/Al, V/Al, and Mn versus TOC (wt. \%), with the defined euxinic, anoxic, and suboxic to oxic thresholds. 99

Figure 4-10. Constellation plots illustrating the relationship between the 6-cluster grouping (first order) and the 16-cluster grouping (second order). 105

Figure 4-11. Table displaying the relative enrichment/depletion (SPM) of elements per cluster. Values greater than one represent an enrichment and are marked by the black horizontal line. 106 
Figure 4-12. Table displaying the enrichment/depletion of elements per cluster relative to AS. Values greater than one represent an enrichment and are marked by the black horizontal line. 107

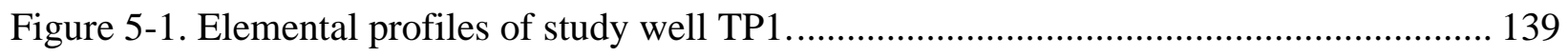

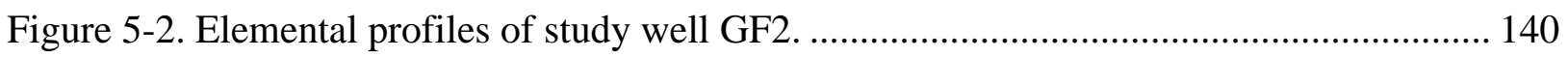

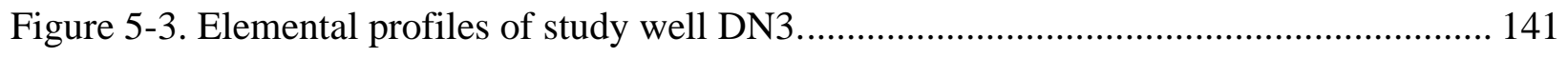

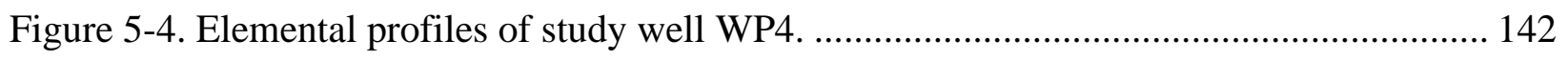

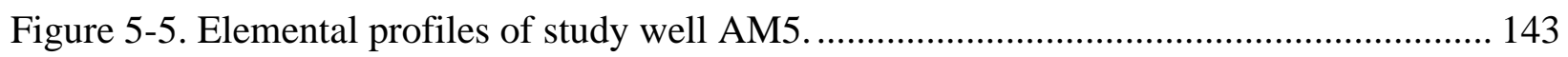

Figure 5-6. Elemental profiles of study well MP6.................................................................. 144

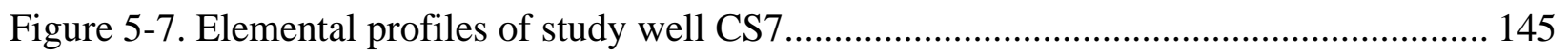

Figure 5-8: Table displaying the relative enrichment/depletion (SPM) of elements per cluster for the hhEDXRF dataset. Values greater than one represent an enrichment and are marked by the black horizontal line. 147

Figure 5-9: Table displaying the relative enrichment/depletion (SPM) of elements per cluster for the hhEDXRF dataset. Values greater than one represent an enrichment and are marked by the black horizontal line. 148

Figure 5-10: 100\% stack bars displaying the percent each cluster makes up within the study intervals for each respective study well. Color-coding; orange/yellow = enriched detrital proxy elements, blue=enriched carbonate proxy elements, pink $=$ enriched anoxia proxy elements, purple $=$ enriched productivity proxy elements. 
Figure 5-11: Northwest-southeast cross section of study wells GF2, DN3, AM5, WP4, and CS7 displaying cluster presence per depth. 150

Figure 5-12: East-west cross section of study wells TP1, WP4, and MP6. Color-coding; orange/yellow $=$ enriched detrital proxy elements, blue=enriched carbonate proxy elements, pink $=$ enriched anoxia proxy elements, purple $=$ enriched productivity proxy elements. Display cluster presence per depth... 


\section{List of Tables}

Table 2-1. Determination limit, calibration, and validation based on CRMs for each element and their respective standard error of estimate (SEE). Values from Conrey (2018). 11

Table 2-2. Comparison of cluster means collected from the hhEDXRF, both raw and calibrated (cal.), and from the WDXRF. 15

Table 2-3. Linear regression statistics from regression analysis of hhEDXRF vs. WDXRF for each element. Minimum and maximum values for each element are from the calibrated hhEDXRF values. All $\mathrm{P}_{\text {values }}$ were $<0.0001$. 17

Table 2-4. For each target element, percent difference (\%Diff) between the calibrated hhEDXRF and WDXRF values. For elements with values below the RDL, the RDL, average percent difference of values $>$ RDL (>RDL Av. \%Diff), number of samples $>$ RDL are displayed. Element that do not have concentrations that approach the RDL are denoted as "na", meaning the RDL is "not achieved.".

Table 4-1. Study well information - Formation abbreviations: ON=Onondaga, LM=Lower Marcellus, MM=Middle Marcellus, UM=Upper Marcellus, MT=Mahantango. 73

Table 4-2. Facies (number) and sub-facies (number with decimal) and their respective number of occurrences (n) within the seven cored intervals. Medium dark gray to medium gray abbreviated as MDG and MG, and grayish black to dark gray is abbreviated as GB to DG. 79

Table 4-3. Average shale values as defined by Wedepohl $(1971,1991)$ 92 
Table 4-5. Total organic carbon and $\delta 13 \mathrm{C}_{\text {org }}$ average and standard deviation per formation. ..... 97

Table 4-6. Percent of redox facies samples (n) for each study interval................................... 98

Table 4-7. Correlation table of detrital proxy elements.................................................... 101 


\section{Overview of Chapters}

A marked increase in unconventional exploration over the fifteen years has significantly improved our knowledge of mudrock systems but has also highlighted areas that are underdeveloped. Depositional and spatial distribution of Middle-Devonian organic-rich facies results from a dynamic process that requires the integration of numerous methodologies to create an accurate representation of the reservoir. This manuscript is comprised of three research papers on the middle Devonian Marcellus Shale of the Appalachian Basin, with the overarching theme of demonstrating the utility of wave-length dispersive X-ray fluorescence (WDXRF) and high-resolution handheld energy-dispersive X-ray fluorescence (hhEDXRF) as a means to facilitate better understanding of mudrock stratigraphy.

First, the creation of a calibration for the hhEDXRF analyzer used for data collection is

discussed in Chapter 2. The primary goal of this chapter is to derive a methodology to create a lithology/formation specific calibration for a hhEDXRF. This methodology is communicated through developing a mudrock calibration on 64 samples from four core throughout the central Appalachian basin. Elemental composition of 64 samples were quantified using both a hhEDXRF analyzer and a quantitatively superior bench-top WDXRF. Utilizing linear regression, the hhEDXRF-derived elemental values were calibrated to the WDXRF-derived values. Such a calibration allows researchers to combine the superior rapid data collection and non-destructive testing abilities from the hhEDXRF with the high-precision/high-accuracy WDXRF. The mudrock calibration is utilized in the following chapters to improve the analytical quality of the highresolution hhEDXRF dataset collected for this research.

Second, the relationship between natural fracture and the chemical composition of the rock matrix hosting the natural fracture is discussed in Chapter 3. The primary goal of this chapter is to 
increase predictability of natural fractures in the subsurface. Natural fractures form as a result of numerous geologic factors, such as paleo-stress, pore pressure, tectonism, fluid movement, differential compaction, catagenesis, etc., all of which make prediction of natural fractures difficult. This chapter demonstrates that the chemical composition of the host rock alone plays a significant role on natural fracture presence. Opposed to geologic factors such as a paleo-stress and tectonism, chemical composition is much easier to quantify with high accuracy, allowing for the prediction of natural fractures that are otherwise difficult to locate. The relationship between chemical composition of the host rock and natural fractures are explored through completing a linear regression between two datasets; (1) high resolution hhEDXRF data collected on a middle Devonian mudrock core from the central Appalachian basin and (2) a continuous P10 (lineal fracture intensity) curve derived from a natural fracture characterization on the same middle Devonian mudrock core.

In Chapter 4, controls on organic carbon accumulation and preservation in mudrock are discussed. Utilizing datasets collected from both WDXRF and high-resolution hhEDXRF on seven cored wells throughout the Appalachian basin, elements and elemental groups are used as proxies to infer paleo-conditions during the deposition of middle Devonian mudrock (Marcellus Shale and Mahantango Formation). Combined with other statistical methods, hierarchical cluster analysis is used to assess the interrelationships between elements and elemental proxies and total organic carbon (TOC) simultaneously to determine the impact of dilution, productivity, and degree of bottom water oxygenation on organic-rich mudrock formation. 


\section{Developing a quantitative regression-based mudrock calibration for a handheld energy dispersive X-ray fluorescence spectrometer}

Keithan G. Martin¹: kgm0002@mix.wvu.edu

Timothy R. Carr¹: tim.carr@mail.wvu.edu

${ }^{1}$ Department of Geology and Geography, West Virginia University, Morgantown, WV 26506

\subsection{Abstract}

Handheld energy dispersive X-ray fluorescence (hhEDXRF) spectrometers enable rapid and nondestructive means of quantifying the elemental composition of rock. Combined with such ability, advances in hhEDXRF technology have resulted in their widespread usage in the geological sciences. Currently, most popular hhEDXRF's lack lithology-specific calibrations and in turn acquire datasets with high precision but in many cases unknown or low accuracy. This study derives a methodology to create an internal regression-based mudrock calibration for a hhEDXRF analyzer, with the aim of increasing the analytical quality of elemental data collected from mudrock core and outcrop. For this study we utilize 64 compositionally diverse Middle Devonian mudrock samples from four cored locations within the central Appalachian basin. Samples were analyzed on both a handheld energy dispersive XRF (hhEDXRF) and a quantitatively superior bench-top wavelength-dispersive XRF (WDXRF) spectrometer. Utilizing linear regressions, hhEDXRF values were calibrated to the values of the WDXRF for individual elements. Measurements from the two XRF modes record the following coefficients of determination: $\mathrm{Zn}$, Mo, and $\mathrm{Ca}\left(\mathrm{r}^{2}>0.99\right), \mathrm{Al}, \mathrm{K}, \mathrm{Ti}, \mathrm{Fe}, \mathrm{Ni}, \mathrm{V}, \mathrm{Cu}$, and $\mathrm{Pb}\left(\mathrm{r}^{2}>0.92\right), \mathrm{Zr}$ and $\mathrm{Si}\left(\mathrm{r}^{2}>0.78\right)$, and $\mathrm{Cr}$ $\left(r^{2}=0.56\right)$. To assess precision, relative standard deviations (RSD) were calculated for each element 
from repeated measurements collected on internal reference samples. All elements recorded RSD values of $<8.8 \%$, excluding $\mathrm{Cr}$, which recorded values of $14-25 \%$. $\mathrm{Mg}, \mathrm{Cl}$, and $\mathrm{Ag}$ were below the limit of detection by the hhEDXRF and thus RSD values could not be computed. To assess hhEDXRF accuracy, we propose an "iterative blind test" approach, which quantifies accuracy through deriving the percent difference between the calibrated hhEDXRF value, derived from the blind test, and WDXRF values for each element. $\mathrm{Si}, \mathrm{Ti}, \mathrm{Al}, \mathrm{Fe}, \mathrm{Ni}, \mathrm{Cu}, \mathrm{Zn}$ record percent difference values of less than $10 \%$. $\mathrm{Zr}$. For $\mathrm{Mn}, \mathrm{Ca}, \mathrm{Cr}, \mathrm{V}, \mathrm{Mo}$ and $\mathrm{Pb}$, a minority of samples $(<13 \%$ on average) record concentrations below their reliable detection limit (RDL). Following the exclusion of these points, the elements record percent difference values between 6-15\%. Potassium recorded measurements outside of the RDL and was the only element that returned percent difference values of $>20 \%$, outside of the acceptable limit. The internal mudrock calibration approach enables investigators to utilize a hhEDXRF to use rapid and non-destructive processes to create high analytical quality datasets for more robust analyses to use in geological studies.

\subsection{Introduction}

\subsubsection{Handheld EDXRF technology in geological sciences}

Handheld energy dispersive X-ray fluorescence (hhEDXRF) analyzers have become a popular tool for determining both the major and trace elemental composition in a wide range of geological studies (Shi et al., 2018; Nulty et al., 2018; Yarbrough et al., 2019). Their acceptance within geological fields can be attributed to their portability, cost effectiveness, rapid data acquisition due to low run time (30-120 seconds), and non-destructive testing capabilities (Croudace et al., 2006). In the past, these benefits came at the cost of gathering lower quality data that lacked accuracy and covered a limited elemental suite (Fitton, 1997). More recent advances in hhEDXRF technology, such as dual energy beam capabilities, silicon drift detectors, and more robust processing, have 
increased the analytical quality of the data and expanded the number of elements determinable (Rowe et al., 2012).

The elemental analysis provided by handheld EDXRF technology is an important tool for augmenting sedimentary core evaluations (Lash and Blood, 2014; Schovsbo et al., 2018; Zhang et al., 2019). Traditionally, in addition to qualitative inspection and analysis of core, low-vertical resolution (every few feet) samples would be taken from the core, powdered, and analyzed with an X-ray diffraction spectrometer or benchtop XRF to delineate mineralogical or elemental variation, aiding lithology and facies determinations. The destructive nature of such testing and lengthy laboratory turnaround time imposes a severe practical limit on the number of samples were typically collected. The result produces a high-quality individual sample data typically with lowvertical resolution (every few feet), leading to a coarser description of the facies and sequences present in the core. The non-destructive and low-run time ( $<120$ seconds) capabilities of hhEDXRF enables the collection of a quality geochemical dataset at finer-scale vertical resolution in a fraction of the time (Croudace et al., 2006). Handheld EDXRF technology is now routinely used on slabbed drill cores to augment traditional sedimentologic evaluations and aiding lithology and facies determination through illuminating geochemical contrasts within the core. High-vertical resolution geochemical datasets have become especially popular in characterizing mudrock, which often appear to lack noticeable distinguishing sedimentologic characteristics (e.g., Rothwell and Rack, 2006; Mainali, 2011; Lowemark et al., 2011; Rowe et al., 2012; Lash and Blood, 2014).

Current hhEDXRF analyzers provide precise, repeatable data, but in many cases lack accuracy for elemental concentrations due to the absence of lithology-specific calibrations. Handheld EDXRF manufacturers create a robust analyzer with the capability of returning compositional data on a variety of materials, such as soil, rock, cement, metal alloys, commercial 
materials, etc. While robust, such generalized abilities lead to datasets that have great precision with a consistent "trend" but within certain materials the hhEDXRF often returns values with low accuracy (i.e., incorrect absolute elemental concentration values), due to numerous variables affecting the hhEDXRF response. Kalnicky and Singhvi (2001) found that the following factors affect the hhEDXRF response; (1) detector resolution and its relationship to spectral interferences; (2) matrix effects from the sample; (3) accuracy and suitability of calibration standards, (4) sample morphology, such as particle size and heterogeneity of the sample, and (5) sample measurement geometry. Careful sample preparation and analysis, such as sufficiently homogenizing samples, collecting multiple data points within a sample to better represent sample composition, ,reducing the large grain or "nugget" effect by creating a smooth sample surface, and maintaining level contact between sample and analyzer can significantly reduce sampling effects on the hhEDXRF response. Even with application of these best practices, the absence of lithology-specific calibrations has a negative impact on the analytical quality of hhEDXRF datasets. Among popular hhEDXRF's, this research found that the Bruker AXS TRACER III-V ED-XRF is the only analyzer with a lithology-specific mudrock calibration (Rowe et al., 2012). In the case where other popular hhEDXRF's are used, mudrock investigators must rely on data with uncertain accuracy and are reduced to using trends and/or ratios of individual or groups of elements. Uncertain elemental accuracy results in research that uses data that is internally consistent but is difficult to replicate in additional studies unless the same XRF analyzer make and model is used. To combat this issue, mudrock calibrations need to be created for individual hhEDXRF's to ensure validity. The purpose of this study is to detail a methodology for creating an internal lithology-specific calibration. This methodology will be demonstrated through a case study, where we create a mudrock calibration for the Olympus Innov-X DELTA Premium Handheld X-ray Fluorescence 
Analyzer for middle Devonian mudrock within the central Appalachian basin. We demonstrate that this internal calibration improves the accuracy, creating a more reliable elemental dataset that can be utilized in future studies of mudrocks.

\subsubsection{Study Area and Data}

This study utilizes 64 compositionally diverse core samples from four Middle Devonian mudrock cores, representing the Hamilton Group. The lower section of the Hamilton Group is referred to as the Marcellus Shale, which is broken into three units; Union Springs Member, which is overlain by the Cherry Valley/Purcell Limestone, and Oatka Creek Member. These units will be informally referred to as the upper (Oatka Creek Member), middle (transition between Oatka Creek Member and Union Springs Member, and lower Marcellus shale (Union Springs Member). Within the Hamilton Group, overlying the Marcellus Shale is the Mahantango Formation. Four cores, located in the central Appalachian Basin (figure 2-1), were utilized to create a mudrock calibration for the Olympus Innov-X DELTA Premium Handheld XRF Analyzer. Figure 2-2 displays the number of samples collected from each formation within each well.

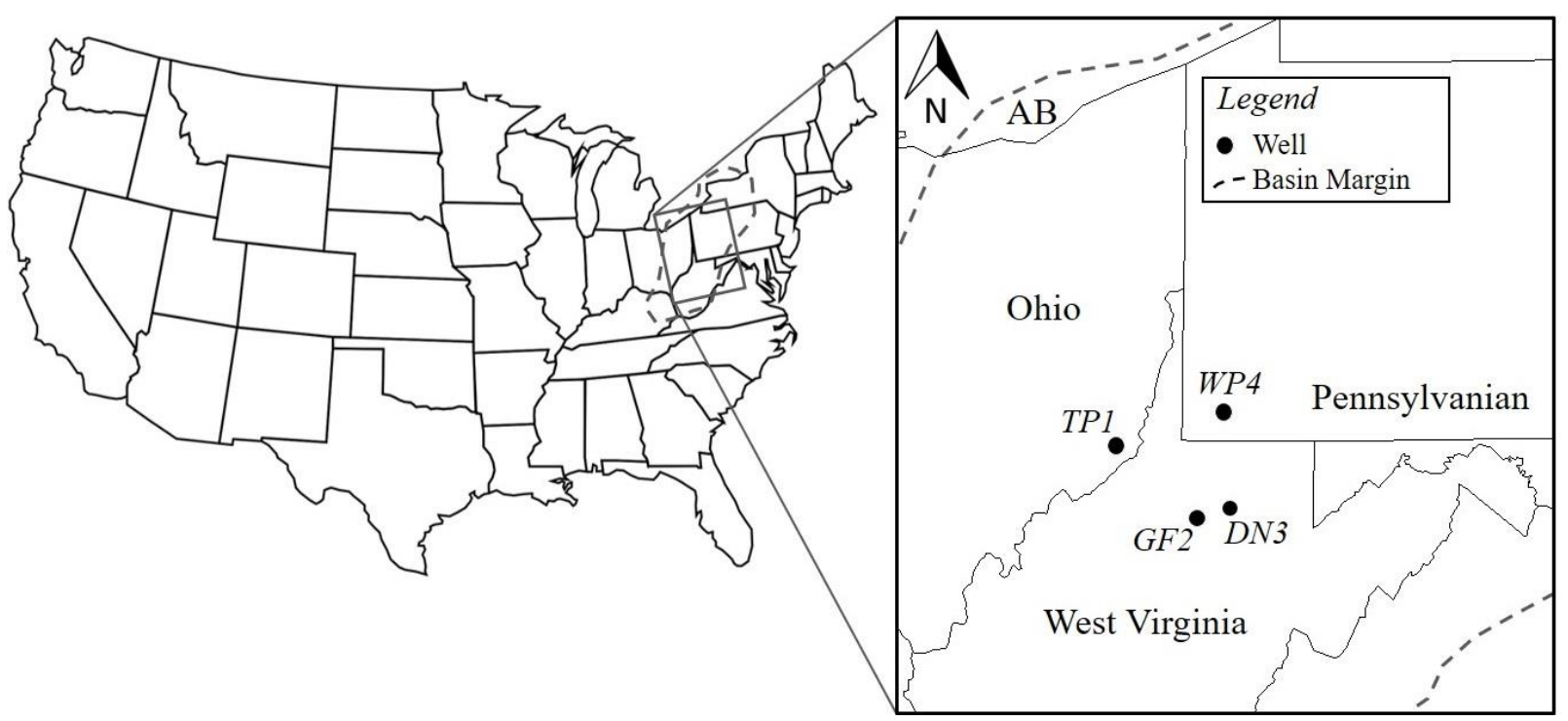


Figure 2-1. The area of study, referenced by the rectangle, is shown in an expanded view, highlighting the four cored wells, represented by black dots, used in this study. The area of study is located in the central Appalachian Basin (AB). The AB is illustrated as dashed lines and the location of the study wells are displayed.

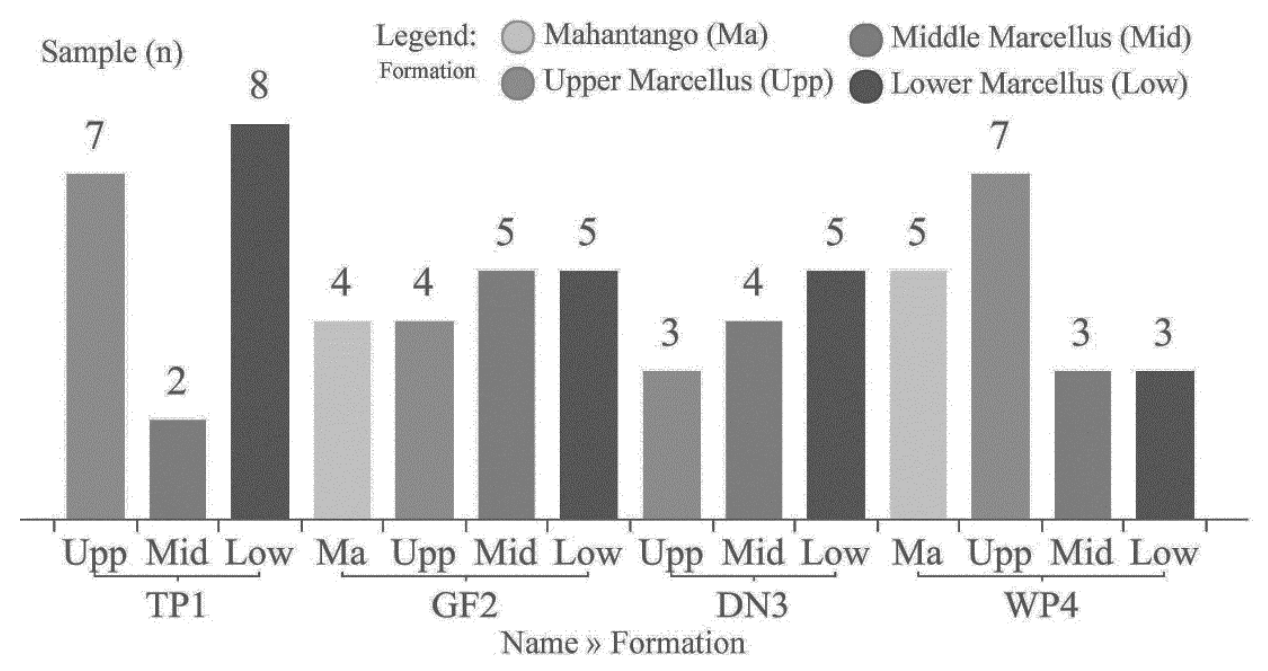

Figure 2-2. Bar graph of number of samples collected from each formation within each well.

\subsubsection{XRF Theory: EDXRF vs WDXRF}

$\mathrm{X}$-ray fluorescence (XRF) spectroscopy is an analytical technique used to determine a wide range of major and trace elements with detection limits in the tens of parts per million range (Lash and Blood, 2014). During XRF analysis, a sample is irradiated by high-energy photons emitted by the XRF analyzer, displacing electrons in the inner orbital shell of an atom, normally the "K-shell" (Brouwer, 2006). This displacement only takes place if the photons emitted into the sample have a higher energy than the energy holding the electron in the K-shell. Once the electron is ejected from the K-shell, the atom becomes unstable, and an electron from a higher orbital shell, normally the "L-shell" or "K-shell" moves down to the newly created vacancy (Haschke, 2014). For an electron to move to a lower energy state, or lower orbital shell, energy must be released. This 
release of energy is known as fluorescence. This energy is then captured by the analyzer's X-ray detector and because the released energy is unique to each element, such elements can be differentiated, and their concentrations quantified.

Energy-dispersive XRF spectrometer's (EDXRF) and wave-dispersive XRF spectrometer's (WDXRF) are the two primary modes of XRF technology. The EDXRF detector captures and sorts the energy of released photons and collects the entire spectrum of elements within seconds of irradiating the sample. The WDXRF utilizes the phenomenon of Bragg diffraction from a crystalline material to disperse the X-ray spectrum according to wavelength (Potts and Webb, 1992). WDXRF's have lower detection limits and higher energy resolution than that of the EDXRF, largely due to fewer spectral overlaps and lower background radiation intensities. Handheld XRF analyzers, including the Olympus Innov-X DELTA Premium Handheld X-ray, are EDXRF spectrometers, while WDXRF are benchtop and typically require destructive sample preparation prior to testing.

\subsection{Equipment and Sampling}

\subsubsection{Analyzer Specifications}

The hhEDXRF spectrometer used for this study was an Olympus Innov-X DELTA Premium equipped with a $40 \mathrm{kV}$ tube and large area silicon drift detector. The Delta's two-beam setting, a high $(40 \mathrm{kV})$ and low $(15 \mathrm{kV})$ beam, is used to increase resolution of both major and trace elements. Like others, this XRF analyzer has multiple user settings for different analyses, which include; (1) Mining, (2) Dual Beam Mining, (3) Soil Environmental, (4) Soil Exploration, and (5) Consumer Goods Analysis mode. The Dual Beam Mining mode was chosen for its two-beam setting, silicon drift detector (SDD), low limit of detection of light elements, and the geologically relevant elemental suite, which includes Mg, Al, Si, P, S, Cl, K, Ca, Ti, V, Cr, Mn, Fe, Co, Ni, Cu, Zn, W, 
As, Pb, Bi, Zr, Mo, Ag, Cd, Sn, and Sb. Young et al. (2016) found that elemental data obtained using the Olympus Innov-X DELTA Premium Handheld XRF Analyzer was comparable to laboratory XRF analysis for geologically important elements (i.e. $\mathrm{Si}, \mathrm{Ca}, \mathrm{Ti}$, and $\mathrm{K}$ ) within basalts, which served as an initial justification for using this analyzer.

Four core intervals, totaling 563 feet, were scanned with the hhEDXRF with exposure time of 60 seconds per beam. Data points were collected every 2 inches and had an exposure time of 60 seconds per beam. This exposure time was chosen in part based on the Newlander et al. (2015) study on the Olympus analyzer, which measured the effect of exposure time on precision and accuracy. Newlander et al. (2015) assessed the percent relative error of the analyzer with run times of 5-100 seconds and concluded, “...that pXRF data obtained at short count times $(<40-60$ s) were almost always as accurate as pXRF data obtained at longer count times, particularity for geologic standards and obsidian."

The hhEDXRF analysis created high-resolution geochemical profiles of each of the four core intervals. These data were used to locate compositionally diverse sequences within the intervals. Based on this analysis, 64 locations, roughly 16 per core, were extracted from the core using a drill press, equipped with a 1 inch in diameter by 3 inches in depth coring bit. It was found that total counts collected by the instrument was extremely sensitive to rough surfaces and/or incomplete contact with the nose of the analyzer and the sample surface. Thus, surfaces of the plugs were made smooth and uniform, so the nose of the analyzer could be flush with the sample. These 64 compositionally diverse plugs were scanned with the analyzer on the Dual Beam Mining mode for 60 seconds on each beam. 


\subsubsection{WDXRF Specifications and Sample Preparation}

Following the hhEDXRF analysis, the top one half of each plug was cut, powdered, and prepped for an analysis using a Thermo Scientific ARL PERFORM'X Sequential X-Ray Fluorescence Spectrometer. This spectrometer is a WDXRF that uses a sequential X-ray fluorescence spectrometer with a programmable aperture capable of reading a suite of 44 elements including major, minor, and trace elements (Thermo Scientific, 2012; Conrey, 2018). This WDXRF yields data that are three to five percent more precise than most hhEDXRFs and is calibrated with a diverse set of more than 70 certified reference materials (CRM) issued by the National Institute of Standards and Technology (NIST), USGS, the British Chemical Society (BCS), and the Geological Survey of Japan (GSJ), and others (Conrey, 2018). For each target element, table 2-1 displays the determination limits, number of CRM's used for calibration, standard error of estimate (SEE), as well as the number of CRM's used to validate the calibration and their respective SEEs. Among the suite of analyzed via the hhEDXRF's Dual Beam Mining mode suite, the WDXRF does not report values for $\mathrm{Ag}, \mathrm{Cd}, \mathrm{Co}, \mathrm{Sb}$, and $\mathrm{W}$.

Table 2-1. Determination limit, calibration, and validation based on CRMs for each element and their respective standard error of estimate (SEE). Values from Conrey (2018).

\begin{tabular}{|c|c|c|c|c|c|}
\hline \multirow{2}{*}{ Element } & \multirow{2}{*}{$\begin{array}{c}\text { Determination Limit at } \\
50 \% \text { RSD }\end{array}$} & \multicolumn{2}{|c|}{ Calibration } & \multicolumn{2}{|c|}{ Validation } \\
\hline & & CRM ( n) & SEE & CRM (n) & SEE \\
\hline $\mathrm{Si}$ & $0.2+/-0.1$ wt. $\%$ & 62 & 0.490 wt. $\%$ & 130 & 0.654 wt. $\%$ \\
\hline $\mathrm{Ti}$ & $0.002+/-0.001$ wt. $\%$ & 63 & 0.016 wt. $\%$ & 125 & 0.018 wt. $\%$ \\
\hline $\mathrm{Al}$ & $0.044+/-0.022$ wt. $\%$ & 66 & 0.199 wt. $\%$ & 131 & 0.242 wt. $\%$ \\
\hline $\mathrm{Fe}$ & $0.003+/-0.0015$ wt. $\%$ & 65 & 0.127 wt. $\%$ & 131 & 0.146 wt. $\%$ \\
\hline Mn & $0.0003+/-0.00015$ wt. $\%$ & 60 & 0.003 wt. $\%$ & 123 & 0.005 wt. $\%$ \\
\hline $\mathrm{Ca}$ & $0.032+/-0.016$ wt. $\%$ & 63 & 0.068 wt. $\%$ & 132 & 0.133 wt. $\%$ \\
\hline $\mathrm{K}$ & $0.002+/-0.001$ wt. $\%$ & 65 & 0.041 wt. $\%$ & 124 & 0.047 wt. $\%$ \\
\hline
\end{tabular}




$\begin{array}{cccccc}\mathrm{Zr} & 3.1+/-1.55 \mathrm{ppm} & 42 & 7.6 \mathrm{ppm} & 80 & 6.9 \mathrm{ppm} \\ \mathrm{Mo} & 2.1+/-1.05 \mathrm{ppm} & 36 & 0.8 \mathrm{ppm} & 65 & 1.1 \mathrm{ppm} \\ \mathrm{Pb} & 4.3+/-2.15 \mathrm{ppm} & 50 & 2.1 \mathrm{ppm} & 95 & 12.4 \mathrm{ppm} \\ \mathrm{Zn} & 3.0+/-1.5 \mathrm{ppm} & 53 & 3.4 \mathrm{ppm} & 107 & 6.4 \mathrm{ppm} \\ \mathrm{Cu} & 4.6+/-2.3 \mathrm{ppm} & 41 & 2.6 \mathrm{ppm} & 92 & 4.6 \mathrm{ppm} \\ \mathrm{Ni} & 3.5+/-1.75 \mathrm{ppm} & 43 & 3.6 \mathrm{ppm} & 94 & 16.3 \mathrm{ppm} \\ \mathrm{Cr} & 7.0+/-3.5 \mathrm{ppm} & 46 & 8.5 \mathrm{ppm} & 99 & 30.0 \mathrm{ppm} \\ \mathrm{V} & 3.5+/-1.75 \mathrm{ppm} & 51 & 4.5 \mathrm{ppm} & 101 & 6.5 \mathrm{ppm}\end{array}$

Each of the 64 mudrock samples were powdered using a WC ringmill. Preparations methods followed Conrey (2018) and are outlined in the following text. Five (5) grams of each powdered sample were placed in a Merson grade UF-4S graphite crucible, heated to $550^{\circ} \mathrm{C}$, weighed, and then heated to $1000^{\circ} \mathrm{C}$. Loss on ignition (LOI) data was gathered through measuring the difference in weight between unheated and heated samples at $500^{\circ} \mathrm{C}$ and $1000^{\circ} \mathrm{C}$. Of the final heated powder, 3.5 grams of the sample was mixed with 7.0 grams of Li-tetraborate flux (Merck Spectromelt A-10). The mixture was placed back into the graphite crucible and heated to $1000^{\circ} \mathrm{C}$. The fused disk was sanded and smoothed to discard any organic matter build-up and powdered using a WC ringmill and fused again at $1000^{\circ} \mathrm{C}$. The glass disks from this final fusion were cleaned ultrasonically in ethanol preceding the XRF analysis. Some elements are volatile during fusion and can lead to defective reports of $\mathrm{Cl}, \mathrm{S}, \mathrm{Br}$, and As, and thus are not reported (Conrey, 2018). Glass disks were then analyzed at an accelerating voltage of $45 \mathrm{kV}$ at $45 \mathrm{~mA}$ and the crystalline material was kept at temperatures of $43^{\circ} \mathrm{C}$ and near constant pressure at $2.0 \mathrm{~Pa}$ (Hupp and Donovan, 2017). Precision of WDXRF results were tested by eight "repeat" mudrock samples from this study. The RSD between each sample and "repeat" sample for each element were calculated. Major and minor elements recorded very low RSD values, with an average RSD of $<1.1 \%$ and $<4.84 \%$, respectively. 


\subsubsection{Defining clusters via Hierarchical Cluster Analysis}

A total of 64 mudrock core plugs were sampled from four Middle Devonian cores, powdered, fused, and analyzed for elemental composition by the WDXRF. The quantitative dataset from this analysis was then used to define geochemically similar mudrock samples. Within the statistical software JMP 14 Pro, hierarchical cluster analysis (HCA) was used to define geochemically similar groups, referred to as "clusters". The overall purpose of using the HCA is to elucidate the composition of the mudrock samples in a digestible form by reducing the sample size from 64 data points to a much smaller set of chemically-similar clusters. Fifteen elements, $\mathrm{Al}, \mathrm{Si}, \mathrm{Ti}, \mathrm{Fe}, \mathrm{Mn}$, $\mathrm{Ca}, \mathrm{K}, \mathrm{Zr}, \mathrm{Mo}, \mathrm{Pb}, \mathrm{Zn}, \mathrm{Cu}, \mathrm{Ni}, \mathrm{Cr}$, and $\mathrm{V}$, and their respective values measured by the WDXRF were input into the HCA. Hierarchical cluster analysis divides chemically-similar samples into several groups, with the goal of grouping samples that are chemically similar while maximizing the distance between clusters (Templ, 2008). The chemical similarities within the groups are calculated using a Euclidian distance to a cluster's centroid (Turner, 2016). Once a new cluster formed, the centroid of the cluster is calculated using Wards method, also referred to as minimum variance (Ward, 1963). The cluster analysis places the clusters in a hierarchy often displayed as a dendrogram. In the most detailed case, each individual sample, 64 in this case, would represent its own cluster and the coarsest case would have one cluster encompassing all 64 samples. Distance, as calculated by Ward's method, between clusters was used to find the optimal number of clusters by using the criterion that a larger distance represents greater dissimilarity between the clusters. As is shown in the $\mathrm{X}-\mathrm{Y}$ scatter plot, consisting of the number of clusters and distances respectively, beyond cluster nine (bottom right point in rectangular black box) the distance between each cluster lessens significantly and becomes nearly constant as the number of clusters increase (figure 2-3a). For this reason, 9 clusters were selected as optimally representing the chemical diversity of the samples. To aid with visualization of the clusters and their relation and distance to other clusters, 
a constellation plot (figure 2-3b) is utilized. The constellation plot is an $\mathrm{X}-\mathrm{Y}$ coordinate graph, which plots the samples within clusters and distance between clusters.

The average value of each element within their respective cluster defined from the HCA are show in table 2-2. The cluster means were calculated by adding the concentrations of each element within the cluster and dividing by the number (n) of samples within the cluster for the WDXRF, hhEDXRF (raw), and hhEDXRF (calibrated) allowing for the comparison of the measured absolute value of elemental concentrations from the WDXRF and the hhEDXRF (both calibrated and uncalibrated). Note that the calibrated hhEDXRF values are derived from the relationship between the WDXRF and (raw) hhEDXRF values and are displayed together in Table 2-2 for purposes of comparison.

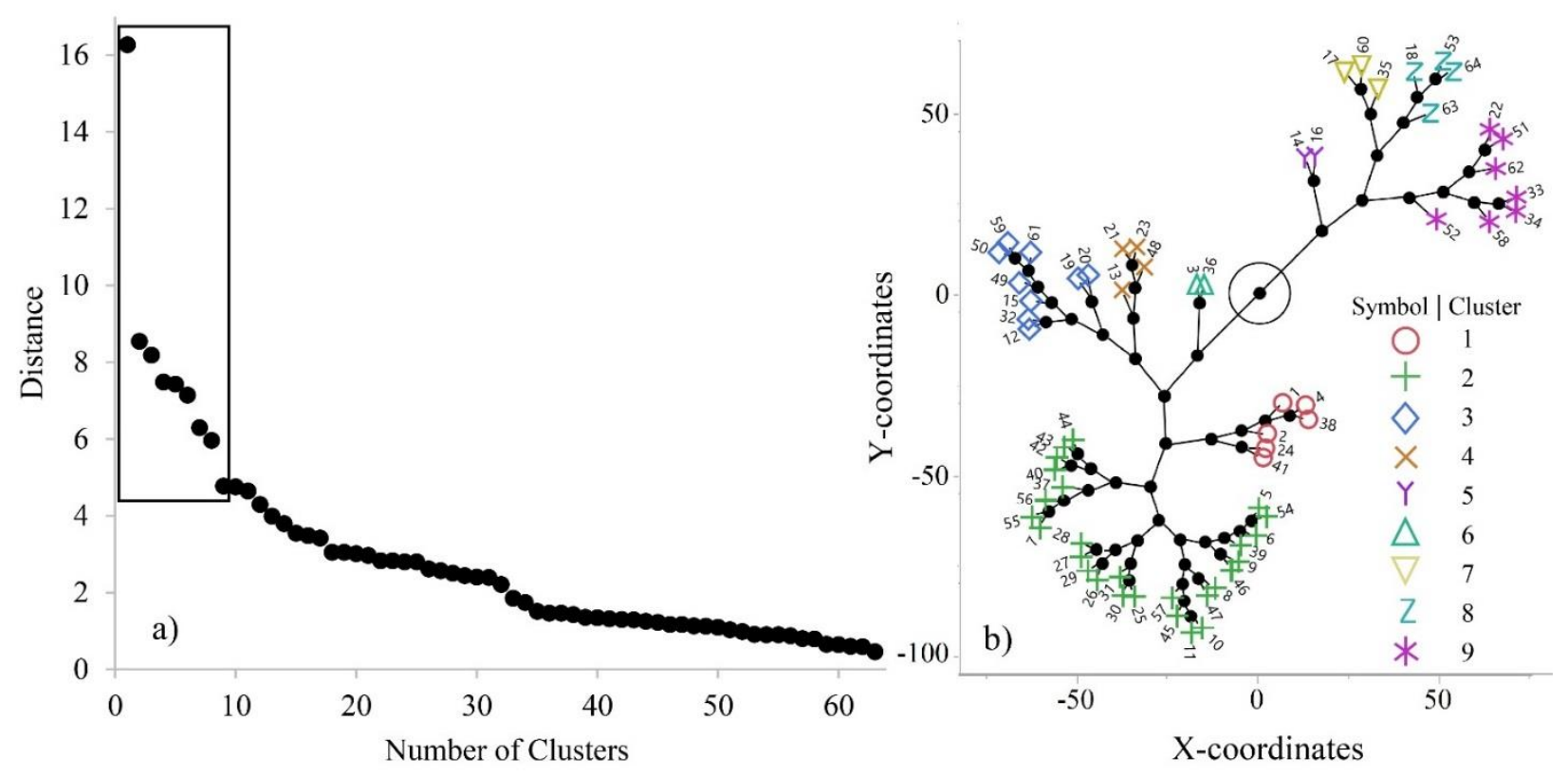

Figure 2-3a, b. a) An X-Y plot showing distance relative to number of clusters. The black rectangle highlights where the cluster cut off was drawn based on distances between points. b) Constellation plot illustrating the relative distance (degree of dissimilarity) between clusters and the samples that are within each of the nine clusters. 
Table 2-2. Comparison of cluster means collected from the hhEDXRF, both raw and calibrated (cal.), and from the WDXRF.

\begin{tabular}{|c|c|c|c|c|c|c|c|c|c|c|c|c|c|c|c|c|}
\hline $\begin{array}{l}\text { Cluster, } \\
\text { Freq. }\end{array}$ & $\begin{array}{l}\text { Mode } \\
\text { (XRF) }\end{array}$ & $\begin{array}{c}\mathrm{Si} \\
\text { (wt. \%) }\end{array}$ & $\begin{array}{c}\mathrm{Ti} \\
\text { (wt. \%) }\end{array}$ & $\begin{array}{c}\mathrm{Al} \\
\text { (wt. \%) }\end{array}$ & $\begin{array}{c}\mathrm{Fe} \\
\text { (wt. \%) }\end{array}$ & $\begin{array}{c}\mathrm{Mn} \\
\text { (wt. \%) }\end{array}$ & $\begin{array}{c}\mathrm{Ca} \\
\text { (wt. \%) }\end{array}$ & $\begin{array}{c}\mathrm{K} \\
\text { (wt. \%) }\end{array}$ & $\begin{array}{c}\mathrm{Ni} \\
(\mathrm{ppm})\end{array}$ & $\begin{array}{c}\mathrm{Cr} \\
(\mathrm{ppm})\end{array}$ & $\begin{array}{c}\mathrm{V} \\
(\mathrm{ppm})\end{array}$ & $\begin{array}{c}\mathrm{Cu} \\
(\mathrm{ppm})\end{array}$ & $\begin{array}{c}\mathrm{Zn} \\
(\mathrm{ppm})\end{array}$ & $\begin{array}{c}\mathrm{Zr} \\
(\mathrm{ppm})\end{array}$ & $\begin{array}{c}\text { Mo } \\
\text { (ppm) }\end{array}$ & $\begin{array}{c}\mathrm{Pb} \\
(\mathrm{ppm})\end{array}$ \\
\hline \multirow{3}{*}{$1, n=6$} & WD & 28.296 & 0.405 & 9.471 & 6.515 & 0.0250 & 1.437 & 3.607 & 195.73 & 111.10 & 536.55 & 155.93 & 125.80 & 115.97 & 95.62 & 77.27 \\
\hline & hhED (cal.) & 28.406 & 0.393 & 9.278 & 6.423 & 0.0258 & 1.427 & 3.561 & 181.03 & 103.34 & 508.86 & 152.64 & 117.70 & 112.44 & 93.51 & 74.99 \\
\hline & hhED (raw) & 25.275 & 0.378 & 8.151 & 4.635 & 0.0404 & 0.870 & 1.915 & 140.76 & 203.75 & 632.36 & 137.44 & 130.71 & 128.45 & 38.37 & 57.95 \\
\hline \multirow{3}{*}{$\begin{array}{c}2, \\
n=27\end{array}$} & WD & 28.981 & 0.406 & 9.507 & 4.860 & 0.0210 & 1.504 & 3.729 & 143.90 & 96.80 & 321.44 & 121.78 & 135.59 & 118.01 & 101.66 & 29.41 \\
\hline & hhED (cal.) & 29.321 & 0.400 & 9.415 & 5.045 & 0.0252 & 1.479 & 3.685 & 141.43 & 97.83 & 340.53 & 120.74 & 143.79 & 119.99 & 102.36 & 28.84 \\
\hline & hhED (raw) & 25.093 & 0.311 & 6.739 & 3.794 & 0.0216 & 2.501 & 1.522 & 227.77 & 196.95 & 799.10 & 251.20 & 280.32 & 121.94 & 124.78 & 36.56 \\
\hline \multirow{3}{*}{$3, n=9$} & WD & 31.029 & 0.358 & 7.043 & 4.343 & 0.0140 & 2.679 & 2.855 & 196.51 & 88.34 & 634.11 & 161.54 & 201.46 & 119.74 & 137.32 & 34.48 \\
\hline & hhED (cal.) & 30.673 & 0.357 & 7.207 & 4.282 & 0.0177 & 2.770 & 2.808 & 206.87 & 89.85 & 642.22 & 160.79 & 187.81 & 118.36 & 135.57 & 35.30 \\
\hline & hhED (raw) & 24.211 & 0.415 & 8.108 & 5.187 & 0.0340 & 2.104 & 2.212 & 196.77 & 191.13 & 654.44 & 197.17 & 192.21 & 144.35 & 85.06 & 46.51 \\
\hline \multirow{3}{*}{$4, n=4$} & WD & 29.542 & 0.399 & 8.159 & 4.466 & 0.0160 & 2.372 & 3.326 & 214.80 & 155.73 & 965.88 & 213.85 & 150.25 & 130.15 & 87.90 & 34.73 \\
\hline & hhED (cal.) & 28.740 & 0.389 & 7.989 & 4.399 & 0.0183 & 2.342 & 3.302 & 224.17 & 138.85 & 948.13 & 230.50 & 148.17 & 124.94 & 83.53 & 34.62 \\
\hline & hhED (raw) & 25.353 & 0.414 & 8.239 & 4.307 & 0.0264 & 1.044 & 2.395 & 145.88 & 196.12 & 558.39 & 119.15 & 140.73 & 135.12 & 92.39 & 28.97 \\
\hline \multirow{3}{*}{$5, n=2$} & WD & 28.880 & 0.551 & 10.011 & 4.744 & 0.0650 & 1.484 & 3.562 & 50.95 & 104.00 & 166.95 & 27.95 & 87.30 & 184.70 & 0.05 & 5.25 \\
\hline & hhED (cal.) & 29.895 & 0.554 & 10.558 & 5.470 & 0.0679 & 1.604 & 3.761 & 49.55 & 106.34 & 168.31 & 46.40 & 95.10 & 189.30 & 5.00 & 1.21 \\
\hline & hhED (raw) & 25.004 & 0.404 & 7.708 & 4.793 & 0.0196 & 1.523 & 1.925 & 177.46 & 231.13 & 617.50 & 225.65 & 49.64 & 140.88 & 82.88 & 33.07 \\
\hline \multirow{3}{*}{$6, n=2$} & WD & 31.793 & 0.265 & 5.404 & 3.496 & 0.0110 & 3.379 & 2.205 & 318.95 & 113.40 & 1610.90 & 209.85 & 7587.05 & 91.65 & 211.85 & 26.65 \\
\hline & hhED (cal.) & 29.502 & 0.254 & 5.284 & 3.177 & 0.0123 & 3.233 & 2.339 & 322.82 & 114.60 & 1516.72 & 207.31 & 7144.60 & 86.85 & 204.91 & 29.94 \\
\hline & hhED (raw) & 26.338 & 0.348 & 6.542 & 3.902 & 0.0169 & 2.425 & 1.207 & 245.55 & 189.02 & 961.72 & 191.91 & 8477.30 & 115.43 & 94.90 & 34.50 \\
\hline \multirow{3}{*}{$7, n=3$} & WD & 22.474 & 0.353 & 6.947 & 4.088 & 0.0210 & 11.231 & 3.056 & 267.70 & 98.50 & 900.40 & 194.20 & 283.70 & 128.07 & 179.53 & 39.67 \\
\hline & hhED (cal.) & 22.968 & 0.346 & 6.621 & 4.003 & 0.0226 & 10.863 & 3.327 & 283.02 & 106.70 & 956.11 & 193.73 & 267.01 & 128.94 & 183.96 & 41.27 \\
\hline & hhED (raw) & 24.360 & 0.271 & 4.479 & 4.023 & 0.0175 & 5.086 & 0.292 & 366.73 & 163.98 & 1482.24 & 339.41 & 609.23 & 120.20 & 163.38 & 46.78 \\
\hline \multirow{3}{*}{$8, n=4$} & WD & 28.777 & 0.218 & 4.408 & 3.758 & 0.0100 & 7.346 & 1.835 & 291.53 & 66.00 & 859.25 & 225.40 & 487.98 & 92.65 & 222.43 & 32.88 \\
\hline & hhED (cal.) & 28.943 & 0.251 & 4.648 & 3.767 & 0.0154 & 7.656 & 2.339 & 319.66 & 94.13 & 935.14 & 224.66 & 501.53 & 108.28 & 234.33 & 34.70 \\
\hline & hhED (raw) & 24.882 & 0.419 & 8.480 & 4.335 & 0.0284 & 1.857 & 2.295 & 161.05 & 200.62 & 681.24 & 185.69 & 73.88 & 134.88 & 79.01 & 33.02 \\
\hline \multirow{3}{*}{$9, n=7$} & WD & 28.628 & 0.305 & 6.255 & 7.086 & 0.0130 & 3.309 & 2.643 & 399.96 & 96.51 & 1093.80 & 275.94 & 913.44 & 121.13 & 292.90 & 48.37 \\
\hline & hhED (cal.) & 27.910 & 0.303 & 6.332 & 5.790 & 0.0158 & 3.303 & 2.681 & 380.06 & 86.99 & 1079.47 & 266.81 & 903.34 & 115.61 & 289.16 & 49.43 \\
\hline & hhED (raw) & 24.501 & 0.287 & 5.518 & 4.564 & 0.0186 & 5.836 & 0.584 & 332.47 & 186.11 & 1081.89 & 273.17 & 883.81 & 117.35 & 183.64 & 41.38 \\
\hline
\end{tabular}




\subsection{Results and Discussion}

\subsubsection{Mudrock Calibration - hhEDXRF vs. WDXRF}

The mudrock calibration developed in this study uses linear regression to find the line of best fit for a series of $\mathrm{x}$ and $\mathrm{y}$ data pairs, which in this case is the hhEDXRF and WDXRF results for each individual element measured from the mudrock samples. By using this equation for each element, the hhEDXRF value can be "calibrated" to the WDXRF value (Table 3). All elements measured from hhEDXRF and WDXRF were displayed individually on an $x-y$ scatter plot to access potential outliers. Outliers can be caused by several factors including; accidental contamination during sample preparation, the hhEDXRF nose not being completely flush with the sample during analysis, irregular surface of the samples, spectral overlap, orientations of specific minerals when in powdered form, the nugget or large grain effect (pyrite/calcite nodules, clay minerals), and heterogeneity issues in non-powdered whole-rock. To define outliers objectively, JMP Pro 14's Multivariate Robust Fit Outliers tool was utilized. This approach uses Mahalanobis distances, a technique that aids in defining outliers in variable space by accounting for the correlation in the data, which is calculated using the inverse of the variance-covariance of the dataset (De Maesschalck et al., 2000). Specifically, the outlier analysis calculates the Mahalanobis distances from each point to the center of the multivariate normal distribution, which is a measure that relates to contours of the multivariate normal density with respect to the correlation structure (Jmp.com, 2019). Data points with the highest values, or in other words, with the greatest distance from the center, are the most likely to be classified as an outlier but is largely at the discretion of the interpreter. Out of 64 measurements, outlying data points for each element were omitted to create the most meaningful regression analysis to assess the performance of the analyzer. The number of samples (n) included in each regression model is displayed in table 2-3. 
Table 2-3. Linear regression statistics from regression analysis of hhEDXRF vs. WDXRF for each element. Minimum and maximum values for each element are from the calibrated hhEDXRF values. All $\mathrm{P}_{\text {values }}$ were $<0.0001$.

\begin{tabular}{cccccccc} 
Element & $\mathrm{n}$ & Min & Max & Calibration Equation & $\mathrm{r}^{2}$ & RMSE & F Ratio \\
\hline $\mathrm{Al}$ (wt. \%) & 62 & 4.38 & 10.91 & $y=1.0934 x+0.4086$ & 0.97 & 0.317 & 1953.4 \\
$\mathrm{Si}$ (wt. \%) & 64 & 22.25 & 34.72 & $y=0.8615 x+7.4595$ & 0.78 & 1.236 & 219.61 \\
$\mathrm{Ti}$ (wt. \%) & 56 & 0.22 & 0.57 & $y=0.9531 x+0.0429$ & 0.93 & 0.021 & 749.83 \\
$\mathrm{Fe}$ (wt. \%) & 63 & 2.45 & 7.59 & $y=1.1414 x+0.0382$ & 0.919 & 0.33 & 687.68 \\
$\mathrm{Mn}$ (wt. \%) & 61 & 0.01 & 0.08 & $y=0.8463 x+0.0016$ & 0.961 & 0.002 & 1443.36 \\
$\mathrm{Ca}$ (wt. \%) & 64 & 0.23 & 14.46 & $y=0.9800 x+0.2318$ & 0.995 & 0.198 & 12488.55 \\
$\mathrm{~K}$ (wt. \%) & 60 & 2.34 & 4.31 & $y=0.5921 x+2.3394$ & 0.928 & 0.157 & 717.04 \\
$\mathrm{Zr}$ (ppm) & 61 & 80.27 & 201.73 & $y=0.9274 x+1.7385$ & 0.826 & 9.746 & 280.7 \\
$\mathrm{Mo}$ (ppm) & 64 & 5 & 429.89 & $y=1.1896 x+4.9992$ & 0.992 & 8.515 & 7376.09 \\
$\mathrm{~Pb}$ (ppm) & 64 & 0.04 & 96.94 & $y=0.9169 x+0.04079$ & 0.97 & 2.989 & 2071.92 \\
$\mathrm{Zn}$ (ppm) & 63 & 14.13 & 2740.82 & $y=0.8749 x-9.6584$ & 0.995 & 30.966 & 11421.46 \\
$\mathrm{Cu}$ (ppm) & 64 & 44.03 & 314.71 & $y=0.6320 x+21.559$ & 0.939 & 16.683 & 950.44 \\
$\mathrm{Ni}$ (ppm) & 64 & 48.91 & 483.14 & $y=0.9517 x-5.956$ & 0.967 & 18.812 & 1821.1 \\
$\mathrm{Cr}$ (ppm) & 63 & 63.99 & 153.76 & $y=0.5315 x-4.0411$ & 0.561 & 14.741 & 77.88 \\
$\mathrm{~V}$ (ppm) & 57 & 121.97 & 1960.56 & $y=1.2237 x-342.57$ & 0.965 & 79.959 & 1530.02 \\
& & \multicolumn{1}{c}{$\mathrm{cal} . \mathrm{hhEDXRF}$} & & & &
\end{tabular}

For each target element, the scatter plot is displayed for the regression analysis between WDXRF and the calibrated hhEDXRF and their corresponding $\mathrm{r}^{2}$, slope, y-intercept, and root mean square error (figure 2-4). $R^{2}$ is a relative measure, while the root mean square error (RMSE), the standard deviation of difference between the WDXRF values and hhEDXRF values (residuals), indicate the absolute fit of the data in the same units as the respective element (ppm or wt. \%). 

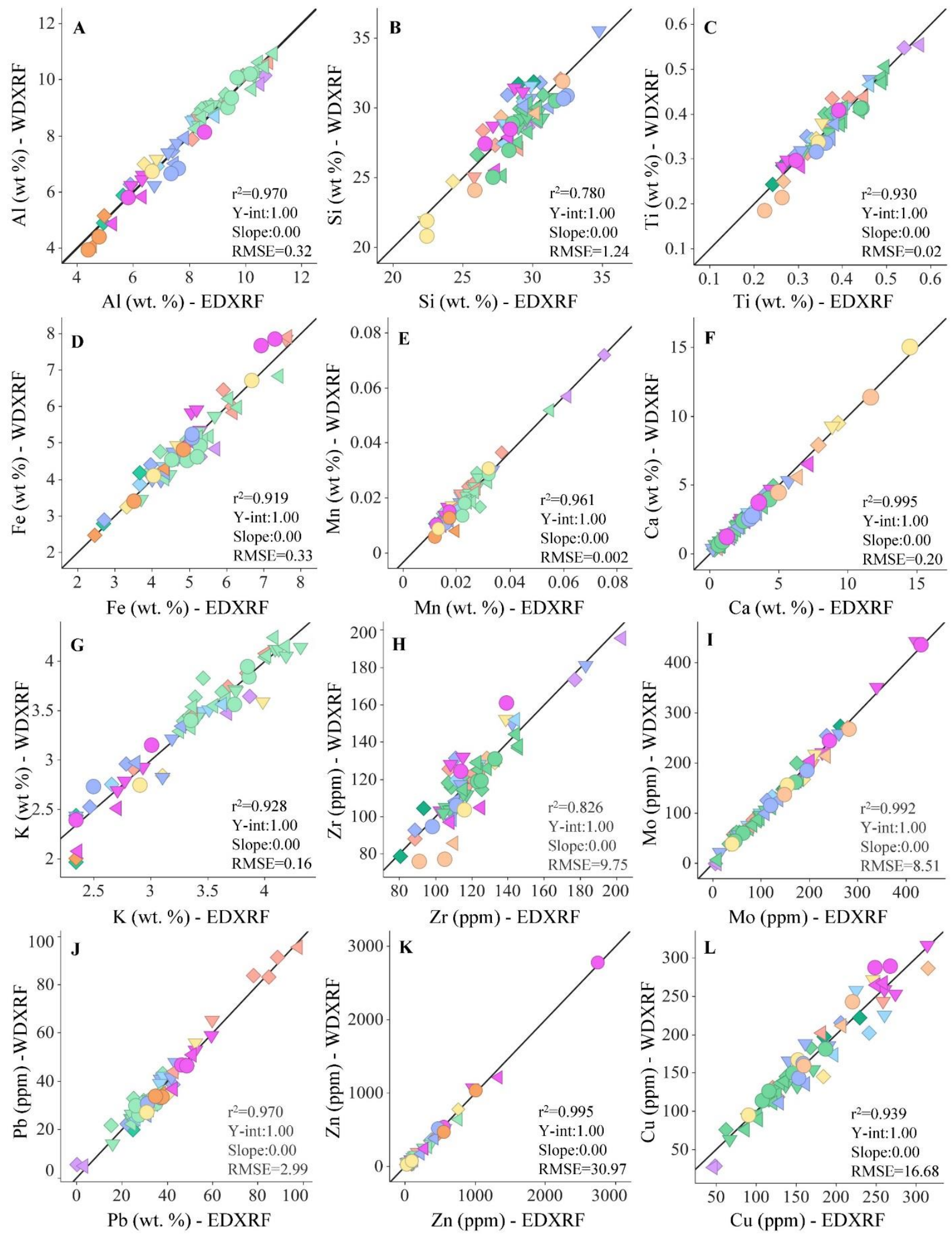

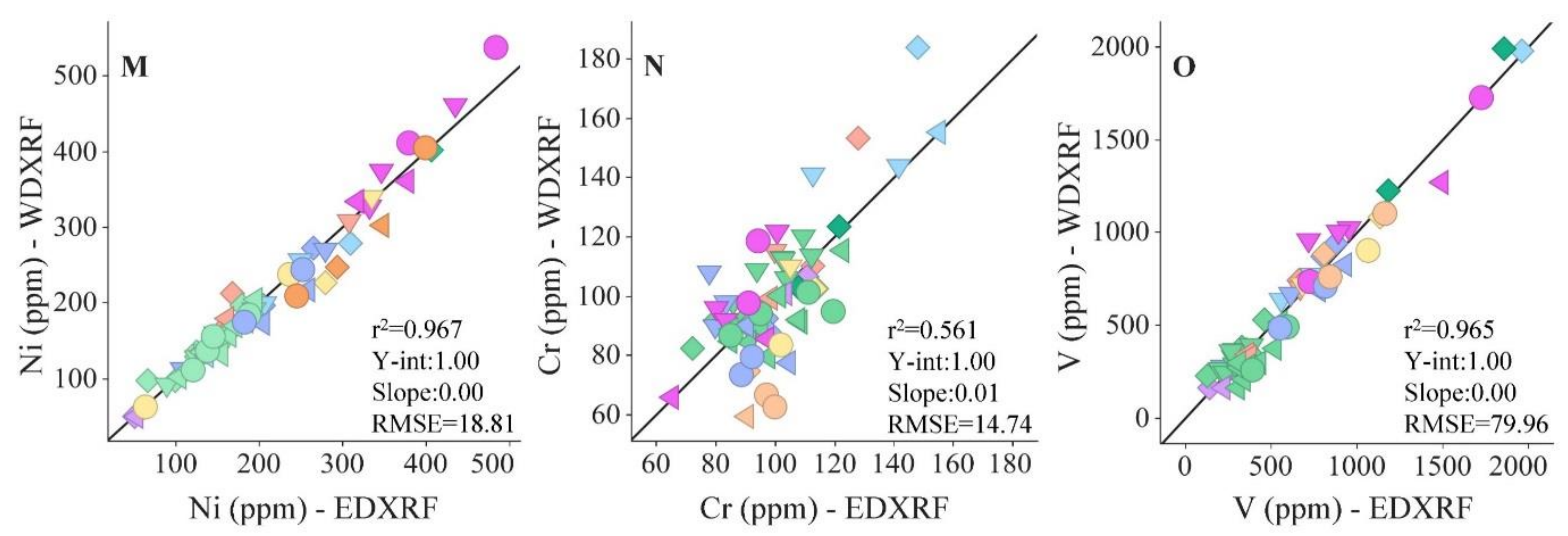

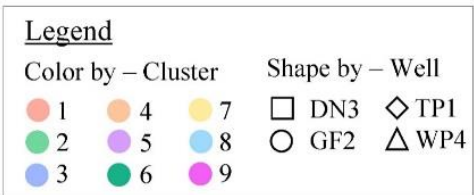

Figure 2-4 (A-O). X-Y scatter with line of best fit and corresponding r2, slope, Y-intercept, and root mean square error (RMSE) values displayed for each element. The X-axis and Y-axis represents elemental values collected from the hhEDXRF and WDXRF, respectively.

A better fit between WDXRF and hhEDXRF for a particular element would record high $\mathrm{r}^{2}$ values and low RMSE values. Between the calibrated hhEDXRF and WDXRF, the target elements produced a slope of 1.00 and y-intercept of 0.00 at alpha $=0.05$, excluding $\mathrm{Cr}$, which generated a slope of 1.00 and a y-intercept of 0.01. Ca, Mo, and $\mathrm{Zn}$ had the strongest correlation, producing an $\mathrm{r}^{2}>0.99$. $\mathrm{Al}, \mathrm{Mn}, \mathrm{Ni}, \mathrm{V}$, and $\mathrm{Pb}$ were the group with the second highest correlation of $\mathrm{r}^{2}>0.96$. The third highest correlation group consisting of $\mathrm{Cu}, \mathrm{Fe}$, Ti, and $\mathrm{K}$ generated an $\mathrm{r}^{2}>0.919$. $\mathrm{Zr}$ and $\mathrm{Si}$ recorded slightly low correlations, $\mathrm{r}^{2}=0.826,0.78$, respectively. Lastly, $\mathrm{Cr}$ logged the weakest correlation, $\mathrm{r}^{2}=0.561$. Additionally, the agreeance between the calibrated hhEDXRF and WDXRF is displayed in log view for each element (figure 2-5), highlighting the change in elemental concentrations relative to depth. 

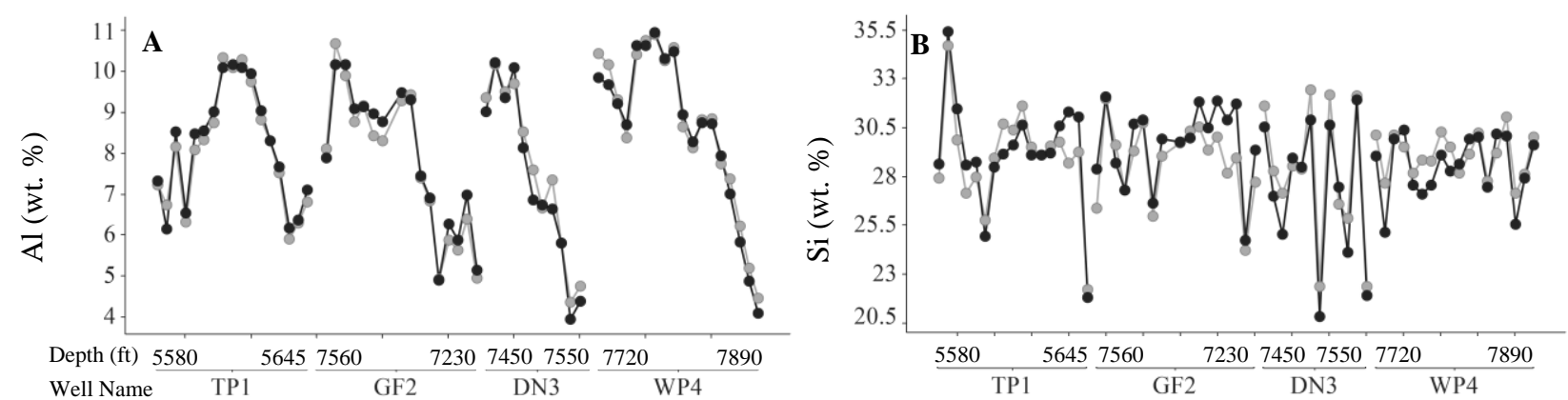

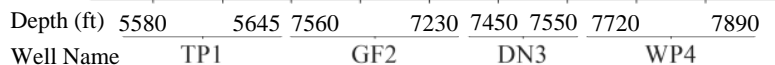
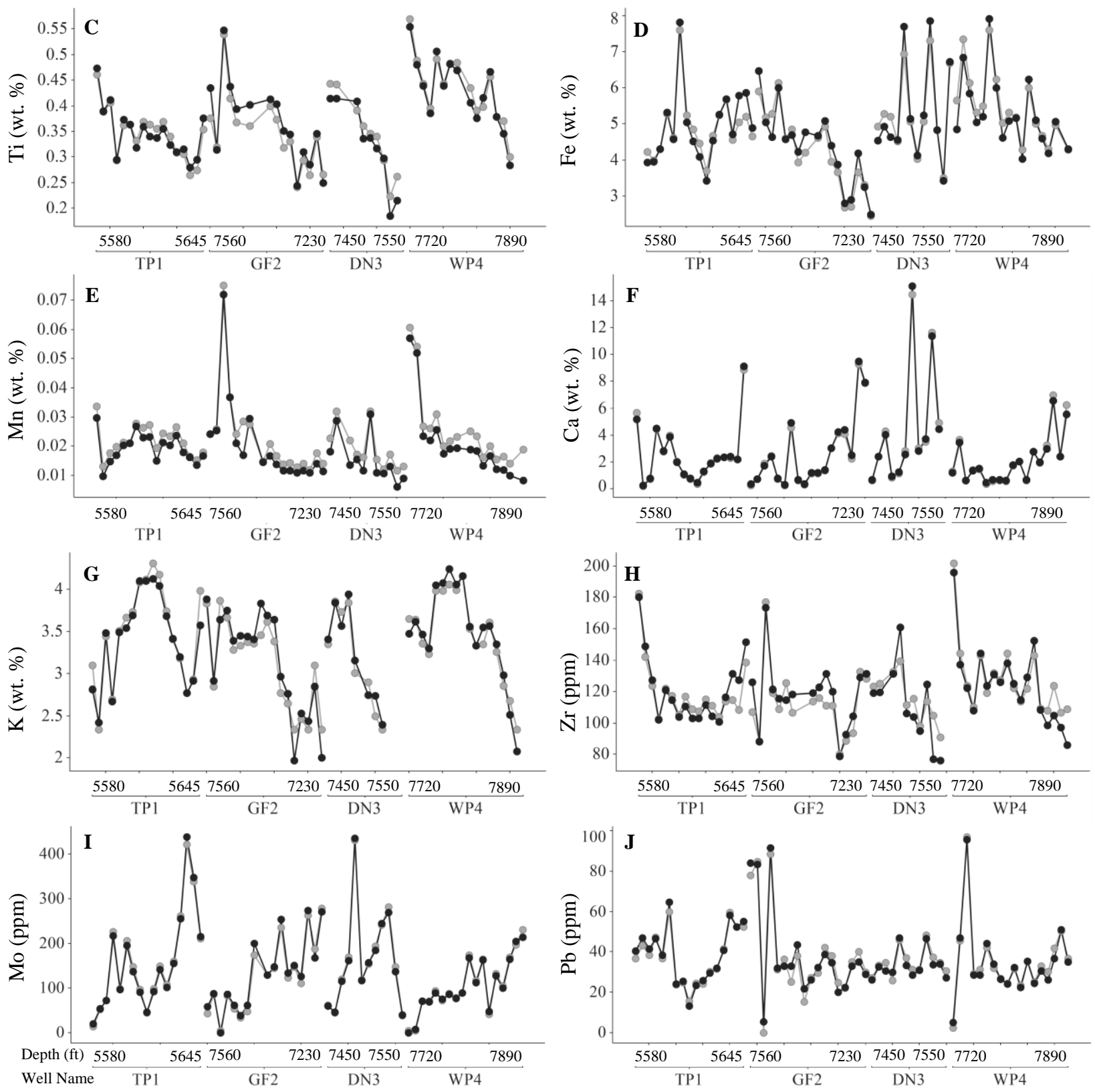

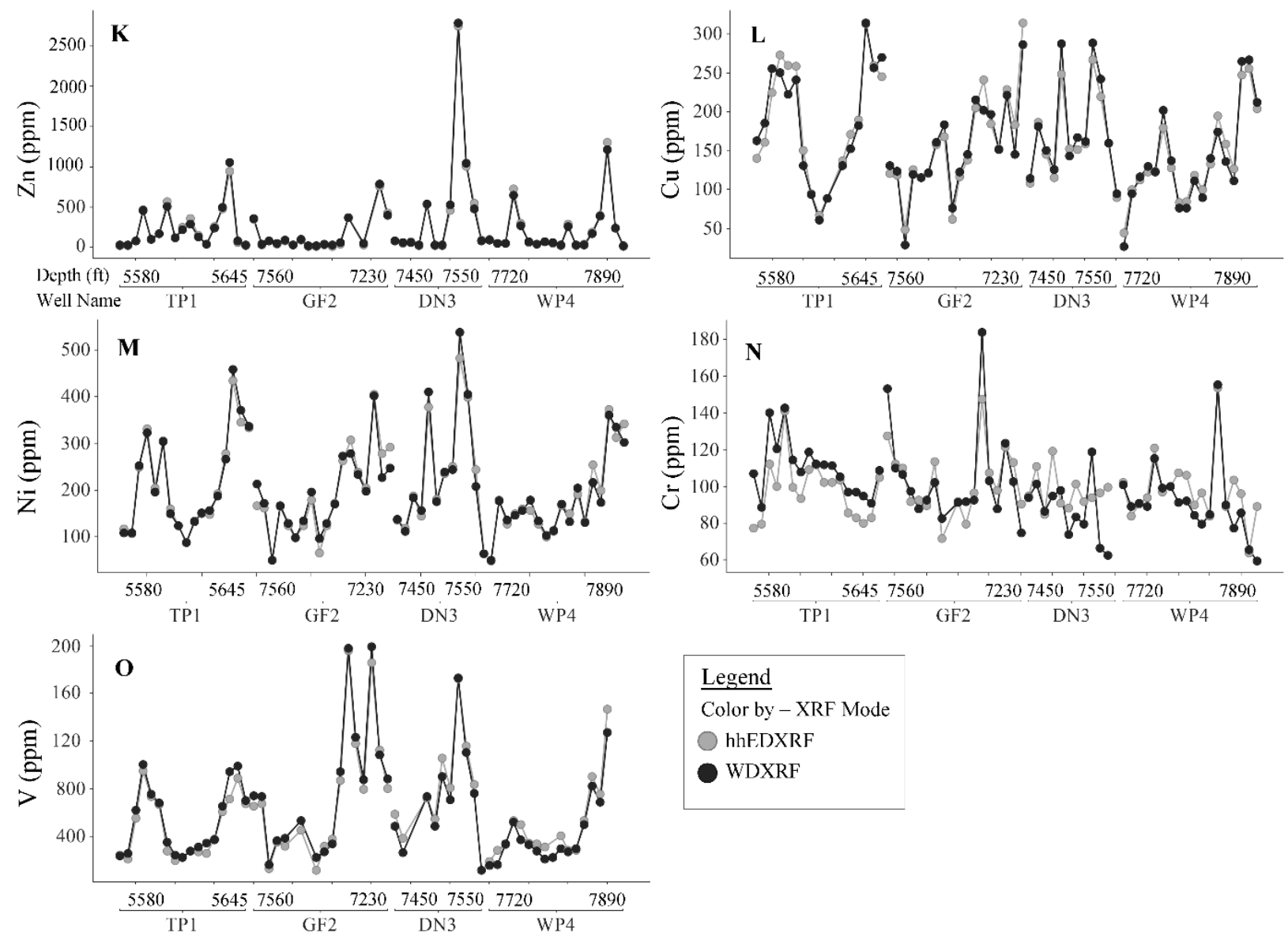

Figure 2-5 (A-O). Well Name and corresponding depths (X-axis) and elemental concentrations (wt. \% and ppm) from the calibrated hhEDXRF and the WDXRF (Y-axis). The log view shows the change in elemental concentrations relative to depth and highlights the strong correlation between measured concentrations from the calibrated hhEDXRF and the WDXRF.

\subsubsection{Analyzer Drift and Precision}

Before and after each scanning session an internal mudrock reference sample (IRS_7542.4) was scanned for 60 seconds on each beam to assess instrument drift, totaling 56 measurements. To assess drift, relative standard deviation (RSD) was calculated and returned values of $<7.8 \%$ for each element, excluding $\mathrm{Cr}$. $\mathrm{Cr}$ recording $\mathrm{RSD}$ of $16.7 \%$, indicating more variation between the measured values. This could be a result of the well documented difficulty of quantifying $\mathrm{Cr}$ in the 
presence of Fe, due to matrix interferences. As stated in EPA (2007), “...chromium (Cr) will be enhanced at the expense of $\mathrm{Fe}$ because the absorption edge of $\mathrm{Cr}$ is slightly lower in energy than the fluorescent peak of iron." Using the Dual Beam Mining mode suite, $\mathrm{Mg}, \mathrm{Cl}, \mathrm{Ag}$, and, in a few cases, $\mathrm{K}$ and $\mathrm{P}$ were under the limit of detection or were unable to be detected by the analyzer.

The criteria for determining the quality of precision for the hhEDXRF follows the three levels of data quality put forth by USEPA (1998); definitive ( $\mathrm{r} 2=0.85-1.0$ and relative standard deviation $(\mathrm{RSD}) \leq 10 \%)$, quantitative $(\mathrm{r} 2=0.70$ to 1.0 and $\mathrm{RSD}<20 \%)$ and qualitative $(\mathrm{r} 2<0.7$ or RSD > 20\%). RSD is calculated by multiplying the standard deviation by 100 and dividing by the mean value, a method commonly used for analyzing precision. To assess precision, two internal reference samples, IRS_7467.7 and IRS_7516.7, were scanned for 60 seconds on each beam at the beginning, intermittently throughout, and at the end of the core plug scanning session for a total of 9 times each. RSD were calculated for both IRS_7467.7 and IRS_7516.7, and all elements recorded values of $<8.8 \%$, excluding $\mathrm{Cr}$, which recorded values of $14-25 \%$. Results from scanning these two internal mudrock samples show that $\mathrm{Mg}, \mathrm{Cl}$, and $\mathrm{Ag}$ were not detected or were below the limit of detection by the hhEDXRF. In total, the precision based on repeat measurements of the internal reference samples (IRS_7542.4; IRS_7467.7; IRS_7516.7) Al, Si, K, Ca, Ti, V, Mn, $\mathrm{Fe}, \mathrm{Co}, \mathrm{Ni}, \mathrm{Cu}, \mathrm{Zn}, \mathrm{Pb}, \mathrm{Zr}$, and $\mathrm{Mo}$ are definitive, and $\mathrm{Cr}$ is qualitative (USEPA, 1998).

\subsubsection{Calibration Accuracy}

One method to assess the accuracy of an empirical calibration is to test the calibration on certified reference materials (CRM) of a known composition. To meaningfully assess accuracy, the CRM must have similar concentrations of the elements of interest and a similar matrix to the target lithology for the calibration. In many cases, finding such a standard or reference material for mudrocks that meets the aforementioned criteria is often difficult. To address this challenge a new 
internal methodology was developed to assess accuracy of the calibration. In the place of utilizing external CRMs, we utilize internal iterative "blind" tests to quantify accuracy (source code appendix A). This is accomplished by using the following methodology; (1) exclude one data point/sample, sample A, from the analysis, (2) for a specific element, element A, calculate a slope/factor from a regression between the WDXRF and hhEDXRF using the new dataset, (3) utilize the newly derived slope/factor to calibrate sample A, (4) for element A, calculate the percent difference between the calibrated sample A and its corresponding WDXRF value, (5) iteratively repeat this process by exhaustively excluding every point one at a time for each target element, and (6) for each element, aggregate the percent difference values and calculate the average. The iterative blind test method provides a comprehensive accuracy test of the regression through testing the calibration quality with samples that range from low, middle, and high concentrations for each element. Favorably, such "internal" blind tests are conducted on the lithology of interest (similar composition and matrix), enabling a direct comparison when calculating accuracy.

The iterative blind test method was executed on all study elements, and results are displayed in Table 4. The effect of elemental concentrations on the percent difference value can provide insight on the reliable detection limit (RDL) for each element. A graph of calcium concentration, as measured by the WDXRF, versus the percent difference demonstrates the concentration effect (figure 2-6). The RDL is defined as values with $<20 \%$ difference at a specified elemental concentration. For majority of elements measured, including Aluminum (figure 2-7), error had no relationship with elemental concentrations, which indicates the RDL was not approached for those specific elements. 
Table 2-4. For each target element, percent difference (\%Diff) between the calibrated hhEDXRF and WDXRF values. For elements with values below the RDL, the RDL, average percent difference of values $>$ RDL ( $>$ RDL Av. \%Diff), number of samples $>$ RDL are displayed. Element that do not have concentrations that approach the RDL are denoted as "na", meaning the RDL is "not achieved."

\begin{tabular}{cccccc} 
Element & Av. \%Diff. & Av. $r^{2}$ & RDL & $\begin{array}{c}\text { > RDL Av. } \\
\text { \%Diff. }\end{array}$ & $\begin{array}{c}\text { of } \\
\text { Samples } \\
\text { RDL }\end{array}$ \\
\hline $\mathrm{Si}$ & 4.42 & 0.78 & $n a$ & $n a$ & $n a$ \\
$\mathrm{Ti}$ & 5.28 & 0.93 & $n a$ & $n a$ & $n a$ \\
$\mathrm{Al}$ & 3.69 & 0.97 & $n a$ & $n a$ & $n a$ \\
$\mathrm{Fe}$ & 5.07 & 0.91 & $n a$ & $n a$ & $n a$ \\
$\mathrm{Mn}$ & 11.32 & 0.95 & $>0.01$ & 8.50 & 91.8 \\
$\mathrm{Ca}$ & 19.52 & 0.99 & $>1$ & 7.88 & 71.9 \\
$\mathrm{~K}$ & 34.19 & 0.51 & $>2.5$ & 26.88 & 90.0 \\
$\mathrm{Ni}$ & 6.45 & 0.96 & $n a$ & $n a$ & $n a$ \\
$\mathrm{Cr}$ & 12.14 & 0.17 & $>70$ & 10.13 & 93.7 \\
$\mathrm{~V}$ & 38.36 & 0.72 & $>350$ & 15.88 & 64.9 \\
$\mathrm{Cu}$ & 9.62 & 0.93 & $n a$ & $n a$ & $n a$ \\
$\mathrm{Zn}$ & 9.50 & 0.99 & $n a$ & $n a$ & $n a$ \\
$\mathrm{Zr}$ & 6.58 & 0.80 & $n a$ & $n a$ & $n a$ \\
$\mathrm{Mo}$ & 11.52 & 0.99 & $>25$ & 6.38 & 93.8 \\
$\mathrm{~Pb}$ & 9.03 & 0.97 & $>10$ & 6.79 & 96.9
\end{tabular}




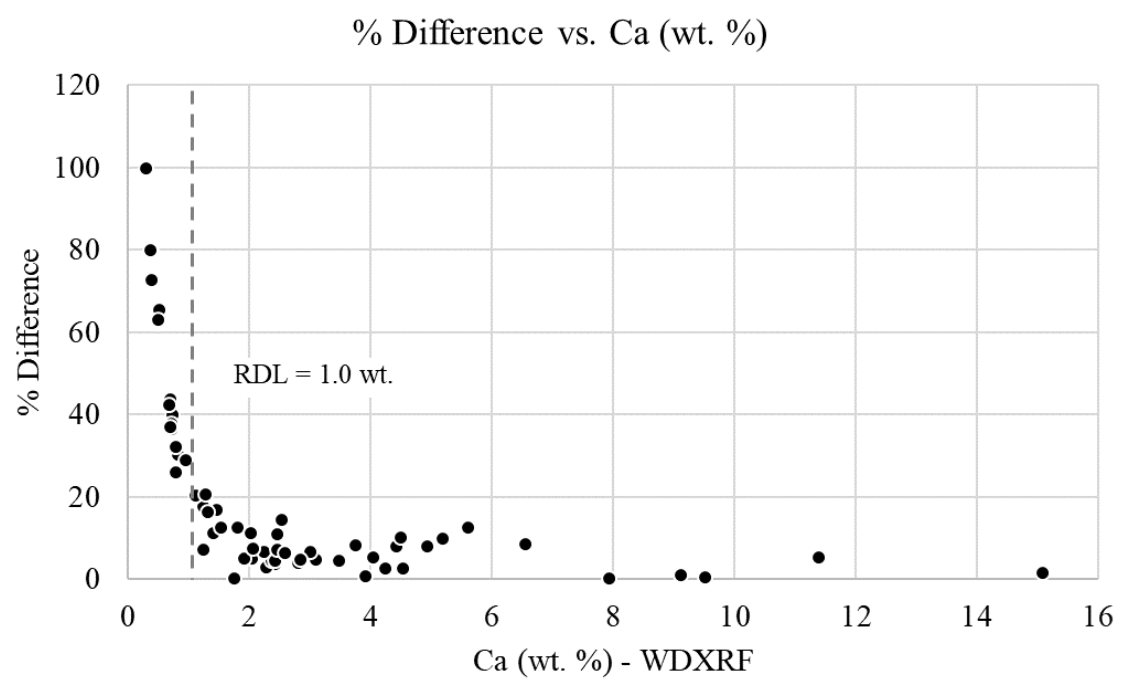

Figure 2-6. Plot of Ca versus percent difference demonstrating the concentration effect and the reliable detection limit (RDL). The RDL is defined at the concentration level of $\mathrm{Ca}$ where all following values are $<20 \%$ difference.

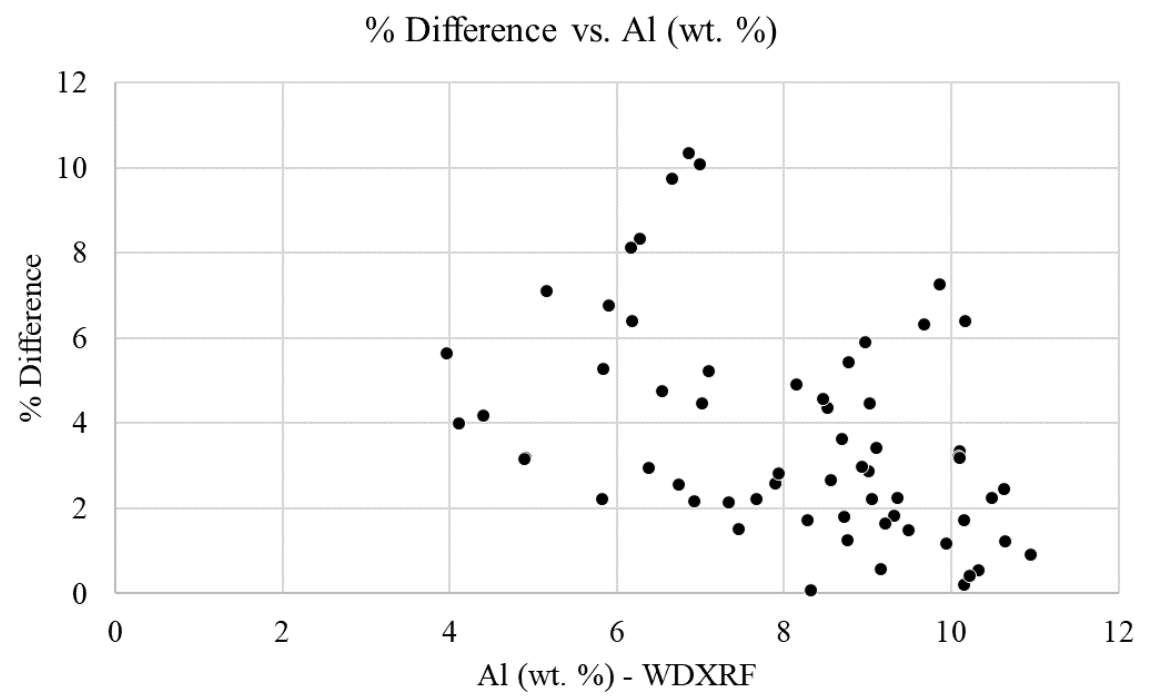

Figure 2-7. Plot of $\mathrm{Al}$ versus percent difference demonstrating the non-existence of the concentration effect as a result of not approach the RDL for this specific element in the measured samples. The absence of relationship between the concentration of $\mathrm{Al}$ and the percent difference is demonstrated. 
For field portable or handheld XRF's, the measured value for each target element should be within $+/-20 \%$ difference of the "true" value for the calibration verification check to be considered acceptable (US EPA, 1998). Si, Ti, $\mathrm{Al}, \mathrm{Fe}, \mathrm{Ni}, \mathrm{Cu}, \mathrm{Zn}$, and $\mathrm{Zr}$ record \% difference values of < 10\%. $\mathrm{Mn}, \mathrm{Ca}, \mathrm{Cr}, \mathrm{V}, \mathrm{Mo}$, and $\mathrm{Pb}$ record measurements below the reliable detection limit (RDL). For $\mathrm{Mn}, \mathrm{Ca}, \mathrm{Cr}, \mathrm{V}, \mathrm{Mo}$, and $\mathrm{Pb}$, when data points that measure below the RDL are excluded, these elements recorded percent difference values of between 6-15\% (table 2-4). Potassium recorded measurements outside of the RDL and was the only element that returned percent difference values of $>20 \%$, which is outside of the acceptable limit.

\subsection{Conclusions}

This case study outlines a methodology for creating an internal mudrock calibration. Handheld energy dispersive XRF's provide a rapid and non-destructive means for collecting elemental data. Of XRF modes typically used, WDXRF is the analytically superior technique, but typically requires sample destruction, more arduous laboratory preparation, and longer run times. Herein we provide a methodology to merge the strongest aspects of both XRF modes through creating a mudrock-specific calibration for the hhEDXRF. The proposed mudrock calibration was created using the method of linear regression to find the line of best fit for a series of $\mathrm{x}$ (WDXRF) and $\mathrm{y}$ (hhEDXDRF) for each individual element measured from the mudrock core plug samples. Results found that $\mathrm{Mg}, \mathrm{Cl}, \mathrm{Ag}$, and $\mathrm{P}$ were under the hhEDXRF's limit of detection in the mudrock samples. Of the elemental suite reported by the hhEDXRF, the WDXRF does not report values

for $\mathrm{Ag}, \mathrm{Cd}, \mathrm{Co}, \mathrm{Sb}$, and $\mathrm{W}$ and were not included in this study. Both XRF methods returned values on the following elements: $\mathrm{Al}, \mathrm{Si}, \mathrm{Ti}, \mathrm{Fe}, \mathrm{Mn}, \mathrm{Ca}, \mathrm{K}, \mathrm{Zr}, \mathrm{Mo}, \mathrm{Pb}, \mathrm{Zn}, \mathrm{Cu}, \mathrm{Ni}, \mathrm{Cr}, \mathrm{V}, \mathrm{Bi}, \mathrm{Hf}, \mathrm{Sn}$, 
and P. A linear equation was then calculated and by using this equation for each element, the hhEDXRF value was "calibrated" to the WDXRF value.

The precision of the hhEDXRF was calculated from repeat measurements of the internal reference samples, and from this we find precision of $\mathrm{Al}, \mathrm{Si}, \mathrm{K}, \mathrm{Ca}, \mathrm{Ti}, \mathrm{V}, \mathrm{Mn}, \mathrm{Fe}, \mathrm{Co}, \mathrm{Ni}, \mathrm{Cu}, \mathrm{Zn}$, $\mathrm{Pb}, \mathrm{Zr}$, and $\mathrm{Mo}$ are definitive, and $\mathrm{Cr}$ is qualitative (EPA, 1998). Measurements from the hhEDXRF and WDXRF recorded the following correlations: Zn, Mo, and $\mathrm{Ca}\left(\mathrm{r}^{2}>0.99\right), \mathrm{Al}, \mathrm{K}, \mathrm{Ti}$, Fe, $\mathrm{Ni}, \mathrm{V}, \mathrm{Cu}$, and $\mathrm{Pb}\left(\mathrm{r}^{2}>0.92\right), \mathrm{Zi}$ and $\mathrm{Si}\left(\mathrm{r}^{2}>0.78\right)$, and $\mathrm{Cr}\left(\mathrm{r}^{2}=0.56\right) . \mathrm{Bi}, \mathrm{Hf}$, and $\mathrm{Sn}$ were found to be only elements uncorrelated, with $\mathrm{r}^{2}$ values of $0.03,0.15$, and 0.004 respectively, and were excluded from the study. Analyzer accuracy, quantified by iterative blind tests, recorded percent difference values of $<10 \%$ for $\mathrm{Si}$, Ti, $\mathrm{Al}, \mathrm{Fe}, \mathrm{Ni}, \mathrm{Cu}, \mathrm{Zn}$, and $\mathrm{Zr}$. $\mathrm{Mn}, \mathrm{Ca}, \mathrm{Cr}, \mathrm{V}, \mathrm{Mo}$, and $\mathrm{Pb}$ record measurements below the reliable detection limit (RDL). For $\mathrm{Mn}, \mathrm{Ca}, \mathrm{Cr}, \mathrm{V}, \mathrm{Mo}$, and $\mathrm{Pb}$, when data points that measure below the RDL are excluded, these elements recorded percent difference values of between 6-15\%. Potassium recorded measurements outside of the RDL and was the only element that returned percent difference values of $>20 \%$, which is outside of the acceptable limit. Strong correlations and inferential statistics for the target elements demonstrate that elemental data collected by the hhEDXRF (Olympus Innov-X DELTA Premium Handheld XRF Analyzer) and calibrated with the internal mudrock calibration returns rapid, precise and accurate results over a large number of samples without sample destruction. Of equal importance as the lithology-specific calibration is careful sample preparation and analysis. Sufficiently homogenizing samples, collecting multiple data points within a sample to better represent sample composition and reducing the large grain or "nugget" effect by creating a smooth sample surface, and maintaining level contact between sample and analyzer provides the foundation for creating a dataset of high analytical quality. 


\subsection{References}

Billets, S., 2006. Innovative Technology verification report XRF technologies for measuring trace elements in soil and sediment XCALIBUR ELVAX XRF analyzer. US Environmental Protection Agency, Washington, DC. EPA/540/R-06/006 (NTIS PB2006-109028).

Brouwer, P., 2006. Theory of XRF. Almelo, Netherlands: PANalytical BV.

Conrey, R. (Ed.). (2018). Instrumentation. Retrieved February 13, 2019, from https://www.hamilton.edu/academics/analytical-lab/instrumentation

Croudace, I.W., Rindby, A., Rothwell, R.G., 2006. Description and evaluation of a new multifunction X-Ray core scanner. In: Rothwell, R.G. (Ed.), New Techniques in Sediment Core Analysis, Geological Society, London, Special Publications, vol. 267, pp. 51-63.

De Maesschalck, R., Jouan-Rimbaud, D., \& Massart, D. L. 2000. The Mahalanobis distance. Chemometrics and Intelligent Laboratory Systems, 50 (1): 1-18.

EPA, U., 2007. Method 6200: Field Portable X-Ray Fluorescence Spectroscopy for the Determination of Elemental Concentrations in Soil and Sediment.

Fitton, G., 1997. X-ray fluorescence spectrometery. In: Gill, Robin (Ed.), Modern Analytical Geochemistry. Addison Wesley Longman. 329 pp. 
Haschke, M., 2014. XRF-Basics. In Laboratory Micro-X-Ray Fluorescence Spectroscopy (pp. 117). Springer, Cham.

Hupp, B.N. and Donovan, J.J., 2018. Quantitative mineralogy for facies definition in the Marcellus Shale (Appalachian Basin, USA) using XRD-XRF integration. Sedimentary Geology, 371, pp.1631.

Innov-X Systems, Delta HHXRF Analyzers Limits of Detection (LODs), 2010. PDF File.

Jmp.com. (2019). Multivariate Robust Outliers. [online] Available at: https://www.jmp.com/support/help/14-2/multivariate-robust-outliers.shtml [Accessed 15 Jan. 2019].

Kalnicky, D.J. and Singhvi, R., 2001. Field portable XRF analysis of environmental samples. Journal of hazardous materials, 83(1-2), pp.93-122.

Lash, G.G. and Blood, D.R., 2014. Organic matter accumulation, redox, and diagenetic history of the Marcellus Formation, southwestern Pennsylvania, Appalachian basin. Marine and Petroleum Geology, 57, pp.244-263.

Löwemark, L., Chen, H.F., Yang, T.N., Kylander, M., Yu, E.F., Hsu, Y.W., Lee, T.Q., Song, S.R. and Jarvis, S., 2011. Normalizing XRF-scanner data: a cautionary note on the interpretation of 
high-resolution records from organic-rich lakes. Journal of Asian Earth Sciences, 40(6), pp.12501256.

Mainali, P., 2012. Chemostratigraphy and the paleoceanography of the Bossier-Haynesville Formation, East Texas Basin, Texas and LA, USA.

McNulty, B.A., Fox, N., Berry, R.F. and Gemmell, J.B., 2018. Lithological discrimination of altered volcanic rocks based on systematic portable X-ray fluorescence analysis of drill core at the Myra Falls VHMS deposit, Canada. Journal of Geochemical Exploration, 193, pp.1-21.

Newlander, K., Goodale, N., Jones, G.T. and Bailey, D.G., 2015. Empirical study of the effect of count time on the precision and accuracy of pXRF data. Journal of Archaeological Science: Reports, 3, pp.534-548.

Office of Solid Waste and Emergency Response, US EPA, Test Methods for Evaluating Solid Waste, $3^{\text {rd }}$ Edition, Update 3, SW-846, December 1996; Field Portable X-Ray Fluorescence Spectrometry for the Determination of Elemental Concentrations in Soil and Sediment, Method 6200, Revision 0, January 1998.

Potts, P.J. and Webb, P.C., 1992. X-ray fluorescence spectrometry. Journal of Geochemical Exploration, 44(1-3), pp.251-296. 
Rothwell, R.G. and Rack, F.R., 2006. New techniques in sediment core analysis: an introduction. Geological Society, London, Special Publications, 267(1), pp.1-29.

Rowe, H., N. Hughes, K. Robinson, 2012, The quantification and application of handheld energydispersive $\mathrm{x}$-ray fluorescence (ED-XRF) in mudrock chemostratigraphy and geochemistry: Chemical Geology, v. 324-325, p. 122-131, doi:10.1016/j.chemgeo.2011.12.023.

Schovsbo, N.H., Nielsen, A.T., Harstad, A.O. and Bruton, D.L., 2018. Stratigraphy and geochemical composition of the Cambrian Alum Shale Formation in the Porsgrunn core, SkienLangesund district, southern Norway. Bulletin of the Geological Society of Denmark, 66(1).

Shi, J., Jin, Z., Liu, Q., Huang, Z. and Hao, Y., 2018. Terrestrial sedimentary responses to astronomically forced climate changes during the Early Paleogene in the Bohai Bay Basin, eastern China. Palaeogeography, Palaeoclimatology, Palaeoecology, 502, pp.1-12.

Templ, M., Filzmoser, P. and Reimann, C., 2008. Cluster analysis applied to regional geochemical data: problems and possibilities. Applied Geochemistry, 23(8), pp.2198-2213.

Thermo Scientific, 2012. Complete Soil and Sediment Analysis Thermo Scientific ARL PERFORM'X Series Advanced X-Ray Fluorescence Spectrometers, tools.thermofisher.com/content/sfs/brochures/XR-AN41665-ARL\%20PERFORMXSoil\%20Sediment-0312.pdf 
Turner, B.W., Tréanton, J.A. and Slatt, R.M., 2016. The use of chemostratigraphy to refine ambiguous sequence stratigraphic correlations in marine mudrocks. An example from the Woodford Shale, Oklahoma, USA. Journal of the Geological Society, 173(5), pp.854-868.

Ward, J.H., 1963. Hierarchical grouping to optimize an objective function. Journal of the American statistical association, 58(301), pp.236-244.

Yarbrough, L.D., Carr, R. and Lentz, N., 2019. X-ray fluorescence analysis of the Bakken and Three Forks Formations and logging applications. Journal of Petroleum Science and Engineering, 172, pp.764-775.

Young, K.E., Evans, C.A., Hodges, K.V., Bleacher, J.E. and Graff, T.G., 2016. A review of the handheld X-ray fluorescence spectrometer as a tool for field geologic investigations on Earth and in planetary surface exploration. Applied Geochemistry, 72, pp.77-87.

Zhang, S., Cao, Y., Liu, K., Jahren, J., Xi, K., Zhu, R., Yang, T., Cao, X. and Wang, W., 2019. Characterization of lacustrine mixed fine-grained sedimentary rocks using coupled chemostratigraphic-petrographic analysis: A case study from a tight oil reservoir in the Jimusar Sag, Junggar Basin. Marine and Petroleum Geology, 99, pp.453-472. 


\subsection{Appendix A}

Source code for Iterative Blind Test

\#Title: Iterative Blind Test - Python 3 Script

\#Author: Keithan Martin

\#Date: 10/16/2019

\#Import

import pandas as pd

import matplotlib.pyplot as plt

import numpy as np

import statsmodels.api as sm

import math

from itertools import chain

import math

\#read in file

Excel_XRF = pd.read_excel(r"(\#file with data)")

Excel_XRF.head()

\#define variables

varx = Excel_XRF["(\#Column with element measured by WDXRF)"]

vary = Excel_XRF["(\#Column with element measured by hhEDXRF)"]

\#mask variables

varx_clean $=$ varx $[$ mask $]$

vary_clean $=$ vary[mask]

\#initiate array to be filled for coefficients, $\mathrm{r}^{\wedge} 2$, and percentError

coef $=[]$

r2 = []

PercDiff $=[]$

for $\mathrm{i}$ in range(len(vary_clean)):

yTest = vary_clean[i] \#tested okay value from data

xTrue = varx_clean[i] \#tested "True" value from data

\#Remove single point iteratively from data set

test $1=$ np.append $\left(\operatorname{varx} \_c l e a n[: i]\right.$, varx_clean[i+1:])

test2 $=$ np.append(vary_clean[:i], vary_clean[i+1:])

\#Put shortened data into linear regression model (fit intercept to 0)

model $=$ LinearRegression(fit_intercept=False).fit(test1.reshape(-1,1), test2)

coef.append(model.coef_) 
r2.append(model.score(test1.reshape(-1,1), test2))

$\mathrm{xTest}=\mathrm{yTest} /$ model.coef

PercDiff.append $(((\operatorname{abs}(x T e s t-x T r u e) /(x T r u e)) * 100)[0])$

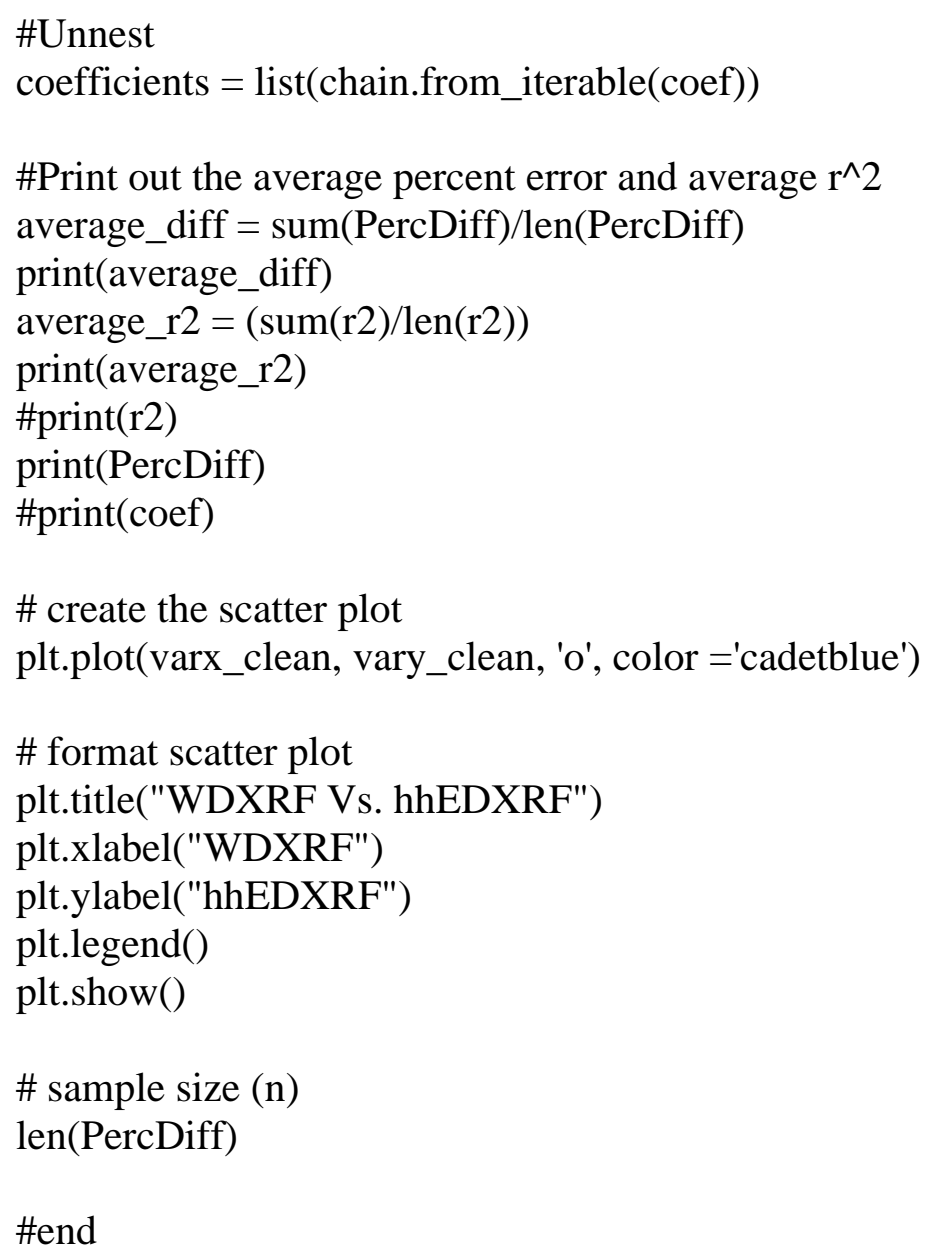




\section{Relationships between Lineal Fracture Intensity and Chemical Composition in the Marcellus Shale, Appalachian Basin}

*Keithan G. Martin¹: kgm0002@mix.wvu.edu

Liaosha Song²: liaoshasong@gmail.com

Payam Kavousi1ํ.pkavousi@mix.wvu.edu

Timothy R. Carr': tim.carr@mail.wvu.edu

${ }^{1}$ Department of Geology and Geography, West Virginia University, Morgantown, WV 26506

${ }^{2}$ Department of Geological Sciences, California State University, Bakersfield, Bakersfield, CA 93311

\subsection{Abstract}

Within mudrock reservoirs, brittle zones undergo failure during hydraulic stimulation, creating numerous artificial fractures which enable hydrocarbons to be liberated from the reservoir. Natural fractures in mudrock reduce the tensile strength of the host rock, creating planes of weaknesses that are hypothesized to be reactivated during hydraulic stimulation. Combined, brittleness and natural fractures contribute to creating more abundant and complex fracture networks during hydraulic stimulation. Research efforts toward quantifying rock brittleness have resulted in numerous mineral-/compositional-based indices, which are used during petrophysical analysis to predict zones most conducive to hydraulic stimulation. In contrast, investigations on the relationship between chemical composition and core-scale natural fractures are limited. For this study, we collected high-resolution energy-dispersive X-ray fluorescence (XRF) data, calibrated 
with a wave-dispersive XRF, from a Marcellus Shale core. Additionally, we characterized corescale natural fractures in terms of length, width, in-filling material or lack thereof, and orientation. Following the characterization, we transformed the natural fracture data into a continuous P10 (lineal fracture intensity) curve, expressed as the number of fractures per a one-half foot window. Using these data sets, we investigated the relationship between rock composition and natural fracture intensity. Regression analyses recorded positive relationships between natural fracture intensity and calcium, silicon/aluminum, and total organic carbon (TOC), and negative relationships with silicon and aluminum. Aluminum recorded the strongest (negative) relationship $(\mathrm{r} 2=0.379)$ with natural fracture intensity. To access the degree to which natural fractures can be predicted based on chemical composition, we applied a partial least-squares analysis, a multivariate method, and recorded an $\mathrm{r} 2=0.56$. Our study illustrates that although numerous factors are responsible for natural fracture genesis, such fractures predictively concentrate in areas of similar chemical composition, largely in zones with low aluminum concentrations.

\subsection{Introduction}

The term "mudrock" will be used following Blatt et al. (1972), who uses mudrock as a broad term for fine- to very fine grained rocks ( $<62.5 \mu \mathrm{m}$ in diameter) dominated ( $>50 \%$ of grains) by varying degrees of silt, mud, and clay concentration, and include both fissile and non-fissile rock. When further divided, fissile and non-fissile mudrock are termed "shale" and "stone" respectively, and are modified by the dominate grain size, such that a silt-rich, non-fissile mudrock would be termed a siltstone. Mudrock is a useful term for the Marcellus Shale specifically, as it contains a spectrum of such fine- to very-fine grained rocks. 
Mudrock reservoirs are characterized by nanometer-to micrometer-size pores and nano-to microdarcy permeability (Loucks et al., 2012; Peng and Loucks, 2016; Milad and Slatt, 2018). Such reservoir characteristics significantly impede the ability for hydrocarbons to flow through the formation into the borehole. Advances in hydraulic fracturing technology over the last decade has allowed for the exploitation of hydrocarbons from mudrock reservoir by generating artificial fractures, which create permeability for liquid and gaseous hydrocarbons to flow through rock into the borehole.

Rock brittleness and ductility are key variables in determining a rock's conduciveness to hydraulic stimulation. A ductile rock will absorb a high amount of energy before fracturing, while a brittle rock will fail and more readily form fractures (Zhang et al., 2015). Research efforts have attempted to quantify brittleness through mechanical testing, mineral content, elastic parameters, and sedimentary characteristics (Chang et al., 2006). Within silica-rich Woodford Shale intervals, anisotropic features, such as laminations and bedding, were characterized by lower resistance to fracture and tensile strength, indicating anisotropic features may contribute to the fracability of a unit (Molinares et al., 2017). In addition to anisotropic features, mineral composition plays a large role in the overall brittleness of a rock (Jarvie et al. 2007; Slatt and Abousleiman, 2011). It is now widely held that enrichment of silica contributes to brittleness, while an enrichment of TOC and clay increase ductility. Jarvie et al. (2007) concluded that silica was the only contributor to brittleness, while clay and carbonate increased ductility. Wang and Gale (2009) found similar results, but differentiated between dolomite and calcite, claiming that while calcite does contribute to ductility, dolomite has a brittle behavior. More recently, Jin et al. (2014) concluded that quartz, feldspars, brittle mica, and carbonate all contribute to brittleness. 
Within unconventional mudrock exploration, units with high total organic carbon (TOC) are desirable. The fact that TOC contributes to ductility complicates locating zones that are both organic rich and also conducive to artificial stimulation. Using Passey's method to derive TOC and the brittleness equation of Wang and Gale (2009), Verma et al. (2016) confirmed that TOC has a negative relationship with brittleness.

In addition to rock brittleness, natural fractures play a significant role in the effectiveness of hydraulic stimulation (Olson et al., 2001; Rijken, 2005; Gale and Holder, 2007). It has been hypothesized that natural fractures form as a result of potentially one or a number of mechanisms, including tectonic events that cause local and regional stress changes, uplift, differential compaction, strain from the accommodation of large structures, and catagenesis (Neuzil and Pollock, 1983; Jowett, 1987; Price, 1997; Rodrigues et al., 2009; Engleder et al., 2009; Gale et al., 2007; Milad and Slatt, 2018). Natural fractures, either mineralized (sealed) or open, can reactivate during hydraulic stimulation and create more complex fracture networks than could be achieved with a single hydraulic fracture (Gale and Holder, 2007). This is largely because natural fractures, in some cases, can act as a plane of weakness. Within the Barnett Shale, Wang and Gale (2009) observed that calcite-filled fractures were half as strong as an unbroken rock due to the lack of chemical bonding between the calcite in-filling the natural fracture and the fractured host rock. In addition to academic studies, empirical observations made during analysis of the Marcellus Shale core show that breakages/fractures along mineralized fractures and anisotropic planes occur at a rate much higher than a fractureless or more massive cored interval.

Both brittleness and natural fractures play a role in the effectiveness of hydraulic stimulation. While knowledge on the relationship between chemical composition and rock brittleness have advanced, studies addressing the relationship between chemical composition and 
core-scale natural fracture presence are lacking. To address this shortcoming, we use highresolution x-ray fluorescence data and detailed natural fracture data collected from the study well core to define the relationship between chemical composition and natural (open and mineralized) fractures. Questions that will be addressed include:

1) Do natural fractures preferentially concentrate in rock of certain chemical composition in a statistically meaningful way,

2) If so, what chemical composition is most likely to have a positive or negative relationship with natural fracture presence,

3) Are the relationships strong enough for natural fracture prediction based on chemical composition,

4) If so, can existing mineral-based brittleness indexes also be utilized for natural fracture prediction,

5) If not, can findings be used to create a chemically-based natural fracture index for natural fracture prediction?

\subsubsection{Middle Devonian Stratigraphy of the Appalachian Basin}

The Marcellus Shale is divided into in three members, namely the Oatka Creek, Cherry Valley or Purcell Limestone, and the Union Springs members (Lash and Engelder, 2011). The Marcellus Shale is overlain by the Skaneateles Formation and overlies the Onondaga Limestone.

The Union Springs Member, informally referred to as the "lower Marcellus", is thinnest in western New York and thickens to the east and southeast, reaching a thickness exceeding $160 \mathrm{ft}$. (49 m.) in northeastern Pennsylvanian (Lash and Engelder, 2011). This member is highly organic, 
calcareous and is characterized as a dark-gray to black mudrock containing skeletal material (Sageman et al., 2003). The lower portion of the Union Springs Member records a particularly high gamma ray response, reaching upwards of 650 API units. This interval is characterized by a decrease in clay content, and a significant increase in quartz, pyrite, and total organic carbon (TOC) (Lash and Engelder, 2011). The Union Springs Member overlies the Onondoga Limestone, which is interpreted as an unconformity, but can be found to be conformable in Pennsylvania, western New York, and Ohio and Maryland (Lash and Engelder, 2011). The Cherry Valley Member, informally referred to as the "middle Marcellus" and is a stratigraphically equivalent unit of the Purcell Limestone of Pennsylvania and West Virginia, overlies the Union Spring Member (Lash and Engelder, 2011). This unit is a medium-gray packstone chiefly composed of significant skeletal debris, and contains intervals of mudrock and siltstone. The thickness of the member ranges from tens of feet in New York well over $100 \mathrm{ft}$. (30 m.) in northeastern Pennsylvania. Overlying the Cherry Valley Member is the Oatka Creek Formation, informally referred to as the "upper Marcellus". This unit is defined as a medium to dark-gray mudstone with an underlying interval of black organic-rich mudstone.

\subsubsection{Study Area and General Character of Core}

A 105-foot Marcellus Shale core, labeled Study Well No. 1, located in the south-central portion of the Appalachian basin was evaluated for this study (figure 3-1). A composite of the general character of the Marcellus Shale core is displayed in figure 3-2. Observations made during core analysis in conjunction with remarks made by Core Laboratories will be outlined starting with the deepest stratigraphic unit. 


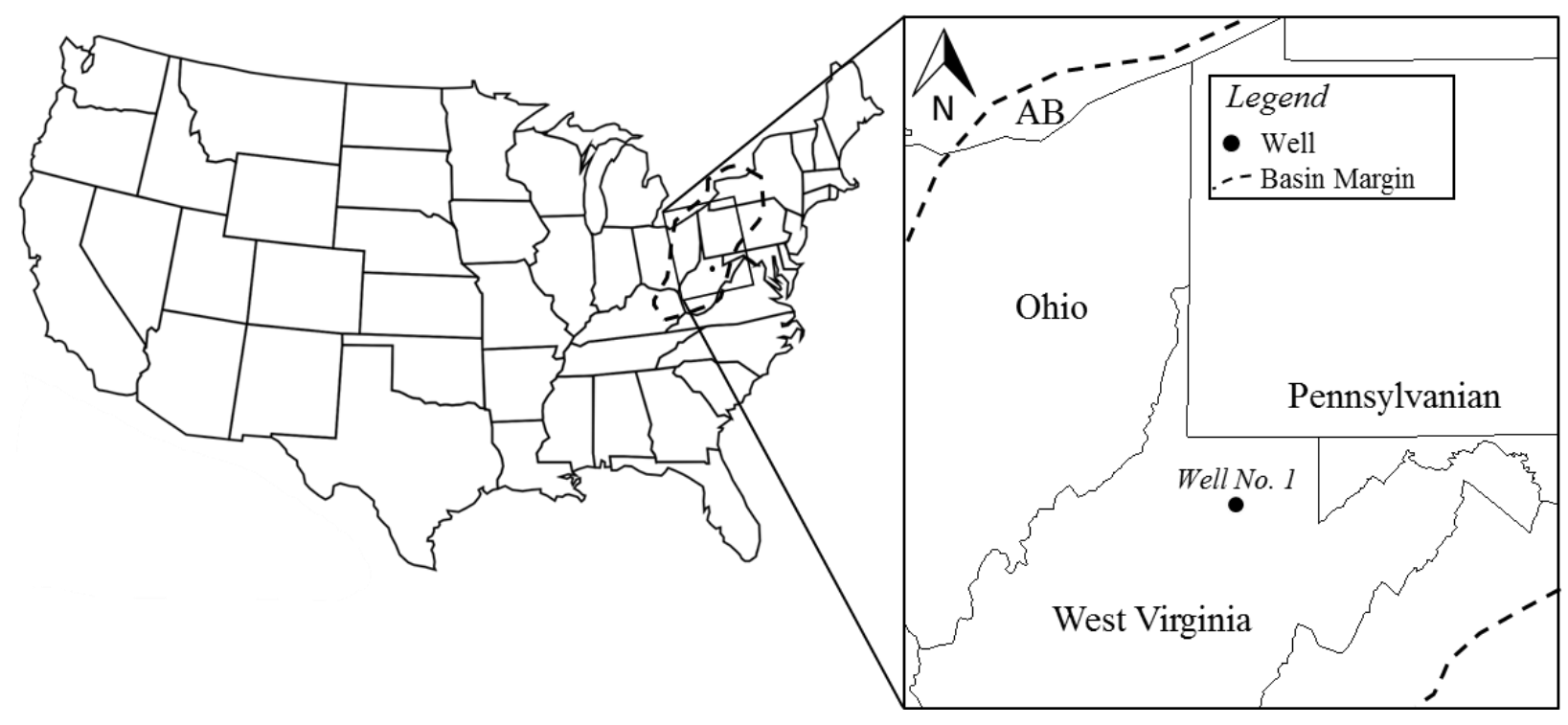

Figure 3-1. (a) United States map displaying the location of Study Well No. 1 within the Appalachian basin. The Appalachian basin, "AB", is represented by the dashed polygon. The skewed rectangle represents the study area for this research; (b) an expanded view of the study area, highlighting the location of Well No. 1 in West Virginia. The dashed lines represent the margins of the Appalachian basin.

The Onondaga Limestone is a medium-gray, heavily bioturbated, laminated, microcrystalline limestone interbedded with silty, calcarerous shale. The interbedded silty shale intervals contain brachiopods, styliolinids, and other disarticulated fossil fragments. Multiple thin volcanic ash beds are distributed throughout most Onondaga intervals. The lower Marcellus Shale is a grayish black to dark gray, massively bedded, calcareous, organic-rich silty shale. This interval contains significant pyritic content; laminations, concretions, and nodules. As this intervals comes in closer contact with the underlying Onondaga Limestone, the silty shale becomes more calcareous and natural fractures concentration increases, most of which are infilled with calcite. Moving up the interval, the upper Marcellus Shale is massive to laminated, and is less calcareous 
than its lower counterpart, although calcareous concretions are still present in small number. Pyrite nodules and pyritized fossils become more prevalent further up the interval and clay content is moderate.

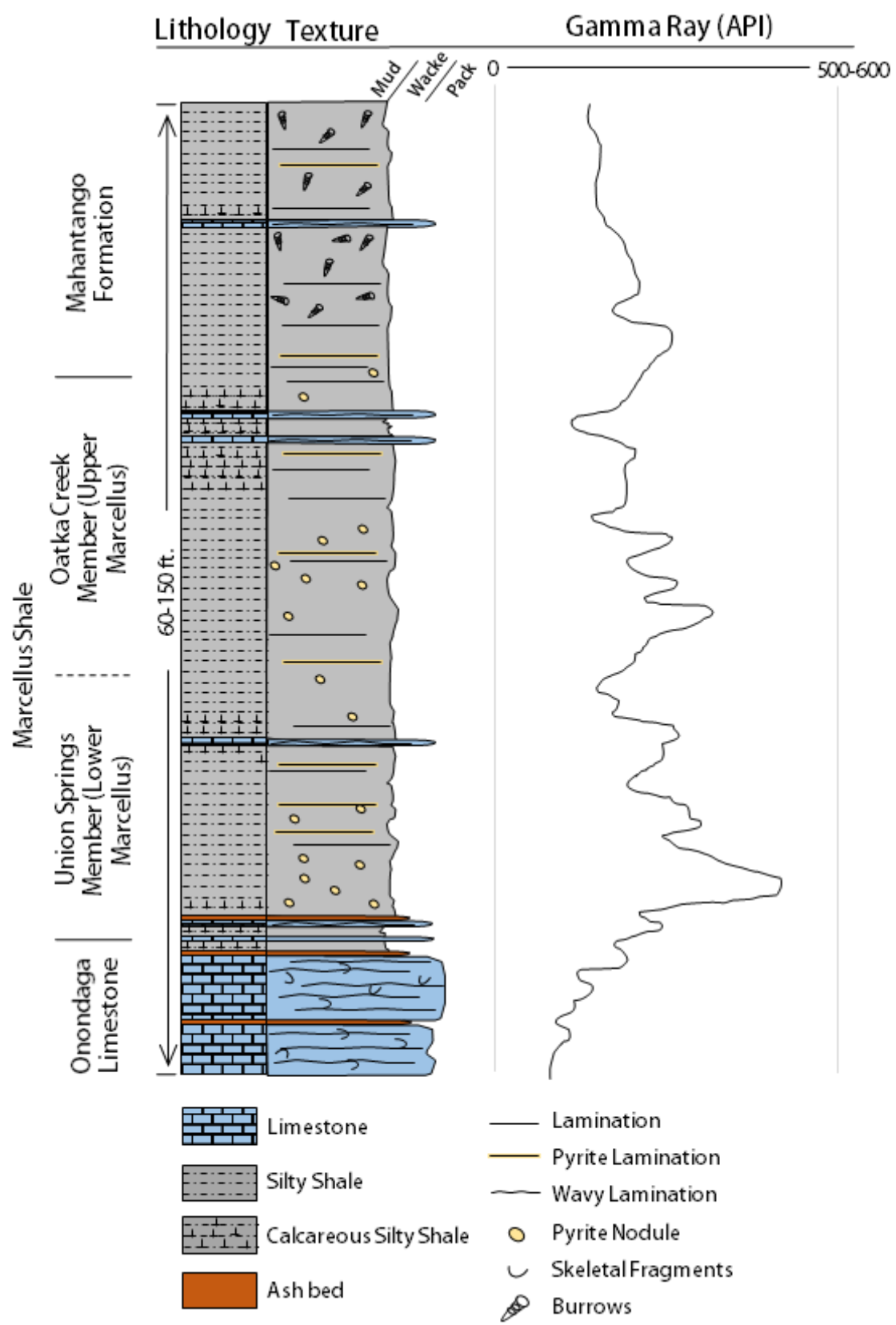

Figure 3-2. Composite of general characteristics of core from Study Well No. 1 and 2 displaying the formations, lithology, texture profile and gamma ray signature. 
Moderate to high organic content continues through most of the Marcellus Shale interval. The lower Manhantango Formation is a medium-dark gray, bioturbated, silty mudstone to calcareous mudstone. Gastropods and brachiopods make up the bulk of skeletal debris, with crinoids, coral, and styliolinids making up the remaining fraction. Burrows are common, with many infilled with pyrite. The upper Manhantango most notable differs through the loss calcareous intervals, trace fossil presence, and pyrite infill, laminations, and nodules.

\subsubsection{Brittleness}

Brittleness is defined as the measurement of the ability of rock to fail (crack or fracture), representing a complex interplay between rock strength, lithology, texture, effective stress, temperature, fluid time, diagenesis, and TOC (Wang and Gale, 2009; Davis and Reynolds, 1996; Wells, 2004). Rock brittleness is a key variable in determining a rock's conduciveness to hydraulic stimulation. Brittleness and, it's inverse, ductility are derived rock properties widely used to describe the deformation of a rock under stress. When brittleness is calculated over numerous feet of rock, it is often referred to as a brittleness index. During hydraulic stimulation, a high brittleness index is most likely to indicate the following three positive characteristics; efficient fracture initiation and propagation, increased fracture complexity, and resistance to proppant embedment (Kais et al., 2015). A ductile rock will absorb a high amount of energy before fracturing, while a brittle rock will fail under a lower amount of energy and will form fractures (Rickman et al. 2008; Kundert and Mullen, 2009: Zhang et al., 2015). In the case that sufficient energy is applied to a ductile rock and is subsequently fractured, and the newly created fractures are held open by proppants, the ductile rock will "heal" the fractures by embedding the proppants, compromising permeability. 
Mineral composition plays a large role in the overall brittleness of a rock (Jarvie et al., 2007; Slatt and Abousleiman, 2011). It is widely held that brittleness has a positive relationship with increasing quartz content, while ductility has a positive relationship with increasing clay minerals and total organic carbon (TOC) (Wang and Gale, 2009; Albouelresh and Slatt, 2012; Jin et al., 2014). Initially, Jarvie et al. (2007) found that incorporating quartz as a brittle materials and calcite and clay minerals as ductile material provided a more comprehensive brittleness equation and is expresses as:

$\mathrm{BI}=\mathrm{Q} /(\mathrm{Q}+\mathrm{C}+\mathrm{CL})$

where

BI: brittleness index

Q: Quartz

C: Carbonate - calcite and dolomite, and

CL: Clay.

This brittleness equation implies quartz is the only mineral contributing to brittleness. Wang and Gale (2009) modified this equation by incorporated ideas from Wells (2004), which determined that the presence of dolomite tends to increase brittleness of mudrock, since dolomite is more brittle that limestone, and organic matter tends to increase ductility. The modified equation is defined as

$\mathrm{BI}=\mathrm{Q}+\mathrm{Dol} /(\mathrm{Q}+\mathrm{Dol}+\mathrm{Lm}+\mathrm{Cl}+\mathrm{TOC})$,

where 


\section{Dol: Dolomite}

Lm: Limestone, and

TOC: Total Organic Carbon.

In addition to defining quartz and dolomite as brittle minerals, Jin et al. (2015) observed that silicate minerals, including feldspar and mica (if the $\mathrm{X}$ ion within the chemical expression of mica, $\mathrm{X}_{2} \mathrm{Y}_{4-6} \mathrm{Z}_{8} \mathrm{O}_{2} \mathrm{O}(\mathrm{OH}, \mathrm{F} 4)$, is $\left.\mathrm{Ca}\right)$ are considered brittle minerals. It was also concluded that carbonate other than dolomite, such as calcite, were more brittle than clay minerals. Jin et al. (2014) utilized these conclusions in a new expression of brittleness:

BI: $\left(\mathrm{W}_{\mathrm{qtz}}+\mathrm{W}_{\text {carb }}\right) / \mathrm{W}_{\text {total }}$

where

$\mathrm{W}_{\mathrm{qtz}}=$ weight of quartz, feldspar, and mica

$\mathrm{W}_{\text {carb }}=$ weight of carbonates, and

$\mathrm{W}_{\text {total }}=$ total mineral weight.

\subsubsection{Geochemical Proxies}

Major elements, which make up multiple weight percent of a rocks composition, have a large effect on a rocks behavior under stress and, for this reason, will be the focal point of this study (Jarvie et al., 2007; Slatt and Abousleiman, 2011). These elements and element ratios include Si, Al, Ca, and $\mathrm{Si} / \mathrm{Al}$. Aluminum is found in common clay minerals such as smectite, illite, and chlorite. For most sedimentary deposits, Al represents the aluminosilicate fraction of the sediments and has little disposition for movement during diagenesis (Calvert and Pedersen, 1993; Morford and Emerson, 
1999; Piper and Perkins, 2004; Tribovillard et al., 2006). Due to these characteristics, it is generally considered as the main proxy for clay minerals (Sageman and Lyons, 2003). While Al, as well as titanium, are almost exclusively a product of crustal weathering, Si can both be continentally and biogenically derived (Pearce and Jarvis, 1992; Pearce et al., 1999; Sageman and Lyons, 2004). To differentiate between detrital quartz and autogenic quartz, a ratio between $\mathrm{Si}$ and $\mathrm{Al}$ is often utilized. This ratio operates off the principle that as detrital $\mathrm{Al}$ decreases or increases, detrital $\mathrm{Si}$ should also decrease or increase. A decrease in $\mathrm{Al}$ with an increase in Si indicates an increase in autogenic influence as ratio increases. Autogenic silica enrichment takes place when dissolved silica is taken from the water column by diatoms and radiolarians to produce their siliceous skeletal frame (Prothero and Schwab, 1996). Opaline quartz is unstable and commonly undergoes a phase transition into a more stable form. Upon transition, silica precipitates into a more stable form and often becomes associated with organic matter, which ultimately ends up as an organic-rich gas reservoir upon burial maturation (Blood et al., 2013). Additionally, as silica is precipitated it permeates the clay fabric of mudstones, ultimately increasing the overall brittleness of a rock unit (Blood et al., 2013). Calcium is incorporated into calcite, dolomite, and aragonite. Carbonate rocks are limestone and dolomite composed of the minerals calcite $\left(\mathrm{CaCO}_{3}\right)$ and dolomite $\left(\mathrm{CaMg}\left(\mathrm{Co}_{3}\right)_{2}\right)$ (Flugel, 2004). Particles that make up carbonate rock either precipitate directly from the sea water or are biologically formed from calcified microbes, calcareous algae, and the articulated or disarticulated skeletons of marine organism (James and Jones, 2016).

\subsection{Methods}

Geochemical data utilized in this study were collected by a handheld X-ray fluorescence (HHXRF) analyzer. HHXRF analyzers provide a non-destructive method for collecting elemental 
concentrations at centimeter resolution with detection limits in the tens of parts per million range (Lash and Blood, 2014). When investigating numerous core over hundreds of feet, the use an HHXRF, compared to other laboratory techniques such as wave-dispersive $\mathrm{x}$-ray fluorescence (WDXRF) and inductively coupled plasma mass spectrometry (ICP-MS) analysis, is significantly more cost effective and time efficient. In addition, more recent advances in the HHXRF technology have increased the analytical quality of the data. This has provoked a wider application of this technology in solving geological problems, including chemostratigraphic studies of mudrock (e.g., Rothwell and Rack, 2006; Mainali, 2011; Lowemark et al., 2011; Rowe et al., 2012; Lash and Blood, 2014).

Core from Study Well No. 1 was analyzed with the Olympus Innov-X DELTA Premium Handheld XRF Analyzer, which is equipped with a 40kV tube and large area silicon drift detector. With Delta's two-beam setting, a high $(40 \mathrm{kV})$ and low $(15 \mathrm{kV})$ beam is used to increase resolution of both major and trace elements. With the Olympus Innov-X DELTA Premium Handheld XRF Analyzer specifically, Young et al., (2016) found that data obtained through the HHXRF analyzer was comparable to bench-top XRF analysis for geologically-important elements, but loses reliability with magnesium, and any element lighter than magnesium. Similar findings were obtained in this study. HHXRF data quality were controlled by scanning internal reference samples of the Marcellus Shale to monitor instrument drift before each data collection session. To address how quantitative the data collect were, fifteen sample points taken throughout the core interval of Study Well No. 1 were scanned and subsequently plugged using a drill press. These core plugs were crushed, powdered, fused into a glass disk, and analyzed using a Thermo ARL Perform'X. The Thermo ARL Perform'X, a WDXRF, is a sequential x-ray fluorescence spectrometer capable of reading a suite of 44 elements. The WDXRF yields data that are three to five more precise than 
most HHXRFs and was calibrated with over 70 certified reference materials. A regression analysis of data collected from the HHXRF and WDXRF recorded the following R-squared values for $\mathrm{Si}$, $\mathrm{Ca}$, and $\mathrm{Al}$ respectively; 0.908, 0.986, and 0.962 (Figure 3-3A, B, and C). Using the slope-intercept equation from the regression analyses, the HHXRF data was calibrated to the WDXRF data.
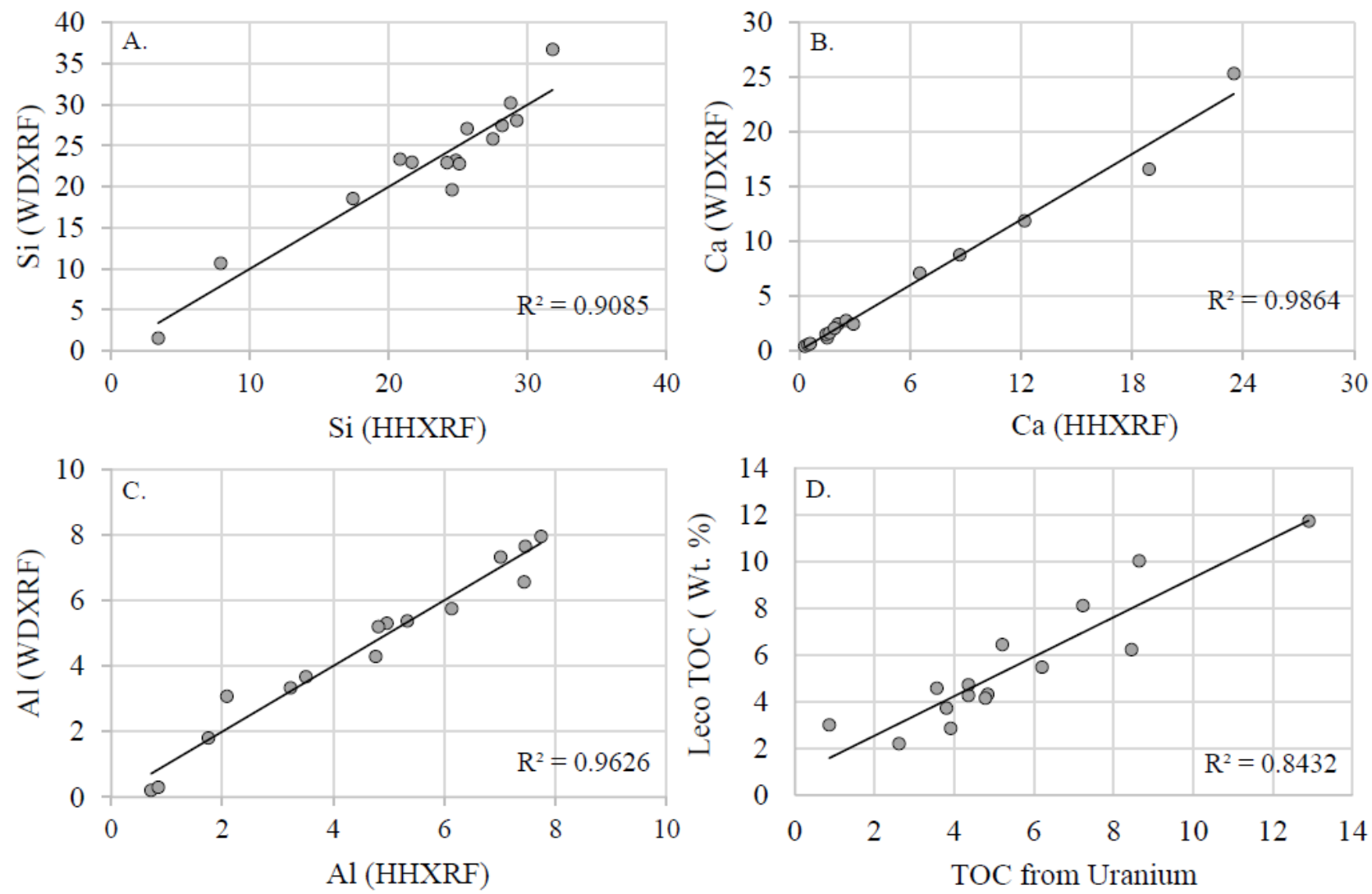

Figure 3-3A, B, and C. A, B, and C) Crossplot of elemental data ( $\mathrm{Si}, \mathrm{Ca}$, and $\mathrm{Al}$ ) collected from WDXRF and HHXRF with R-square values on display. D) Crossplot of TOC and uranium with the R-square value on display.

TOC data were available for both study wells, as well as core spectral gamma ray data. Spectral gamma ray records concentrations of thorium, potassium, and uranium. Relationships have been defined to predict TOC from uranium content collected from spectral gamma ray (Bell et al., 1940; Schomoker, 1981; Zelt, 1985; Luning Kolonic, 2003). A regression analysis between 
TOC and uranium (from spectral gamma) in Study Well No. 1 recorded an R-squared value of 0.843. To create a continuous TOC curve, the slope-intercept equation from the regression analysis was used to calibrate the uranium values to TOC (Figure 3-3D).

To access the relationship between natural fractures and chemical composition, two regression-based methods were used. First, a standard bivariate analysis was used to assess the relationship between the continuous variables. A "simple moving average" smoothing model was applied to both the natural fracture data and elemental data. Both data were smoothed over a one foot moving window. This upscaling process created a continuous lineal fracture intensity (P10) curve. The P10 curve, expressed as the number of fractures per foot, was derived to enable regression analyses between $\mathrm{P} 10$ and $\mathrm{Si}, \mathrm{Al}, \mathrm{Ca}, \mathrm{Si} / \mathrm{Al}$, and TOC. A least partial square analysis was conducted to evaluate the capabilities of $\mathrm{Al}, \mathrm{Si}, \mathrm{Ca}, \mathrm{TOC}$, and $\mathrm{Si} / \mathrm{Al}$ to predict natural fracture presence. This regression analysis method combines regression modeling, data structure simplification, and correlation analysis between two groups of variables, which maximizes the correlativity between independent and dependent variable, and improves the correlation analysis accuracy of the model (Huang, 2018).

\subsection{Results}

\subsubsection{Fracture Characterization}

Natural fracture data were collected from the Study Well No. 1 and 2 core intervals. Fractures within evaluated core intervals include drilling-induced, mineralized, and open fractures. Criteria used for differentiating artificial or drilling-induced fractures from open, natural fractures included the presence of slickensides, any signs of mineralization on the fracture surface, and rubble zones. 
Fractures evaluated include bedding-parallel fractures, vertical to sub-vertical fractures, concretion related fractures, and compacted fractures (Figure 3-4).

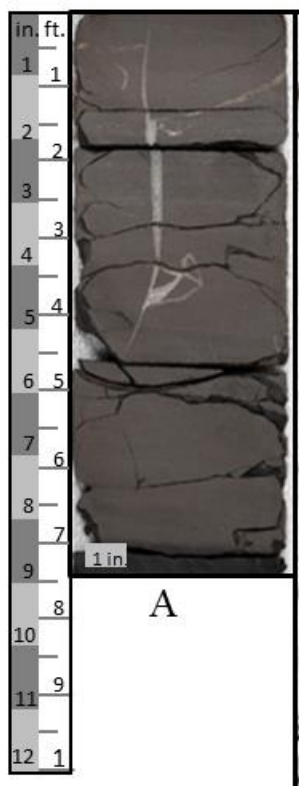

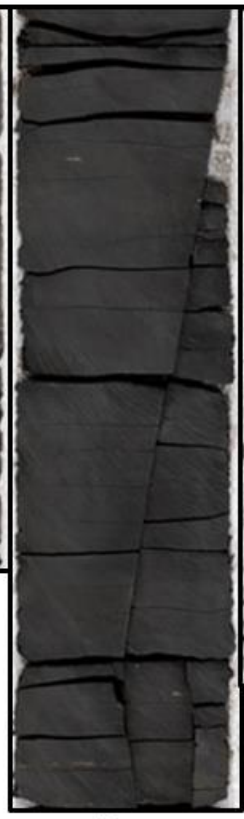

B

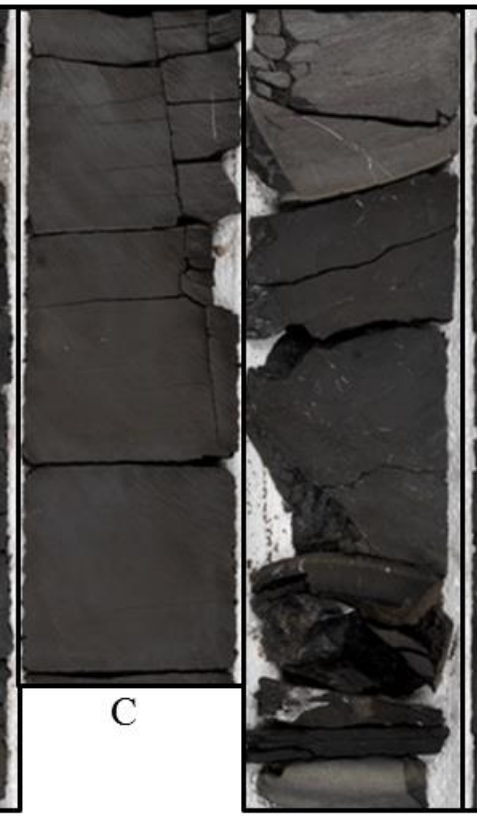

$\mathrm{D}$

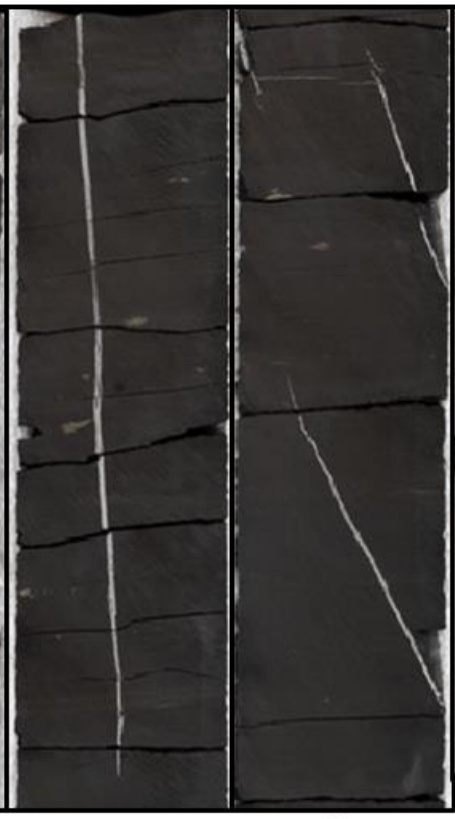

F

E

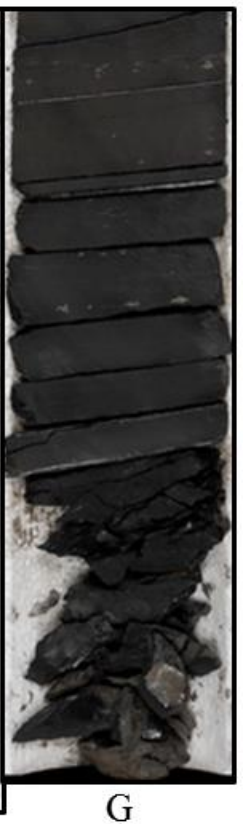

G

Figure 3-4. Display of the variety of natural and open fractures defined in this study. All mineralized fractures are infilled with calcite. A - Semi-compacted vertical mineralized fracture; B and C - Vertical to sub-vertical open fracture; D - Sub-vertical to bedding parallel open fractures; E - Vertical mineralized fractures; F - Sub-vertical mineralized fractures; G - Bedding parallel mineralized and open fractures.

Calcite is the dominate infilling mineral of the mineralized fractures, although pyrite and dolomite were scarcely present. Within the 105 -foot core from Study Well No. 1, the number of mineralized and open fractures observed were 319 and 204 respectively, with the sum of natural fractures equaling 523. Figure 3-5 integrates the natural fracture data and elemental curves in a log view. Open, mineralized, and natural (total) fractures are shown as natural fracture intensities per a halffoot window. Relatively large smoothing windows coarsen and decrease the resolution of the data, 
therefore smaller smoothing windows are desired. The half-foot window was found to be the optimal smoothing interval because it was the smallest interval that sufficiently smoothed the data to enable comparability with the geochemical data.

The foundation of this study comes from the HHXRF response of the Marcellus Shale core. To illustrate the relationships derived in this study, it is useful to see the direct elemental response to fracture presence (Figure 3-6). Figure 3-6 displays a core photo, CT scan, and standardized elemental values of $\mathrm{Si}, \mathrm{Si} / \mathrm{Al}, \mathrm{Al}$, and $\mathrm{Ca}$, as well as TOC. Figure 3-6A is an example of a core interval that contains drilling induced fractures along laminated surfaces but contains no natural fractures. As seen in the standardized elemental response, Al and silica are enriched throughout this core interval. Next, in Figure 3-6B, there is a naturally fractured zone between 7526.8 and 7527.2ft. This corresponds with a significant depletion of Si and Al, while Si/Al, an autogenic quartz proxy, is enriched. Figure 3-6C displays two zones of natural fractures. First, between 7541.6 and $7542.1 \mathrm{ft}$ there are horizontal natural fractures that corresponds with a significant depletion of $\mathrm{Si}$ and $\mathrm{Al}$, and an enrichment in $\mathrm{Si} / \mathrm{Al}$. The second set of fractures is located within a calcitic zone between 7542.6 and 7543.2. The corresponding elemental response includes a very significant depletion of $\mathrm{Si}$ and $\mathrm{Al}$, and a large enrichment of $\mathrm{Ca}$. 


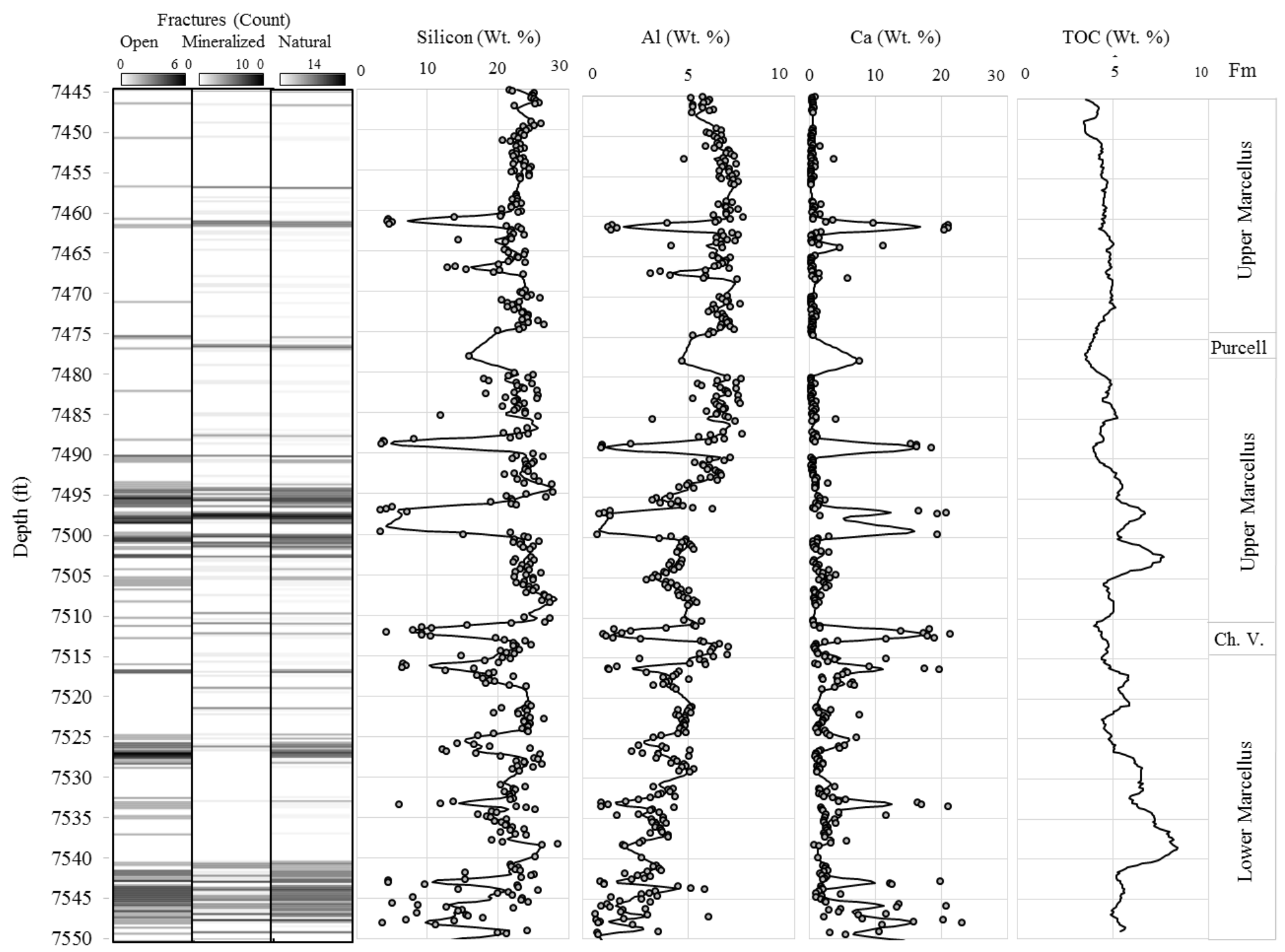

Figure 3-5. Starting on the left, fracture intensity of open, mineralized, and natural (total) fractures are displayed relative to depth. The color gradient indicates intervals that have higher frequency of fractures within a half-foot window, with white representing low to no fractures and increasing intensity becoming progressively darker. $\mathrm{Si}, \mathrm{Al}$, and $\mathrm{Ca}$ are displayed as individual data points and a smoothed curve to highlight gross trends. Formations (Fm) are located on the far right, with "Ch. V." abbreviating Cherry Valley. 

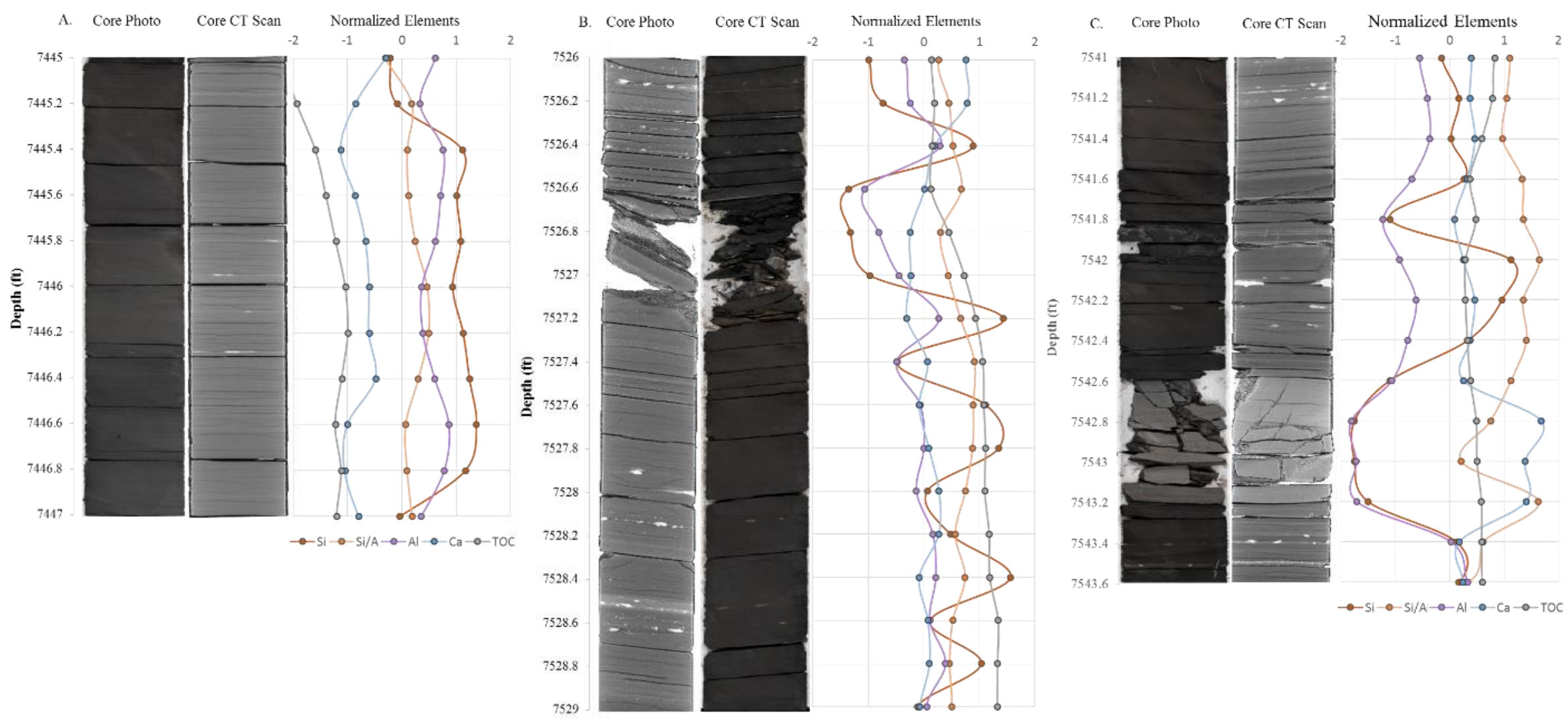

Figure 3-6A, B, and C. Display of three core intervals, including core photos, core CT scans, and normalized elemental concentrations (unitless). 


\subsubsection{Regression-Based Analyses}

From the bivariate analysis, Si recorded a weak negative relationship $\left(r^{2}=0.159\right)$ with fracture intensity, while TOC recorded a very weak positive relationship with fracture intensity $\left(\mathrm{r}^{2}=0.047\right)$. $\mathrm{Ca}$ and $\mathrm{Si} / \mathrm{Al}$ recorded weak positive relationships with fracture intensity, with $\mathrm{r}^{2}$ values of 0.118 and 0.283 respectively. $\mathrm{Al}$ recorded the strongest (negative) relationship with fracture intensity, with an $r^{2}$ value of 0.379 . The least partial square analysis, which integrated all variables to predict P10, recorded an $r^{2}$ values of 0.562 , indicating that natural fractures predictively concentrate in compositionally similar intervals (Figure 3-7 and 3-8).

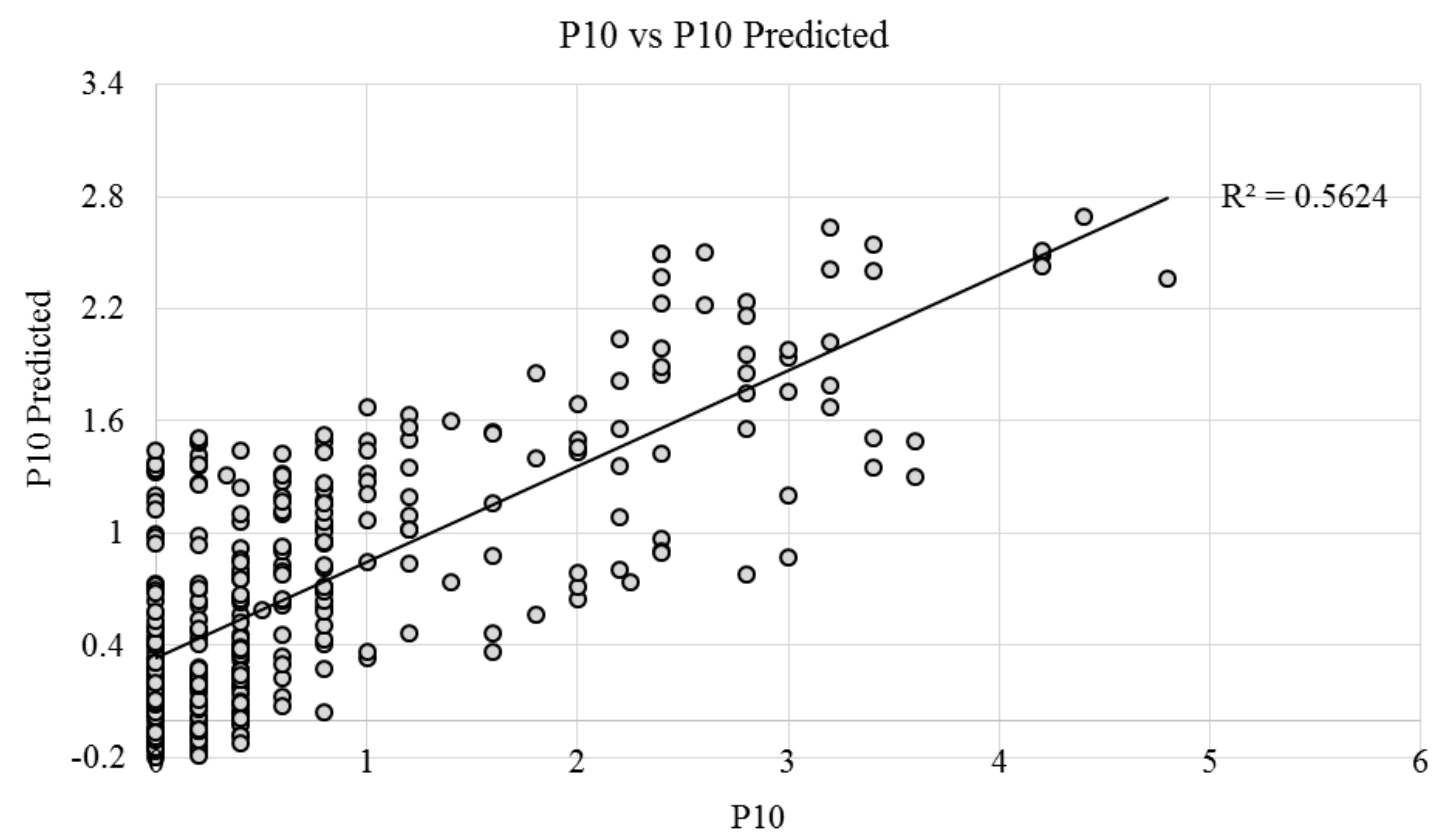

Figure 3-7. Cross plot displaying P10 predicted from the least partial square analysis on the y-axis and P10, which represents natural fracture intensity derived from core evaluation, on the $\mathrm{x}$-axis. 


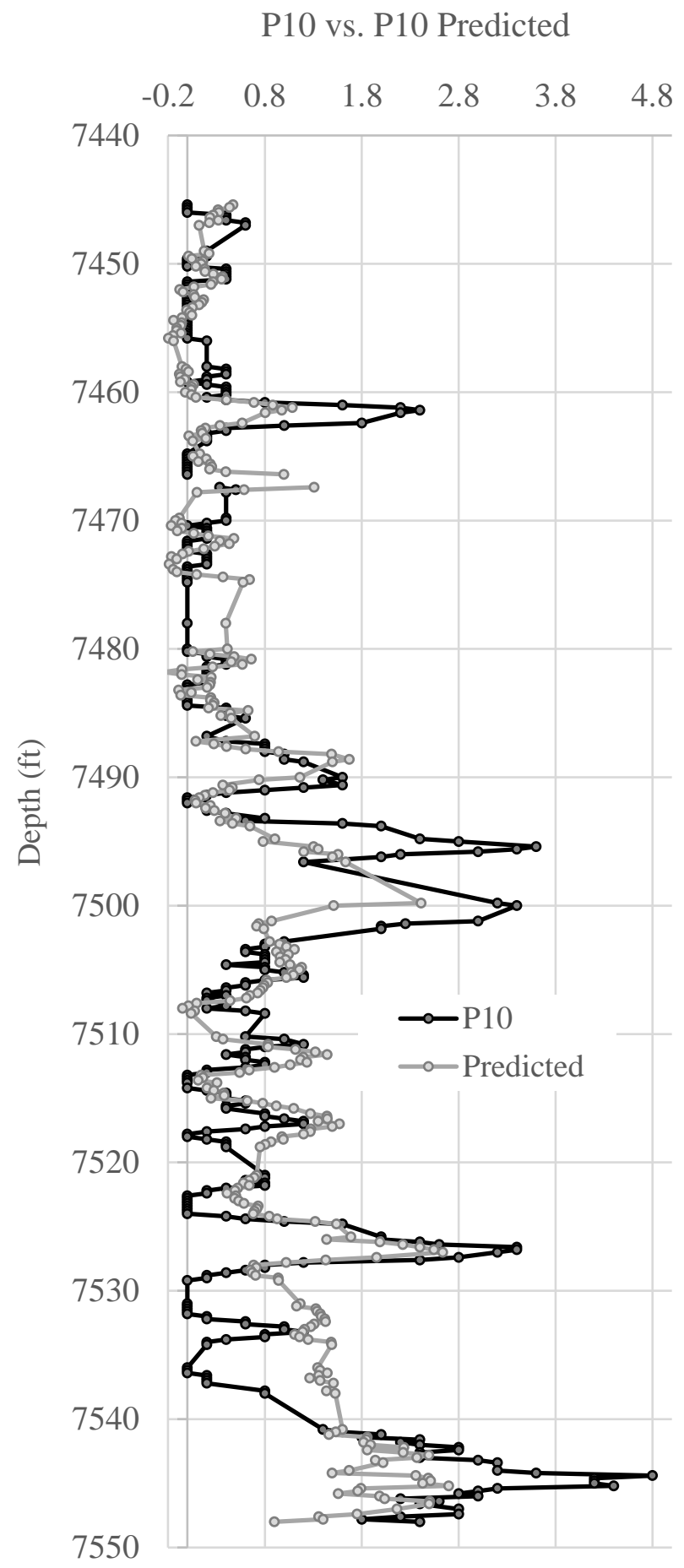

Figure 3-8. Log view showing the correlation between P10 predicted from plot the least partial square analysis in light gray and P10, which represents natural fracture intensity derived from core evaluation, in black. 


\subsection{Discussion}

Natural fractures form as a result of potentially one or a number of mechanisms, including tectonic events that cause local and regional stress changes, uplift, differential compaction, strain from the accommodation of large structures, and catagensis (Neuzil and Pollock, 1983; Jowett, 1987; Rodrigues et al., 2009; Engleder et al., 2009; Gale et al., 2007). While such variables are often difficult to quantify, numerous methods can be employed to measure, model, and predict chemical composition of rock units. Thus, this study attempts to answer the degree to which natural fractures preferentially concentrate in compositionally similar rock intervals.

Results from the statistical analyses show $\mathrm{Ca}, \mathrm{TOC}$, and $\mathrm{Si} / \mathrm{Al}$ have moderate positive relationships with $\mathrm{P} 10$, while $\mathrm{Si}$ and $\mathrm{Al}$ record negative relationships with $\mathrm{P} 10$. Enrichment in $\mathrm{Ca}$ is largely responding to calcite nodules and calcitic zones (Figure 3-6C). A conclusion that could be drawn from the weak positive correlation between $\mathrm{Ca}$ and P10 is that the material infilling mineralized fractures, which is overwhelmingly calcite, could be causing the enrichment of Ca. In this case, the enrichment could potentially be responding to the calcite infill and not the composition of the rock matrix. There are two reasons that an enrichment in $\mathrm{Ca}$ is more than a response to calcite infilling the natural fractures, and is in fact a response to the host rock. First, the HHXRF data was collected in evenly spaced increments down the center of the core to avoid sampling bias. Mineralized fractures would have to be consistently located within the center of the core for the calcite enrichment to source from mineralized fractures, which wasn't a characteristic found during core evaluation. Secondly, in general, open and mineralized fractures have a positive relationship with each other. Zones of high fracture presence with open, non-mineralized fractures often coincide with high fracture presence of mineralized fractures (Figure 3-5). This provides 
evidence that $\mathrm{Ca}$ enrichment within highly fractured zones is a response to the overall chemical composition of rock, as opposed to the calcite infilling the natural fracture.

TOC has a complex relationship with natural fracture presence. As made clear by Wang and Gale (2009) and others, TOC contributes to ductility, although TOC displayed a weak positive relationship with increasing fracture intensity (Figure 3-6B). As stated previously, autogenic silica (approximated by $\mathrm{Si} / \mathrm{Al}$ ) enrichment takes place when dissolved silica is taken from the water column by diatoms and radiolarians to produce their opaline skeletal frame. Upon dissolution, silica precipitates into a more stable for and often associates with organic matter (Blood et al., 2013). It was found by Blood et al. (2013) that, within organic-rich reservoirs, autogenic quartz provides a high-modulus medium, ultimately increasing the brittleness of the reservoir rock. This would indicate when an increase in TOC won't behave in a ductile manner contingent on the coincidence with elevated levels of $\mathrm{Si} / \mathrm{Al}$.

Within the brittleness indices discussed above (e.g. Jarvie et al., 2007; Wang and Gale, 2009; Jin et al., 2014), silica is claimed to contribute to the over-all brittleness of a unit, while $\mathrm{Al}$ is claimed to contribute to the over-all ductility of a unit. The hypothesis that brittle zones contain higher fracture intensity appears to be straightforward, although results from the statistical analyses between $\mathrm{P} 10$, and $\mathrm{Si}$ and $\mathrm{Al}$ demonstrate a weak to moderate negative relationship, respectively. $\mathrm{Al}$ has the strongest (negative) relationship with P10, recording an $\mathrm{r}^{2}$ value of 0.379 . Regression analysis between $\mathrm{Si}$ and $\mathrm{Al}$ records an $\mathrm{r}^{2}$ value of 0.562 . Due to the $\mathrm{Al}$ having the strongest relationship with P10, Si's negative relationship with P10 is most likely resulting from its covariation with $\mathrm{Al}$, which is demonstrated by $\mathrm{Si} / \mathrm{Al}$ having a positive relationship $\left(\mathrm{r}^{2}=0.283\right)$ with P10. This indicates that existing brittleness indices cannot predict natural fracture presence within the Marcellus Shale. 


\subsection{Conclusion}

Prior to this study, the relationship between chemical composition and natural fracture intensity within the Marcellus Shale was underdeveloped. In addition, the applicability of existing brittleness indexes for predicting areas of high natural fracture intensity was also unclear. The following were concluded from this investigation:

1. Existing brittleness indexes are not optimal for predicting natural fracture presence in the Marcellus Shale,

2. Ca has a strong positive relationship with increasing fracture intensity,

3. Al has a strong negative relationship with increasing fracture intensity,

4. Si and TOC have a moderate-to-weak relationship with natural fracture intensity, and

5. Natural fractures preferentially concentrate in host rocks of similar chemical composition.

\subsection{References}

Abouelresh, M., and R. M. Slatt, 2012, Lithofacies and sequence stratigraphy of the Barnett Shale in east-central Forth Worth basin, Texas: AAPG Bulletin, v. 96, no. 1, p. 1-22, doi:10.1306/04261110116.

Bell, K.G., Goodman, C., Whitehead, W. L., 1940, Radioactive of sedimentary rocks and associated petroleum: AAPG Bulletin, v. 24, doi:10.1306/3d933230-16b1-11d7$8645000102 \mathrm{c} 1865 \mathrm{~d}$ 
Blatt, H., Middleton, G. V., Murray, R. C., 1972. Origin of Sedimentary Rocks. Prentice-Hall Inc., Englewood Cliffs, 634 pp.

Blood, R., Lash, G. and Bridges, L., 2013. Biogenic silica in the Devonian shale succession of the Appalachian Basin, USA: Search and Discovery Article, 50864.

Calvert, S., and T. Pedersen, 1993, Geochemistry of Recent oxic and anoxic marine sediments: Implications for the geological record: Marine Geology, v. 113, no. 1-2, p. 67-88, doi:10.1016/0025-3227(93)90150-t.

Chang, C., M. D. Zoback, and A. Khaksar, 2006, Empirical relations between rock strength and physical properties in sedimentary rocks: Journal of Petroleum Science and Engineering, v. 51, no. 3-4, p. 223-237, doi:10.1016/j.petrol.2006.01.003.

Davis, D., and S. J. Reynold, 1996, Structural geology of rocks and regions, 2nd ed.: Wiley, New York.

Engelder, T., G. G. Lash, and R. S. Uzcátegui 2009, Joint sets thatenhance production from Middle and Upper Devonian gasshales of the Appalachian Basin: AAPG Bulletin, v. 93,no. 7, p. 857-889, doi:10.1306/03230908032

Flgel, E., 2004. Microfacies of carbonate rocks. Analysis, Interpretation and Application. 
Gale, J. F. W., R. M. Reed, and J. Holder, 2007, Natural fractures in the Barnett Shale and their importance for hydraulic fracture treatments: AAPG Bulletin, v. 91, no. 4, p. 603-622, doi:10.1306/11010606061.

Grainger, P. 1984 The classification of mudrocks for engineering purposes. Quarterly Journal of Engineering Geology, London, 17, 381-7.

Huang, Z., 2018, Partial least squares regression analysis to factor of influence for ecological footprint. Cluster Computing, pp.1-9.

James, N. P., \& Jones, B., 2016, Origin of carbonate sedimentary rocks. Chichester, West Sussex: John Wiley \& Sons, Inc.

Jarvie, D. M., R. J. Hill, T. E. Ruble, and R. M. Pollastro, 2007, Unconventional shale-gas systems: The Mississippian Barnett Shale of north-central Texas as one model for thermogenic shale-gas assessment: AAPG Bulletin, v. 91, no. 4, p. 475-499, doi:10.1306/12190606068.

Jin, X., S. N. Shah, J.-C. Roegiers, and B. Zhang, 2014, Fracability Evaluation in Shale Reservoirs - An Integrated Petrophysics and Geomechanics Approach: SPE Hydraulic Fracturing Technology Conference, doi:10.2118/168589-ms. 
Jowett, E. C., 1987, Formation of sulfide-calcite veinlets in the Kupferschiefer Cu-Ag deposits of Poland by natural hydraulic fracturing during basin subsidence: Journal of Geology, v. 95, no. 4, p. 513-526, doi:10.1086/jg.1987.95.issue-4.

Kias, E., R. Maharidge, and R. Hurt, 2015, Mechanical Versus Mineralogical Brittleness Indices Across Various Shale Plays: SPE Annual Technical Conference and Exhibition, doi:10.2118/174781-ms.

Kundert, D. and Mullen, M. 2009. Proper Evaluation of Shale Gas Reservoirs Leads to a More Effective Hydraulic-Fracture Stimulation. Presented at the SPE Rocky Mountain Petroleum Technology Conference, Denver, Colorado, 14-16 April. SPE-123586-MS. http://dx.doi.org/10.2118/123586-MS.

Lash, G. G., and D. R. Blood, 2014, Organic matter accumulation, redox, and diagenetic history of the Marcellus Formation, southwestern Pennsylvania, Appalachian basin: Marine and Petroleum Geology, v. 57, p. 244-263, doi:10.1016/j.marpetgeo.2014.06.001.

Lash, G. G., and T. Engelder, 2011, Thickness trends and sequence stratigraphy of the Middle Devonian Marcellus Formation, Appalachian Basin: Implications for Acadian foreland basin evolution: AAPG Bulletin, v. 95, no. 1, p. 61-103, doi:10.1306/06301009150. 
Loucks, R. G., R. M. Reed, S. C. Ruppel, and U. Hammes, 2012, Spectrum of pore types and networks in mudrocks and a descriptive classification for matrix-related mudrock pores: AAPG Bulletin, v. 96, p. 1071-1098, doi:10.1306/08171111061.

Löwemark, L., H.-F. Chen, T.-N. Yang, M. Kylander, E.-F. Yu, Y.-W. Hsu, T.-Q. Lee, S.-R. Song, and S. Jarvis, 2011, Normalizing XRF-scanner data: A cautionary note on the interpretation of high-resolution records from organic-rich lakes: Journal of Asian Earth Sciences, v. 40, no. 6, p. 1250-1256, doi:10.1016/j.jseaes.2010.06.002.

Luning, S., and S. Kolonic, 2003, Uranium Spectral Gamma-Ray Response As A Proxy For Organic Richness In Black Shales: Applicability And Limitations: Journal of Petroleum Geology, v. 26, no. 2, p. 153-174, doi:10.1111/j.1747-5457.2003.tb00023.x.

Mainali, P., 2011. Chemostratigraphy and the Paleoceanography of the BossierHaynesville Formation, East Texas Basin, TX and LA (MS thesis). The University of Texas at Arlington, 90 pp.

Milad, B., and R. Slatt, 2018, Impact of lithofacies variations and structural changes on natural fracture distributions: Interpretation, 6, no. 4, 1-15. https://doi.org/10.1190/INT-2017-0138.1

Molinares, C. E., Slatt, R.M, Sierra, R., 2017, The Effects of Lamination/Bedding on the Brittleness for the Woodford Shale Silica-Rich Intervals, From the Wyche-1 Core-Well Analysis, Pontotoc County, Oklahoma. In AAPG Annual Convention and Exhibition. 
Morford, J. L., and S. Emerson, 1999, The geochemistry of redox sensitive trace metals in sediments: Geochimica et Cosmochimica Acta, v. 63, no. 11-12, p. 1735-1750, doi:10.1016/s0016-7037(99)00126-x.

Neuzil, C. E., and D. W. Pollock, 1983, Erosional unloading and fluid pressures in hydraulically "tight" rocks: Journal of Geology, v. 3, no. 1, p. 179-193.

Olson, J. E., Q. Yuan, J. Holder, and P. Rijken, 2001, Constraining the Spatial Distribution of Fracture Networks in Naturally Fractured Reservoirs Using Fracture Mechanics and Core Measurements: SPE Annual Technical Conference and Exhibition, doi:10.2118/71342-ms.

Pearce, T., B. Besly, D. Wray, and D. Wright, 1999, Chemostratigraphy: a method to improve interwell correlation in barren sequences — a case study using onshore Duckmantian/Stephanian sequences (West Midlands, U.K.): Sedimentary Geology, v. 124, no. 1-4, p. 197-220, doi:10.1016/s0037-0738(98)00128-6.

Jarvis, T. J. P. I., 1992, Applications of Geochemical Data to Modelling Sediment Dispersal Patterns in Distal Turbidites: Late Quaternary of the Madeira Abyssal Plain: SEPM Journal of Sedimentary Research, v. Vol. 62, doi:10.1306/d4267a64-2b26-11d7-8648000102c1865d.

Peng, S., and B. Loucks, 2016, Permeability measurements in mudrocks using gas-expansion methods on plug and crushed-rock samples: Marine and Petroleum Geology, 73, 299-310, doi: 10.1016/j.marpetgeo.2016.02.025 
Piper, D., and R. Perkins, 2004, A modern vs. Permian black shale-the hydrography, primary productivity, and water-column chemistry of deposition: Chemical Geology, v. 206, no. 3-4, p. 177-197, doi:10.1016/j.chemgeo.2003.12.006.

Prothero, D. R., and Schwab, F.,1996, Sedimentary geology, Freeman, New York.

Rickman, R., M. J. Mullen, J. E. Petre, W. V. Grieser, and D. Kundert, 2008, A Practical Use of Shale Petrophysics for Stimulation Design Optimization: All Shale Plays Are Not Clones of the Barnett Shale: SPE Annual Technical Conference and Exhibition, doi:10.2118/115258-ms.

Rijken, P., 2005, Petrographic and chemical controls on subcritical fracture growth: Ph.D. dissertation, University of Texas at Austin, Austin, Texas, 239 p.

Rodrigues, N., P. R. Cobbold, H. Loseth, and G. Ruffet,2009, Widespread bedding-parallel veins of fibrous calcite('beef') in a mature source rock (Vaca Muerta Formation,Neuquén Basin, Argentina): Evidence for overpressureand horizontal compression: Journal of the GeologicalSociety, v. 166, no. 4, p. 695-709, doi:10.1144/0016-76492008-111.

Rothwell, R. G., and F. R. Rack, 2006, New techniques in sediment core analysis: an introduction: Geological Society, London, Special Publications, v. 267, no. 1, p. 1-29, doi:10.1144/gsl.sp.2006.267.01.01. 
Rowe, H., N. Hughes, and K. Robinson, 2012, The quantification and application of handheld energy-dispersive $\mathrm{x}$-ray fluorescence (ED-XRF) in mudrock chemostratigraphy and geochemistry: Chemical Geology, v. 324-325, p. 122-131, doi:10.1016/j.chemgeo.2011.12.023.

Sageman, B. B., A. E. Murphy, J. P. Werne, C. A. V. Straeten, D. J. Hollander, and T. W. Lyons, 2003, A tale of shales: the relative roles of production, decomposition, and dilution in the accumulation of organic-rich strata, Middle-Upper Devonian, Appalachian basin: Chemical Geology, v. 195, no. 1-4, p. 229-273, doi:10.1016/s0009-2541(02)00397-2.

Sageman, B., and T. Lyons, 2003, Geochemistry of Fine-grained Sediments and Sedimentary Rocks: Treatise on Geochemistry, p. 115-158, doi:10.1016/b0-08-043751-6/07157-7.

Slatt, R. M., and Y. Abousleiman, 2011, Merging sequence stratigraphy and geomechanics for unconventional gas shales: The Leading Edge, v. 30, no. 3, p. 274-282, doi:10.1190/1.3567258.

Tribovillard, N., T. J. Algeo, T. Lyons, and A. Riboulleau, 2006, Trace metals as paleoredox and paleoproductivity proxies: An update: Chemical Geology, v. 232, no. 1-2, p. 12-32, doi:10.1016/j.chemgeo.2006.02.012.

Verma, S., T. Zhao, K. J. Marfurt, and D. Devegowda, 2016, Estimation of total organic carbon and brittleness volume: Interpretation, v. 4, no. 3, doi:10.1190/int-2015-0166.1. 
Wang, F. P., and J. F. W. Gale, 2009, Screening criteria for shale -gas systems: Gulf Coast Association of Geological Societies Transactions, 59, 779-793.

Wells, F., 2004, A new method to help identify unconventional targets for exploration and development through integrative analysis of clastic rock properties: Houston Geological Society Bulletin, 52, $34-49$.

Young, K. E., C. A. Evans, K. V. Hodges, J. E. Bleacher, and T. G. Graff, 2016, A review of the handheld X-ray fluorescence spectrometer as a tool for field geologic investigations on Earth and in planetary surface exploration: Applied Geochemistry, v. 72, p. 77-87, doi:10.1016/j.apgeochem.2016.07.003.

Zelt, F.B., 1985. Natural gamma-ray spectrometry, lithofacies, and depositional environments of selected Upper Cretaceous marine mudrocks, western United States, including Tropic Shale and Tununk Member of Mancos Shale, Ph.D. Dissertation, Princeton University, 284 p.

Zhang, B., T. Zhao, X. Jin, and K. J. Marfurt, 2015, Brittleness evaluation of resource plays by integrating petrophysical and seismic data analysis: Interpretation, v. 3, no. 2, doi:10.1190/int2014-0144.1. 


\section{Controls on Organic Matter Accumulation and Preservation: An Investigation into the Marcellus Shale, Appalachian Basin, USA}

*Keithan G. Martin ${ }^{1}$ (corresponding author): kgm0002@mix.wvu.edu

Timothy R. Carr¹: tim.carr@mail.wvu.edu

${ }^{1}$ Department of Geology and Geography, West Virginia University, Morgantown, WV 26506

\subsection{Abstract}

Dilution, productivity, and degree of bottom water oxygenation have been at the forefront of understanding controls on organic carbon enrichment/depletion in mudrock. Within organic-rich mudrock studies, investigators have historically emphasized in organic-rich mudrock the importance of a single control to the exclusion of others. Within studies on Devonian mudrock of the Appalachian basin specifically, recent investigators emphasize an interplay between dilution, productivity, and degree of bottom water oxygenation, but nonetheless determine a chief control on organic carbon enrichment, which often differ significantly. The source of the recent disparate explanations/emphases on specific controls of enrichment of organic carbon in mudrock may be explained by studies limited to a single well or core. In such studies, local variation in the depositional system can profoundly impact conclusions. In this study we significantly expand the data base to multiple samples from seven cored intervals distributed across the basin. We use hierarchical cluster analysis (HCA) analysis to better understand the interrelationships between elements and elemental proxies and TOC and from this analysis conclude the following: 1) detrital proxy values equivalent to slightly enriched relative to average shale can still coincide with elevated levels of TOC, upwards of $5 \mathrm{wt} . \%$, if anoxia and productivity proxies are significantly 
enriched relative to average shale; 2) high concentration of $\mathrm{Ca}$ hinders $\mathrm{TOC}$ enrichment, but for Ca concentrations $<15$ wt. $\%$, Ca does not impact TOC enrichment; 3) the negative correlation observed between detrital proxy elements and TOC becomes uncorrelated at very high levels (> 8 wt. \%) of TOC, such that very organic rich samples are not necessarily the most depleted in detrital proxy elements; and 4) and observed strong positive covariation between anoxia and productivity proxy elements and TOC, as well as a strong relationship (r2>0.7) between anoxia and productivity proxy elements. Multiple lines of evidence indicate a strong depletion of detrital proxy elements accompanied by a strong enrichment of anoxia, productivity, and sulfidic proxy elements played a dominate role in the enrichment of organic carbon within the middle Devonian mudrock study intervals.

\subsection{Introduction}

\subsubsection{Origin of organic-rich sedimentary rocks}

When studying organic-rich mudrock, an initial question investigators have historically asked is, "what depositional environment and conditions are necessary to produce an organic-rich finegrained rock?" For the last 50 years, source rock investigators have addressed fundamental questions regarding the genesis of organic-rich sedimentary rocks, focusing on factors such as; (1) key influences on organic matter preservation in a marine environment, (2) types of water conditions that are conducive to organic matter production and preservation, and (3) development of oxic/anoxic conditions in water bodies and their subsequence effects on organic matter preservation. Oceanographic and geochemical data have served as the foundation in answering such questions. Researchers in this area have long proposed at the highest level that organic matter accumulation in sediment is a result of biological factors, such as primary biological productivity 
within surface waters and bottom-water biochemical degradation of deposited organic matter, and physical factors, including such factors as sediment particle size and sediment accumulation rate (Demaison and Moore, 1979; Pederson and Calvert, 1990; Canfield, 1994). Herein the following redox terms, and their respective oxygen levels, are utilized; oxic $\left(>2.0 \mathrm{ml} \mathrm{O}_{2} \mathrm{~L}^{-1}\right)$, dysoxic $(\sim 0.2-$ $\left.2.0 \mathrm{ml} \mathrm{O}_{2} \mathrm{~L}^{-1}\right)$, suboxic $\left(0.2 \mathrm{e} 0 \mathrm{ml} \mathrm{O}_{2} \mathrm{~L}^{-1}\right)$, anoxic $\left(0 \mathrm{ml} \mathrm{O}_{2} \mathrm{~L}^{-1}, 0 \mathrm{ml} \mathrm{H}_{2} \mathrm{~S} \mathrm{~L}^{-1}\right)$, and euxinic $0 \mathrm{ml} \mathrm{O}_{2}$ $1^{-1} \mathrm{H}_{2} \mathrm{O}$ and the presence of free $\mathrm{H}_{2} \mathrm{~S}$ in the water column (Edwards, 1985; Tyson and Pearson, 1991; Algeo and Maynard, 2004).

Early research from Demaison and Moore (1979) advanced the "preservation model", concluding from investigating numerous modern anoxic settings, that there is a necessity of anoxic bottom water conditions for the preservation of organic matter. They found that a water-column containing a maximum oxygen saturation below 0.5 to $0.3 \mathrm{ml} / 1$ strongly depress metazoan benthic biomasses, especially bioturbation by deposit-feeders. Demaison and Moore (1979) referred to an extensive study by Moore (1975) to conclude that “... (Moore) could not find a systematic correlation between primary biological productivity and organic carbon enrichments of bottom sediments in the oceans." This view was challenged by Pedersen and Calvert (1990), who concluded that high surface primary productivity, as opposed to water-column anoxia, is the chief control on the accumulation of organic-rich sediments in modern oceans. The model put forth in Pederson and Calvert (1990) referred to as the "primary productivity model" casted doubt on the proposed relationship between low-to-no dissolved oxygen in the water column and decreased organic matter oxidation. They stated that once oxygen is exhausted, both in sediment and the water column nitrate and sulfate, albeit less effective than oxygen, are used as oxidants by other bacteria to degrade the organic matter (Goldhaber and Kaplan, 1974; Froelich et al., 1979; and Berner, 1980). Furthermore, in the rare case that all oxidants are consumed, oxidative-based 
degradation on organic matter would cease, and a much slower and less effective degradation via fermentation would take place (Schink, 1985).

Canfield (1994) found a middle ground between the "preservation model" and "productivity model", putting forth that at high sedimentation rates limited preservation with various degrees of bottom-water oxygenation, while in lower sedimentation rate regimes sediments deposited in oxygenated bottom water become progressively more aerobic, while euxinic sediments remain anaerobic. This study and others (Stein, 1986; Henrichs and Reeburg, 1987) concluded that sediment deposition rate was the fundamental control on organic matter preservation, where (1) at higher sedimentation rates $\left(>0.04 \mathrm{~g} \mathrm{~cm}^{-2} \mathrm{yr}^{-1}\right)$ similar preservation potential of organic deposition is independent of oxygen concentration and (2) at lower sedimentation rates $\left(<0.04 \mathrm{~g} \mathrm{~cm}^{-2} \mathrm{yr}^{-1}\right)$ enhanced preservation is found within sediments deposited in low oxygen and euxinic environments.

Marcellus Shale investigators have heavily relied on and built off these previous studies. Sageman et al. (2003) investigated the processes responsible for the accumulation of organic carbon in the Middle and Upper Devonian of the Appalachian basin within the New York state area. The interval with the highest organic carbon in Marcellus subgroup (lower Marcellus shale) corresponded with a maximum of clastic starvation, a complete shutdown of carbonate production, and the interval was defined as a maximum flooding surface (Johnson and Sandberg, 1998). No direct evidence of enhanced primary production was observed, but strong evidence through trace metal data indicated a pervasive anoxic bottom water condition, and euxinic conditions towards the base of the Marcellus subgroup interval., This study concluded that relative sea level fluctuations controlled key variables responsible for organic-matter accumulation, such as clastic dilution, preservation, and organic matter production. Sageman et al. (2003) concluded that 
deepening events prompted by relative sea-level rise halted clastic sedimentation, increased organic-carbon concentrations in deeper, anoxic to euxinic portions of the basin, and decreased the influence of shorter term dysoxic events.

Lash and Blood (2014) conducted a study on the organic-matter accumulation and redox conditions of the Marcellus Shale based on data collected from a single cored interval located in southwestern Pennsylvania. Utilizing elemental concentrations and elemental ratios, along with pyrite framboid size distribution, this study focused on the effects of relative sea-level fluctuations within a sequence stratigraphic framework on depositional conditions. Elemental data indicated that anoxic, to even euxinic conditions were prevalent, with seasonal to longer term periods of dysoxia. These fluctuations in oxygen concentrations were corroborated by framboids with varying size distributions, also interpreted as indicating low-to-no oxygen to even sulfidic bottom conditions with intermittent dysoxic periods. Increasing concentrations of aluminum was interpreted as resulting from progradation of clastic sedimentation, while enrichment of redoxsensitive elements, such as uranium and molybdenum, represented deteriorating bottom water conditions as relative sea level rose.

Chen and Sharma (2016) concluded that organic-enrichment within the Marcellus Shale resulted in part from the regeneration of bio-limiting nutrients, which in turn increased primary productivity. Trace metal data approximating anoxic water conditions correlate with an organically enriched Lower Marcellus Shale interval and progressively moves towards suboxic conditions up the intervals into the Middle and Upper Marcellus (Chen and Sharma, 2016; Lash and Blood 2016). Suboxic conditions created by the progradation of the Middle Devonian clastic units were approximated by a consistent increasing trend in aluminum from the base of the lower Marcellus to the upper Marcellus into the Mahantango Formation. 
Consistent themes were found when reviewing Marcellus Shale studies focusing on mechanisms responsible for extreme organic-carbon enrichment. First, the usage of low-resolution geochemical data were common (data collected every few feet). Secondly, datasets collected from a single well was the most common approach (Werne et al., 2002; Sageman et al., 2003; Chen and Sharma, 2016; Lash and Blood, 2016). Of Marcellus Shale studies cited, two studies focused on the same cored interval in New York state, and the remaining two focused on a single core interval from the same county in southwestern Pennsylvania. Investigating single cores and/or relying on low-resolution geochemical data increases uncertainty of correlations and relationships and risks overstating vertical homogeneity. Additionally, such past studies have come to disparate conclusions or at least emphasize certain mechanisms over others.

In this study, we attempt to improve our understanding of mechanisms responsible for organiccarbon enrichment in mudrocks through investigating seven Middle Devonian cored intervals ( $\sim 850 \mathrm{ft}$. $(260 \mathrm{~m})$ combined) distributed throughout three different portions of the Appalachian basin; (1) central Pennsylvania (central basin), (2) northern West Virginia (eastern, marginal basin), and (3) eastern Ohio (western, marginal basin) (figure 4-1; table 4-1). Using a combination of WDXRF data as well as high-resolution hhEDXRF (data points collected every 2 inches) collected within all seven study cores and a multivariate numerical analysis (hierarchical cluster analysis (HCA)), we increased the detail and spatial distribution of samples used to:

1. Infer the paleo-depositional conditions present during the deposition of the Marcellus Shale and the overlying Mahantango Formation,

2. Assess the role of bottom-water conditions, primary productivity, dilution through sedimentation and autogenic carbonate production on TOC enrichment/depletion, and 
3. Assess spatial variations in paleo-deposition conditions throughout the Appalachian basin through analyzing cluster frequency, as derived from the HCA, within the study wells.

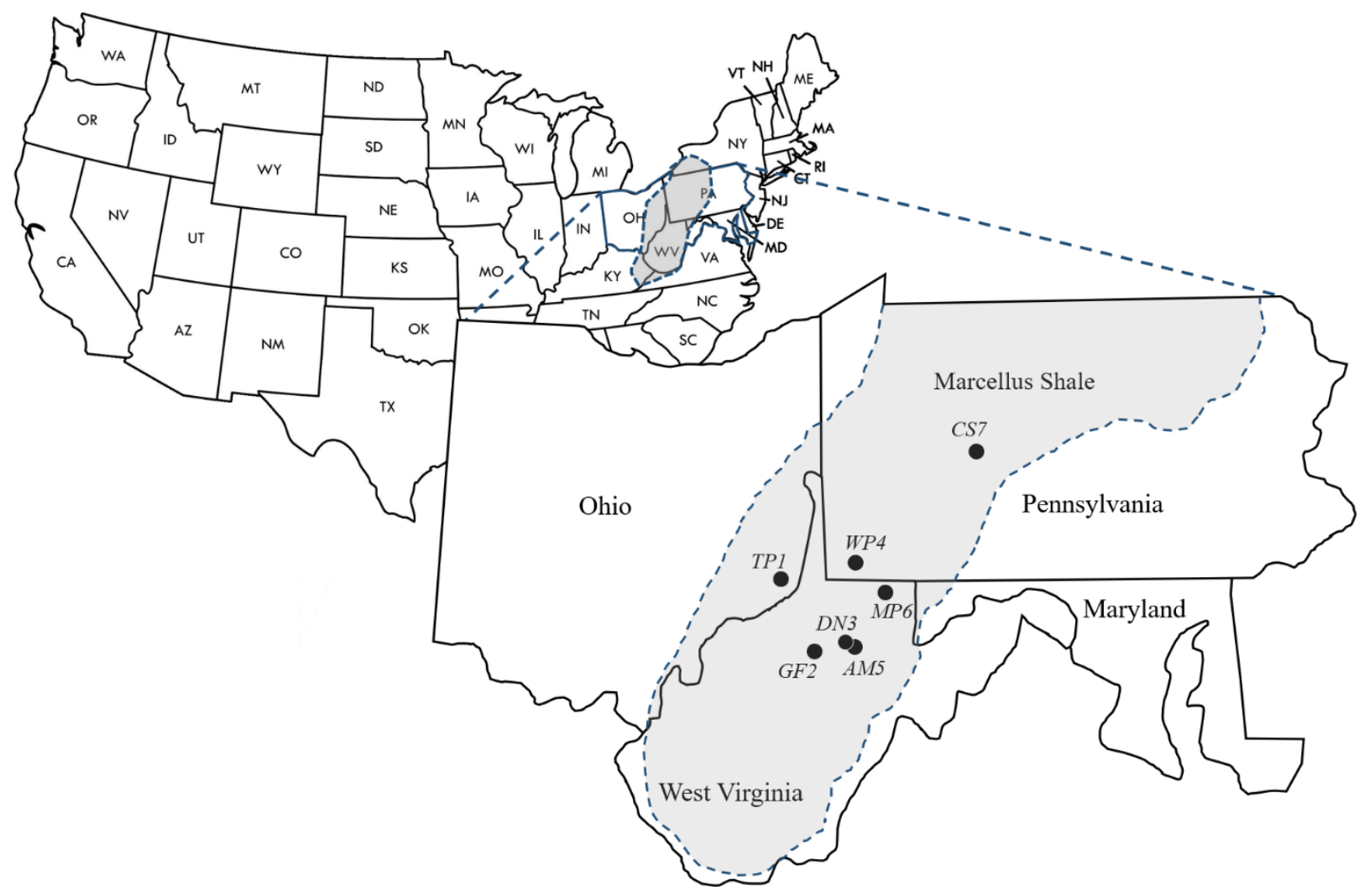

Figure 4-1. United States map displaying the location of the Marcellus Shale within the Appalachian basin across the states of Pennsylvania, West Virginia, and Ohio, represented by the dashed polygon. The expanded view of the study area shows the location of the seven study wells.

Table 4-1. Study well information - Formation abbreviations: ON=Onondaga, LM=Lower Marcellus, MM=Middle Marcellus, UM=Upper Marcellus, MT=Mahantango. 


\begin{tabular}{|c|c|c|c|c|c|c|c|c|}
\hline \multirow{2}{*}{$\begin{array}{c}\text { Study } \\
\text { Well No. }\end{array}$} & \multirow{2}{*}{$\begin{array}{c}\text { Well } \\
\text { Name }\end{array}$} & \multicolumn{3}{|c|}{ Location } & \multicolumn{3}{|c|}{ Cored Interval (ft) } & \multirow{2}{*}{$\begin{array}{c}\text { Formations } \\
\text { Present } \\
\end{array}$} \\
\hline & & Latitude $(N)$ & Longitude $(W)$ & County, State & Top & Bottom & Total & \\
\hline 1 & TP1 & 39.678551 & 81.025461 & Monroe, $\mathrm{OH}$ & 5555.2 & 5663 & 107.8 & ON, LM, MM, UM \\
\hline 2 & GF2 & 39.281369 & 80.392692 & Harrison, WV & 7043 & 7133.6 & 90.6 & ON, LM, MM, UM, MT \\
\hline 3 & DN3 & 39.336404 & 80.129587 & Taylor, WV & 7445 & 7564.6 & 119.6 & ON, LM, MM, UM \\
\hline 4 & WP4 & 39.9235415 & 80.0033923 & Greene, PA & 7719 & 7910.8 & 191.8 & ON, LM, MM, UM, MT \\
\hline 5 & AM5 & 39.291926 & 80.08322 & Taylor, WV & 7545 & 7689 & 144 & ON, LM, MM, UM, MT \\
\hline 6 & MP6 & 39.602203 & 79.976624 & Monongalia, WV & 7517.2 & 7553.2 & 36 & ON, LM, MM \\
\hline \multirow[t]{2}{*}{7} & CS7 & 41.1131167 & 78.4070417 & Clearfield, PA & 7002 & 7168.8 & 166.8 & ON, LM, MM, UM, MT \\
\hline & & & & & 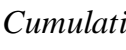 & Total $=$ & 856.6 & \\
\hline
\end{tabular}

\subsubsection{Stratigraphic Nomenclature}

The Marcellus Shale divided into three members; Oatka Creek Member, Cherry Valley Member or Purcell Member, and the Union Springs Member is interpreted within the central Appalachian basin as three transgressive-regressive cycles (Lash and Engelder, 2011) (Figure 4-2). The Marcellus Shale overlies the Onondaga Limestone, and is overlain by the Mahantango Formation.

The Union Springs Member, informally divided into the "lower Marcellus" and "middle Marcellus", is thinnest in western New York and thickens to the east and southeast, reaching a thickness exceeding $160 \mathrm{ft}$. (49 m) in northeastern Pennsylvanian (Lash and Engelder, 2011). This member is highly organic, calcareous and characterized as a dark-gray to black mudstone containing skeletal material (Sageman et al., 2003). The lower portion of the Union Springs Member records a particularly high gamma-ray response, reaching upwards of 650 API units characterized by a decrease in clay content, and a significant increase in quartz, pyrite, and total organic carbon (TOC) (Lash and Engelder, 2011). The Union Springs Member overlies the Onondaga Limestone, which is interpreted as an unconformity, but can be found to be conformable in Pennsylvania, western New York, and Ohio and Maryland (Lash and Engelder, 2011). 


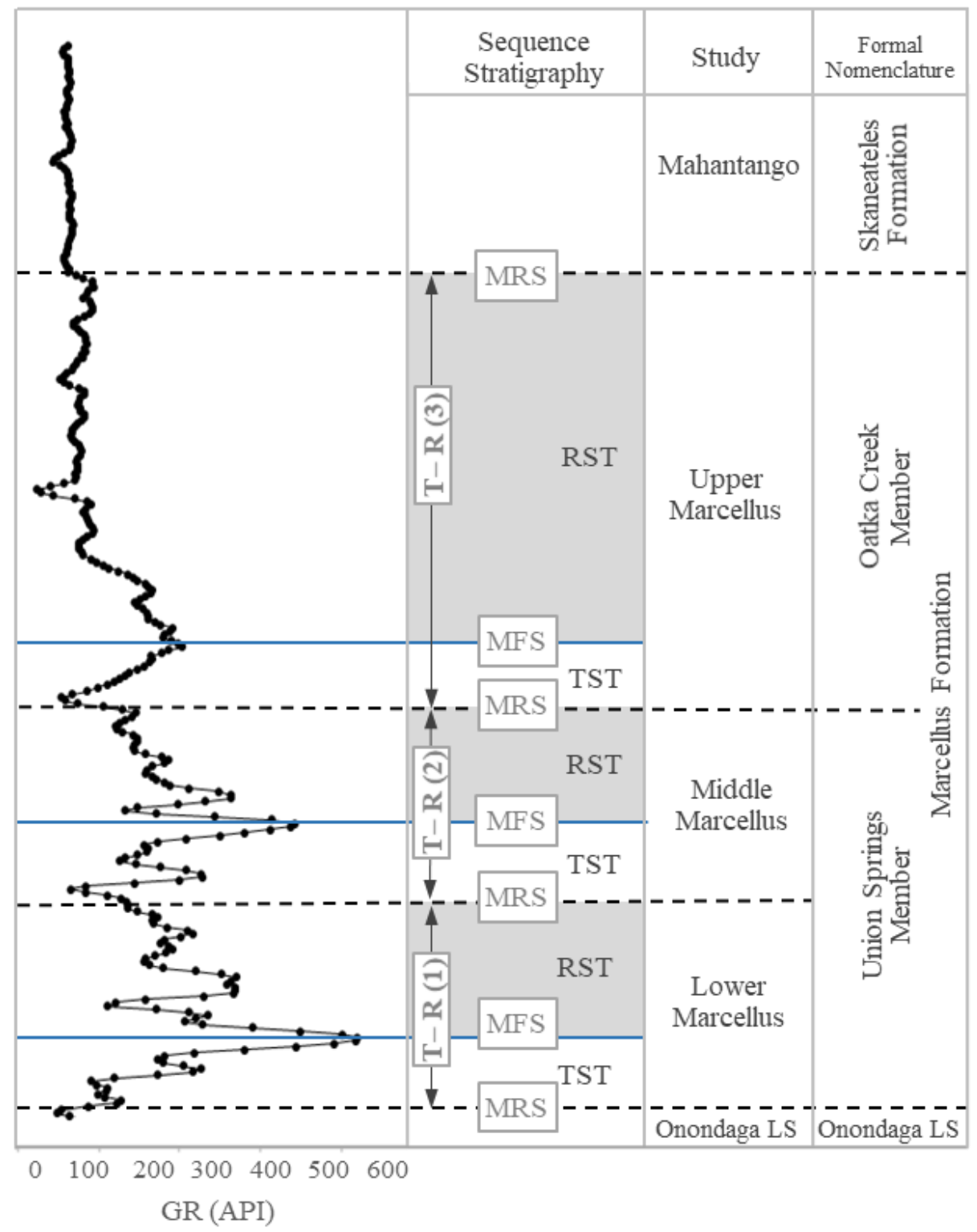

Figure 4-2. $\mathrm{TST}=$ transgressive systems tract, $\mathrm{RST}=$ regressive systems tract, $\mathrm{T}-\mathrm{R}=$ transgressive - regressive, MRS $=$ maximum regressive surfaces, MFS $=$ maximum flooding surfaces. Sequence stratigraphic framework modified from Lash and Engelder (2011).

The Cherry Valley Member is a stratigraphically equivalent unit of the Purcell Limestone of Pennsylvania and West Virginia, and overlies the Union Springs Member (Lash and Engelder, 2011). The Cherry Valley Member is a medium-gray packstone chiefly composed of skeletal 
debris, and contains intervals of shale and siltstone. The thickness of the member ranges from tens of feet in New York to well over 100 feet $(30 \mathrm{~m})$ in northeastern Pennsylvania. Overlying the Cherry Valley Member is the Oatka Creek Formation, informally referred to as the "upper Marcellus". This unit is described as a medium to dark-gray mudstone with basal intervals of black organic-rich mudstone (Lash and Engelder, 2011; Wonnell and Carr, 2015). Stratigraphically above the upper Marcellus is the Mahantango Formation, which is a clay-rich silty shale that reaches up to $100 \mathrm{ft}$. in thickness within central Appalachian basin. This formation records significantly lower TOC levels, as well as higher detrital input than the Marcellus Shale.

\subsubsection{Rock Classification and Characterization}

\subsubsection{Classification}

The fine-grained sedimentary rock classification scheme will follow Blatt et al. (1972), who proposed the term mudrock as a general term to encompass fine-grained sedimentary rocks that are either fissile and/or laminated, referred to as "shale", or non-fissile and/or non-laminated, referred to a "stone." The dominate grainsize is placed in from of the either "shale" or "stone" to complete the facies classification, such that a nonfissile/non-laminated rock made up of $2 / 3$ 's silt would be termed a "siltstone." Additionally, a fissile/laminated rock made up of 2/3's silt would be termed a "silty shale."

Rock classification schemes are used to group rock intervals based on physical and chemical characteristics. At the highest level, formations are defined from contacts within core and geophysical log signatures guided by historical picks (Boyce and Carr, 2010; Lash and Engelder, 2011; Blood and Lash, 2014). In the case of the Middle Devonian mudrock, the formations are thick (25-75 feet) sedimentary packages that are useful for larger scale correlations, 
but lack resolution for in-depth facies characterization. Facies were initially defined during the evaluation of the seven cored intervals based on color, approximate grainsize, laminations, pyritic content, and fossil material. Additionally, $\mathrm{Si}, \mathrm{Al}$, and $\mathrm{Ca}$ gathered from the hhEDXRF were used to highlight contrasts between facies. Detailed core descriptions provided by Core Laboratories served as an additional guide in defining lithology. A ternary diagram for fine-grained sedimentary rocks developed by Gamero et al. (2012) was modified and used for facies classification based on $\mathrm{Si}, \mathrm{Al}$, and Ca (figure 4-3). Three aspects of the Gamero et al. (2012) were modified. First, the blanket term for fine-grained sedimentary rocks used in the original ternary diagram is "mudstone", which does not follow Blatt et al. (1972)'s classification, and thus "mudstone" was replaced with "mudrock." Additionally, two end member names, "Silica-dominate lithotype" and "Carbonate-dominated lithotype" were changed to "Autogenic Silica-enriched Siliceous Mudrock" and "Muddy Limestone" to better reflect the lithologies of the Middle Devonian strata. Finally, the "argillaceous" classification as wells as the modifier "clay-rich" where replaced with "aluminous" and "aluminum-rich" respectively. The modifications were made to shift terminology from mineral-based to element- to reflect the elemental dataset used within this study. Seven facies defined from the ternary diagram were subdivided into sub-facies based on textural data collected during core evaluation. 

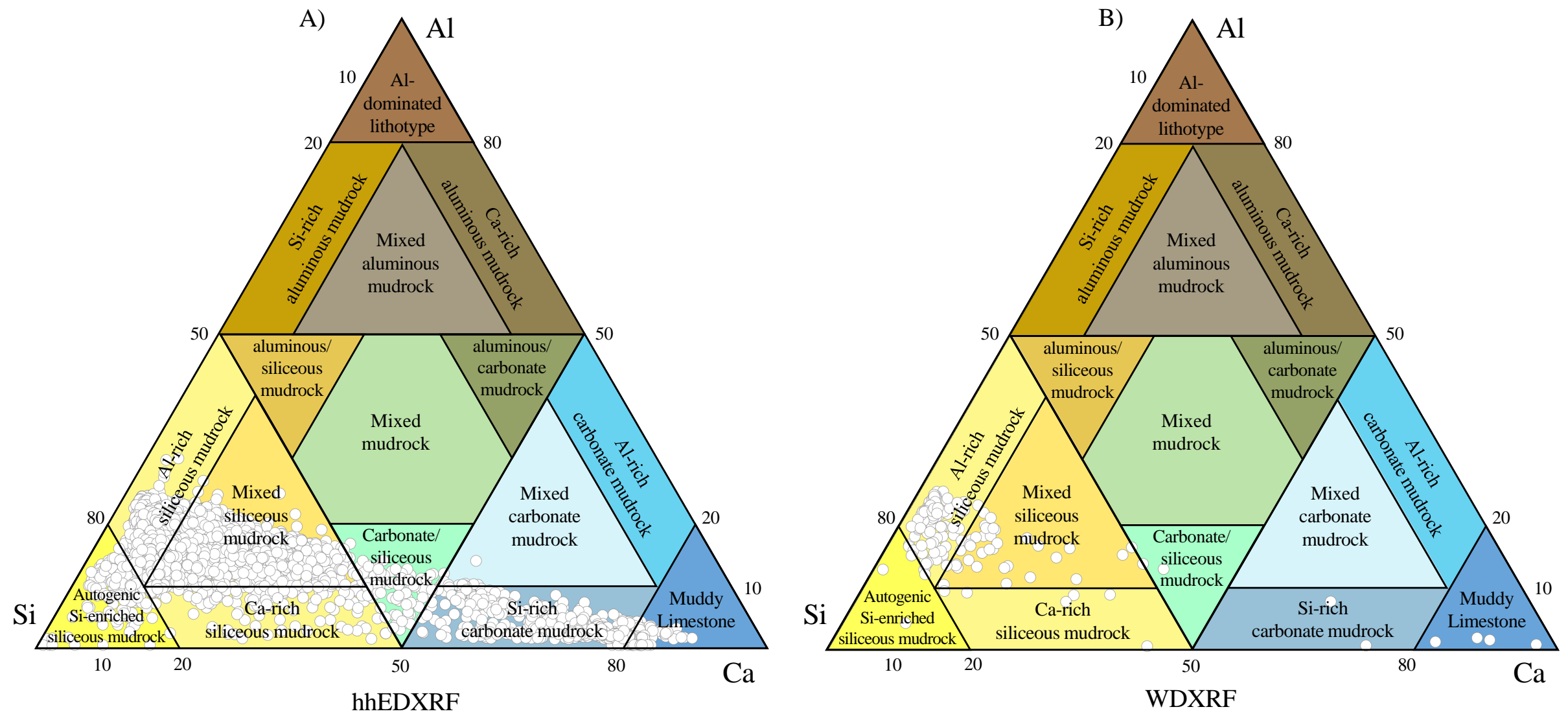

Figure 4-3. A) hhEDXRF, and B) WDXRF data points determined for this study populating the ternary defined by $\mathrm{Si}, \mathrm{Ca}$ and $\mathrm{Al}$ was modified from Gamero et al. (2012). 
The sub-facies nomenclature adopted herein brings together the textural data and the compositional data gathered from the modified ternary diagram. The sub-facies naming scheme order starts with the 1) color(s) observed, 2) prevalent visible materials, such as fossil content and pyrite nodules, 3) ternary diagram classification, 4) dominate approximated grainsize, and 5) presence or lack of fissility/laminations (table 4-2). The ternary classification's power lies in deterministic cutoffs and standardized terminology that can used with a wide variety of datasets.

Table 4-2. Facies (number) and sub-facies (number with decimal) and their respective number of occurrences (n) within the seven cored intervals. Medium dark gray to medium gray abbreviated as MDG and MG, and grayish black to dark gray is abbreviated as GB to DG.

Facies and Sub-facies $n$

1. Autogenic Si-enriched Siliceous Mudrock 177

1.1 MDG to MG Fossiliferous Autogenic Si-enriched Siliceous Muddy Siltstone 12

1.2 MDG to MG Autogenic Si-enriched Siliceous Muddy Siltstone 37

1.3 GB to DG Pyritic Autogenic Si-enriched Siliceous Silty Shale 25

1.4 GB to DG Pyritic Autogenic Si-enriched Siliceous Muddy Siltstone 57

1.5 GB to DG Autogenic Si-enriched Siliceous Muddy Siltstone 46

2. Al-rich Siliceous Mudrock 2082

2.1 MDG to MG Pyritic Al-rich Siliceous Silty Shale 66

2.2 MDG to MG Pyritic Al-rich Siliceous Muddy Siltstone $\quad 70$

2.3 MDG to MG Fossiliferous Al-rich Siliceous Muddy Siltstone 19

2.4 MDG to MG Al-rich Siliceous Silty Shale 126

2.5 MDG to MG Al-rich Siliceous Muddy Siltstone $\quad 180$

2.6 GB to DG Pyritic Fossiliferous Al-rich Siliceous Silty Shale 17

2.7 GB to DG Pyritic Fossiliferous Al-rich Siliceous Muddy Siltstone 26

2.8 GB to DG Pyritic Al-rich Siliceous Silty Shale 377

2.9 GB to DG Pyritic Al-rich Siliceous Muddy Siltstone 663

2.11 GB to DG Fossiliferous Al-rich Siliceous Muddy Siltstone 33

2.12 GB to DG Al-rich Siliceous Silty Shale $\quad 250$

2.13 GB to DG Al-rich Siliceous Muddy Siltstone 246

2.14 Gray Al-rich Siliceous Muddy Siltstone 9

3. Ca-rich Siliceous Mudrock $\quad 79$ 
3.1 MDG to MG Ca-rich Siliceous Muddy Siltstone 20

3.2 GB to DG Pyritic Ca-rich Siliceous Silty Shale 9

3.3 GB to DG Pyritic Ca-rich Siliceous Muddy Siltstone 11

3.4 GB to DG Ca-rich Siliceous Silty Shale $\quad 16$

3.5 GB to DG Ca-rich Siliceous Muddy Siltstone 23

4. Mixed Siliceous Mudrock 1661

4.1 MDG to MG Pyritic Mixed Siliceous Silty Shale 27

4.2 MDG to MG Pyritic Mixed Siliceous Muddy Siltstone 42

4.3 MDG to MG Mixed Siliceous Silty Shale $\quad 79$

4.4 MDG to MG Mixed Siliceous Muddy Siltstone 47

4.5 MDG to MG Fossiliferous Mixed Siliceous Muddy Siltstone 73

4.6 GB to DG Pyritic Mixed Siliceous Silty Shale 263

4.7 GB to DG Pyritic Mixed Siliceous Muddy Siltstone 337

4.8 GB to DG Pyritic Fossiliferous Mixed Siliceous Muddy Siltstone 38

4.9 GB to DG Mixed Siliceous Silty Shale 486

4.11 GB to DG Mixed Siliceous Muddy Siltstone 195

4.12 GB to DG Fossiliferous Mixed Siliceous Silty Shale 9

4.13 GB to DG Fossiliferous Mixed Siliceous Muddy Siltstone 51

4.14 Gray Mixed Siliceous Muddy Siltstone 14

5. Carbonate/Siliceous Mudrock 73

5.1 MDG to MG Carbonate/Siliceous Muddy Siltstone 16

5.2 GB to DG Pyritic Carbonate/Siliceous Muddy Siltstone 13

5.3 GB to DG Carbonate/Siliceous Silty Shale $\quad 14$

5.4 GB to DG Carbonate/Siliceous Muddy Siltstone 12

5.5 Gray Carbonate/Siliceous Muddy Siltstone 18

6. Si-rich Carbonate Mudrock 351

6.1 MDG to MG Si-rich Carbonate Silty Shale $\quad 21$

6.2 MDG to MG Si-rich Carbonate Muddy Siltstone 244

6.3 MDG to MG Pyritic Si-rich Carbonate Silty Shale 35

6.4 MDG to MG Pyritic Si-rich Carbonate Muddy Siltstone 9

6.5 MDG to MG Fossiliferous Si-rich Carbonate Muddy Siltstone 32

6.6 GB to DG Si-rich Carbonate Muddy Siltstone 10

7. Muddy Limestone $\quad 68$

$\begin{array}{ll}\text { 7.1 MDG to MG Muddy Limestone } & 68\end{array}$ 


\subsubsection{Stratigraphic Distribution of Ternary-derived Facies}

Based on the seven study well cores, the lower Marcellus Show an average composition of Mixed Siliceous Mudrock (43\%), Al-rich Siliceous Mudrock (30.8\%), Si-rich Carbonate Mudrock (8.2\%), Autogenic Si-enriched Siliceous Mudrock (7.7\%), Ca-rich Siliceous Mudrock (6.1\%), Carbonate/Siliceous Mudrock (2.2\%), and Muddy Limestone (2.0\%). The lower Marcellus is a massive to weakly laminated, calcareous, pyritic, dark-gray to gray-black muddy siltstone. Pyrite is in the form of both nodules and horizontal laminations throughout the interval. Ash beds, commonly referred to as the Tioga Ash Beds, of thickness $<10 \mathrm{~cm}$ are common in the lower section. Thin $(<1 \mathrm{ft}$.) carbonate layers are most prevalent lower in the interval, and progressively decrease moving up section. Both horizontal and vertical fractures, dominantly filled with calcite, are present throughout the interval. The lower Marcellus is the most organic-rich, with TOC values ranging between $8-15 \%$, and is the most lithologically diverse interval within the larger Marcellus Shale, with six of the eight facies present. Directly overlying the lower Marcellus is the Cherry Valley Member, which is a thin $(<2 \mathrm{ft}$.) carbonate-rich layer. The middle Marcellus is dominated by Al-rich Siliceous Mudrock (48.9\%) and Mixed Siliceous Mudrock (40.8\%) and lesser amounts of Si-rich Carbonate Mudrock (5.6\%), and the remaining facies making up less than five percent. TOC concentrations range between 4-7\%. The middle Marcellus is a massive to weakly laminated, slightly calcareous, pyritic, organic rich silty mudstone. Thin $(<1 \mathrm{ft}$.) limestone intervals are present throughout, although in lower frequency than the lower Marcellus. 


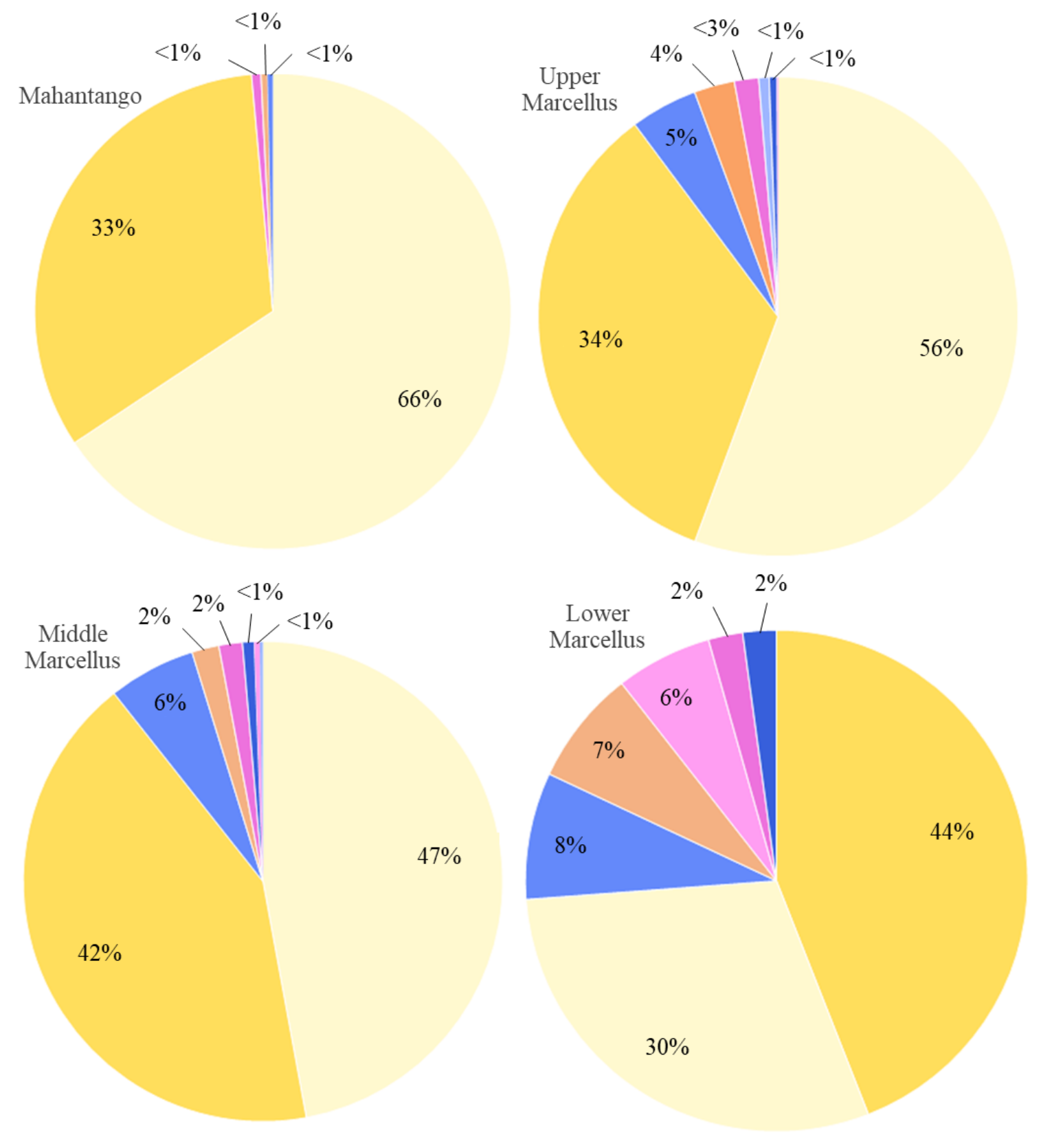

Color by: Ternary Facies

Al-rich Siliceous Mudrock

Mixed Carbonate Mudrock

Autogenic Si-enriched Siliceous Mudrock $\square$ Mixed Siliceous Mudrock

Ca-rich Siliceous Mudrock

$\square$ Muddy Limestone

Carbonate/Siliceous Mudrock

$\square$ Si-rich Carbonate Mudrock

Figure 4-4. Distribution of ternary-derived facies within the study intervals. 
The upper Marcellus is dominated by Al-rich Siliceous Mudrock (48.9\%) and Mixed Siliceous Mudrock (40.8\%), and minor Si-rich Carbonate Mudrock (4.6\%) and Autogenic Si-enriched Siliceous Mudrock (3.5\%), with the remaining facies making up less than four percent. TOC ranges between 3-5\%. The Mahantango Formation is dominated almost exclusively by Al-rich Siliceous Mudrock (64.6\%) and Mixed Siliceous Mudrock (33.9\%). TOC ranges between 1-3\%. This interval is characterized as a medium-gray to medium dark-gray, burrowed, fossil-rich, laminated silty shale. Skeletal debris present includes brachiopods, coral, crinoids, and styliolinids.

\subsection{Overview of Elemental Geochemical Proxies}

\subsubsection{Paleo- productivity and nutrients}

Oceanic productivity is the process by which phytoplankton take up carbon dioxide, water, and sunlight to convert inorganic carbon to organic carbon in the euphotic zone. The newly "produced" organic carbon is either consumed by other organisms, such as zooplankton, recycled through water movement, or sinks into the disphotic, and eventually, the aphotic zone (Sarmiento and Gruber, 2006) (figure 4-5a,b). This process is often referred to as "export production." Much of export production is sourced from zooplanktonic excretion from previously consumed organic matter. Of all organic matter created in the photic zone, only $10 \%$ sinks to the aphotic zone and less than $1 \%$ of this organic matter achieves burial and preservation (Aristegui et al., 2005).

Paleo-productivity proxy elements used in this study include $\mathrm{Ni}, \mathrm{Cu}$, and $\mathrm{Zn}$, which behave, at least in part, as micronutrients (figure 4-6). Phytoplankton uptake dissolved carbon and other macro-/micro-nutrients for growth, including hard body parts and metabolic pathways, and for producing organic matter. Complexation of $\mathrm{Ni}$ and/or $\mathrm{Zn}$ with organic matter will cause an increase in scavenging in the water column (Calvert and Pederson, 1993; Whitfield, 2002; Algeo and Maynard, 2004; Tribovillard et al., 2006). This uptake causes depletion of micronutrients in the 
euphotic zone and, resulting from export production, an enrichment towards the base of the water column (figure 4-5a,b). Upon decay of the organic matter, the $\mathrm{Ni}$ and/or $\mathrm{Zn}$ will be released in pore waters around the sediment-water interface (Tribollard et al., 2006). These trace metals can be cycled into overlying waters, incorporated into pyrite under more reducing conditions, and in some cases, can be assimilated into sediments as organic matter.

\subsubsection{Anoxia and Euxinia}

Anoxia refers to the absence of oxygen within a water column or the sediment-water interface, while euxinia occurs when the water column or the sediment-water interface is both anoxic and a raised level of free hydrogen sulfide $\left(\mathrm{H}_{2} \mathrm{~S}\right)$. Molybdenum (Mo), vanadium (V), and uranium (U) are found to have conservative concentrations in seawater but are preferentially concentrated in anoxic organic-rich sediments, and are the most well understood geochemically (Emerson, 1991). Thus, Mo, V, and U act as anoxia proxy elements (figure 4-6). In addition, molybdenum and vanadium are paleoredox indictors due their strong correlation between organic carbon and their concentrations in numerous ancient black shale units (e.g., Meyers et al., 2005). Molybdenum and $\mathrm{U}$ is relatively unreactive in seawater and preferentially concentrated in sediment overlain by anoxic or sub-oxic waters (Emerson, 1991) (4-5A, B). Numerous studies have confirmed that extremely low to zero oxygen presence is necessary for the formation of authigenic Mo and V (Hallberg, 1974; Pilipchuk and Volkov, 1974; Francois, 1988; Shaw et al., 1990; Emerson, 1991). The mechanism of the removal of molybdenum into anoxic sediment takes place across the sediment-water interface with restricted movement within the sediment (Emerson, 1991). 

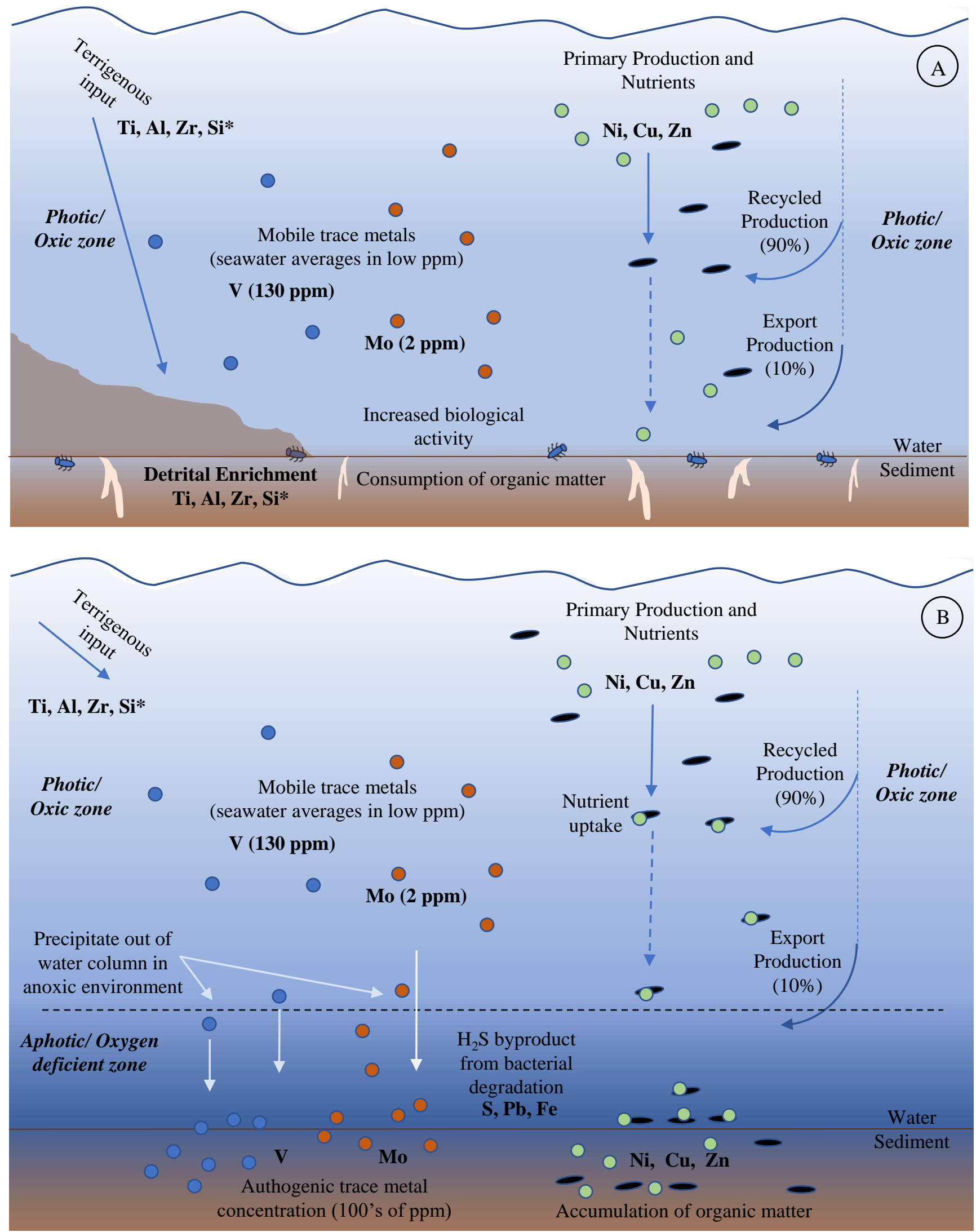

Figure 4-5A, B. Mechanistic illustration of trace metal and organic carbon accumulation in both an (a) oxic and (b) anoxic setting. 


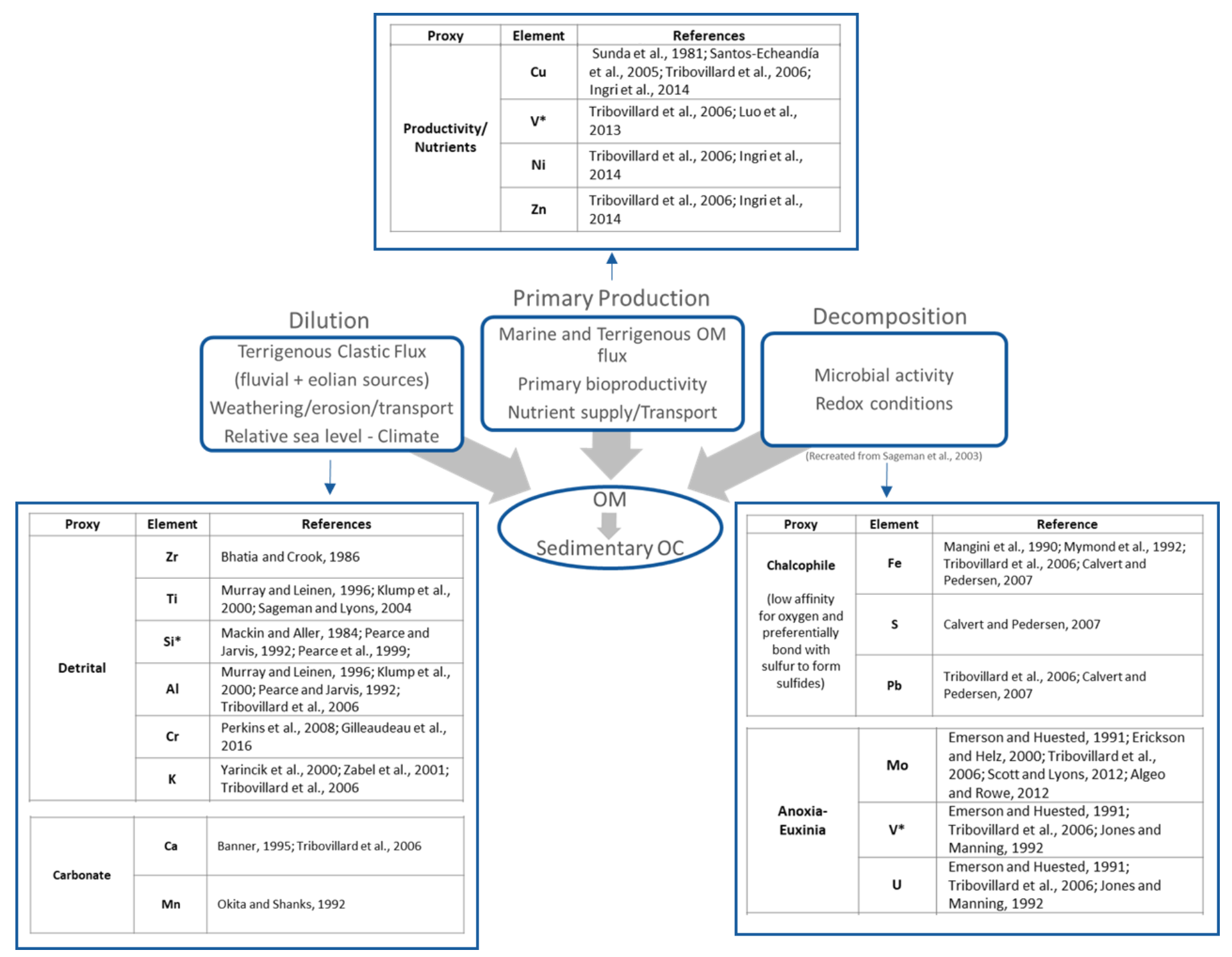

Figure 4-6. Graphic displaying the three more significant contributors to organic matter deposition and preservation. Also the elements used to approximate dilution, primary productivity, and redox state, along with numerous references from literature on the veracity of use of each element for specific depositional conditions (dilution, primary production, and decomposition summary recreated from Sageman (2003)). 


\subsubsection{Dilution - Detrital Influx and Carbonate Enrichment}

Detrital proxy elements include $\mathrm{Si}, \mathrm{Cr}, \mathrm{Al}, \mathrm{Zr}$, Th, and Ti (figure 4-6). Aluminum (Al) is found in common clay minerals such as smectite, illite, and chlorite. For most sedimentary deposits, aluminum represents the aluminosilicate fraction of the sediments and has little disposition for movement during diagenesis (Brumsack, 1989; Calvert and Pedersen, 1993; Morford and Emerson, 1999; Piper and Perkins, 2004; Tribovillard et al., 2006). Aluminum occurs only within clay minerals, while Ti occurs in both clays as well as sand-to-silt sized grains such as ilmenite, rutile, and augite, which leads to the inference that higher $\mathrm{Ti} / \mathrm{Al}$ ratios represents an increase in the volume of coarser-grained sediments (Calvert, 1976; Caplan and Bustin, 1998; Rimmer et al., 2004). Thorium is principally immobile in low-temperature subaqueous settings and within mudrock is usually found in the detrital portion associated with heavy minerals or clays (Jones and Manning, 1994). While Al, Ti, and Th, are almost exclusively a product of crustal weathering, silicon can both be continentally and biogenically derived (Pearce and Jarvis, 1992; Pearce et al., 1999; Sageman and Lyons, 2004). Calcium is incorporated into calcite and aragonite $\left(\mathrm{CaCO}_{3}\right)$ and dolomite $\left(\mathrm{CaMg}\left(\mathrm{CO}_{3}\right)_{2}\right)$ forming carbonate rocks (Flugel, 2004). Particles that make up carbonate rock either precipitate directly from the sea water or are biologically formed from calcified microbes, calcareous algae, and the articulated or disarticulated skeletons of marine organism (James and Jones, 2015).

\subsection{Data, Materials, and Methods}

\subsubsection{X-Ray Fluorescence}

High-resolution (data point collected every 2 inches [5cm]) XRF data, collected by the Olympus Innov-X DELTA Premium Handheld XRF Analyzer, an energy-dispersive handheld XRF 
(hhEDXRF), was gathered on seven study well cores. The Olympus Innov-X DELTA Premium equipped with a $40 \mathrm{kV}$ tube and large area silicon drift detector. With Delta's two-beam setting, a high $(40 \mathrm{kV})$ and low $(15 \mathrm{kV})$ beam is used to increase resolution of both major and trace elements. For each data point, the hhEDXRF was ran for 60 seconds on both the high and low beam setting. In addition to the high resolution hhEDXRF data, 64 compositionally diverse sample locations, roughly 16 per core, were extracted from the core and analyzed using a Thermo Scientific ARL PERFORM'X Sequential X-Ray Fluorescence Spectrometer. This XRF spectrometer uses wavedispersive XRF technology (WDXRF) and yields data that are three to five percent more precise than most hhEDXRFs and is calibrated with a diverse set of more than 70 certified reference materials (CRM) issued by the National Institute of Standards and Technology (NIST), USGS, the British Chemical Society (BCS), and the Geological Survey of Japan (GSJ), and others (Conrey, 2018). Using both data sets, the hhEDXRF values were calibrated using the mudrock calibration. Martin and Carr (under review) and Chapter 2 explores in detail the hhEDXRF calibration process, precision, and accuracy.

\subsection{2 $\mathrm{C} / \mathrm{H} / \mathrm{N} / \mathrm{S}$ Elemental Analysis}

Total organic carbon (TOC) values were measured via C/H/N/S Elemental Analysis (EA) using the Elemental Combustion System 4010. Eight-seven samples collected on six of the study core, were powdered using a WC ring mill, and prepped for analysis. Inorganic carbon was extracted from the samples using hydrochloric acid, leaving only organic carbon in the samples. The prepped sample powder was placed into a tin capsule and placed into the analytical cycle of the system, which heated between 1700-1800 degrees Celsius. The subsequent gases liberated from the sample travel through a gas chromatograph separation column and are separated and detected by the 
thermal conductivity detector (TCD), which generates a signal proportional to the amount of the specific element in the sample (Costech Analytical Technologies Inc., 2005). Following calibration, the EAs software compares the elemental peak to a known standard material and returns values for element in weight percent. Repeatability of the analyzer was tested by analyzing seven duplicate samples. The percent difference between the duplicate and original samples returned a range between $0.00 \%$ and $2.81 \%$, with a favorably small average percent difference of $1.35 \%$.

\subsubsection{Modeling TOC}

Multiple regression modeling was utilized to create a predicted concentration of TOC at every point a measurement was collected by the hhEDXRF. TOC prediction was achieved through a least partial squares analysis. TOC, collected from EA analysis, was the response variable and 14 elements (Mo, V, S, Ti, Zr, Ni, Zn, Mn, Cu, Ca, Si, Pb, Al, and Fe) were predictor variables. A regression between response variable and the fitted or "modeled" result recorded a slope of one and a y-intercept of zero. The $\mathrm{r}^{2}$ value was 0.89 , with root mean square error (RMSE) and mean absolute error (MAE) values of 1.12 wt. \% and 0.86 wt. \%, respectively (figure 4-7a). A graph of residuals versus modeled TOC values is displayed in figure 4-7b. Additionally, the variable importance, which is the absolute value of the t-statistic derived from the linear regression model, is shown in figure 4-7c. Between the high $r^{2}$ value and low RMSE and MAE values, the predictability of TOC based on the suite of target elements is very high. Using the relationship derived from this analysis, continuous TOC curves were created for all seven study wells. 

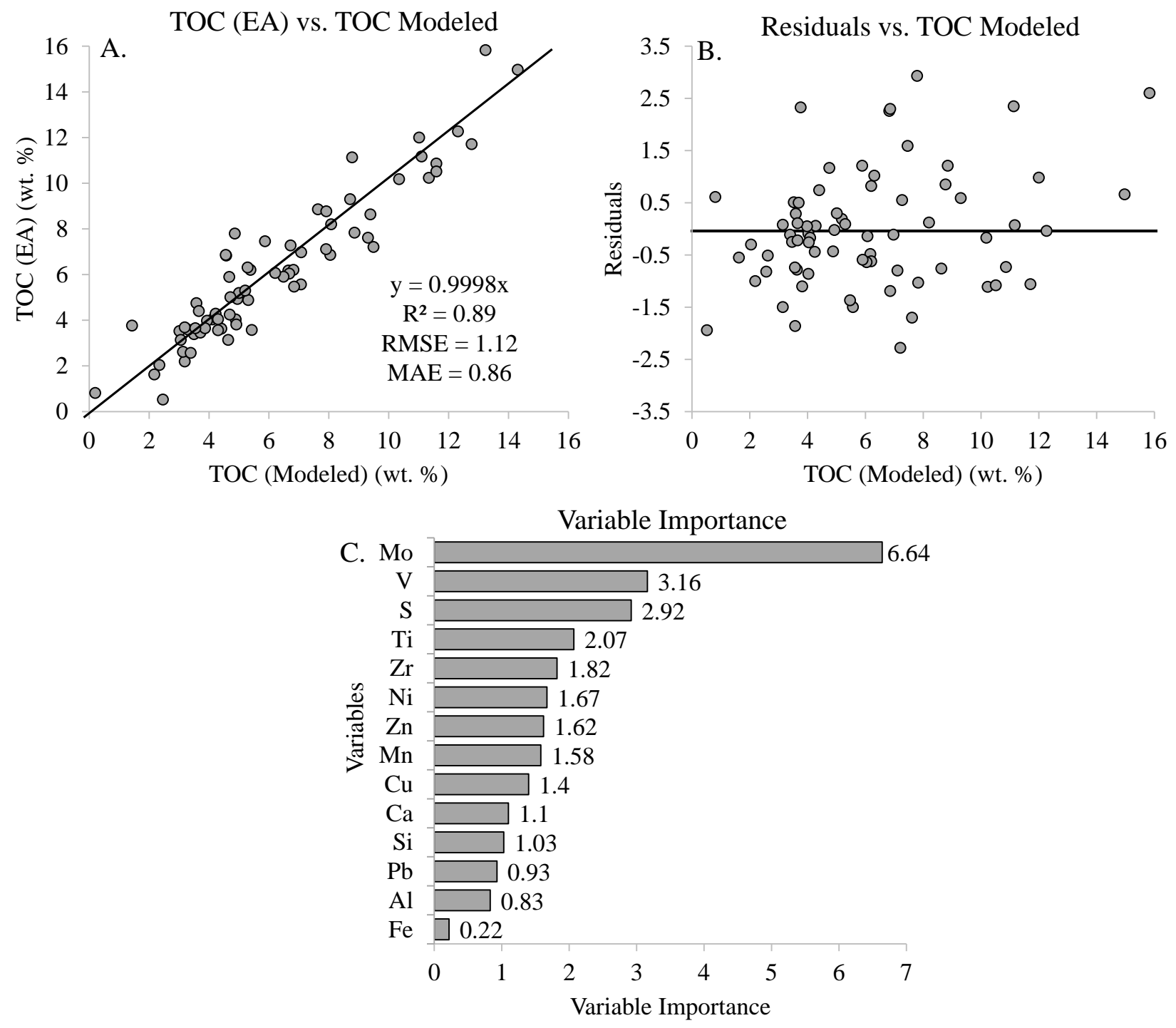

Figure 4-7. A) Graph of TOC (EA) versus modeled TOC. B) Graph of residuals versus modeled TOC. C) Variable importance, the absolute value of each component's t-statistic, as determined from the coefficients calculated in the regression model.

\subsubsection{Hierarchical Cluster Analysis}

Within the statistical software JMP 14 Pro, hierarchical cluster analysis (HCA) was conducted on the geochemical datasets. HCA is a multivariate statistical method that partitions chemical data points into a number of groups with the goal of grouping or "clustering" data points that are 
chemically similar while maximize the distance between clusters (Templ, 2006). The chemical similarities within the groups are calculated using a Euclidian distance to a cluster's centroid (Turner, 2016). Once a cluster is defined, the centroid is calculated using Ward's method, also known as "minimum variance," due to the method's goal of maintaining the lowest minimum variance as clusters are combined together (Ward, 1963). HCA is especially useful for large geochemical datasets with numerous variables (elements) and data points, as it organizes the dataset into a digestible form through reducing the sample size to a much smaller set of chemicallysimilar clusters. Two-way (column (elements) and row (samples)) clustering allows for both clustering of samples as well elements, utilizing the same principle. For visualization, dendrograms are utilized to display distances between clusters, and are commonly to provide a level of objectivity in the number of clusters chosen. HCA is conducted on both the WDXRF dataset and hhEDXRF dataset and are discussed in the following sections.

\subsubsection{Defining Enrichment/Depletion}

To assess degrees of enrichment or depletion of specific elements, "average shale" and an internal "sample population mean" (SPM) are used. The largest amount of fine-grained material composed

of mud or clay is accumulated under oxidizing conditions in nearshore waters and is considered to represent normal clay and shale, also referred to as "average shale" (Wedepohl, 1971). Average shale (AS) values are derived from Turekian and Wedepohl (1961) and Wedepohl (1971). These studies collected major chemical constituents (a compilation from 277 samples from literature) and minor element abundances in fine-grained rocks (table 4-3). Another approach, not taken in this paper, to evaluate enrichment and depletion of elements is to derive an internal equivalent of AS from Wedepohl (1971). This approach was taken by Sageman et al. (2003), where the "proxy 
baseline" for enrichment and depletion was set by using elemental values from an internal gray shale facies, interpreted as being deposited under normal marine, oxic conditions that ideally represents continental values for metals and other elements. In the cored Marcellus Shale interval, no sample met the criteria for qualifying as internal "average shale" (a grey shale deposited under well-oxygenated conditions)., Due to enrichment throughout the Marcellus Shale of trace metals such as Mo, $\mathrm{V}, \mathrm{U}$, and $\mathrm{Ni}$ as well as $\mathrm{Ca}$, thus AS values compiled from the literature is used. The following classification scheme is used to quantify level of enrichment factor (EF) relative to AS: $\mathrm{EF}<0.75$, depleted to strongly depleted; $0.75<\mathrm{EF}<1.25$, comparable to average shale; $1.25<\mathrm{EF}<5$, moderately enriched; $5<\mathrm{EF}<20$, significantly enriched; $20<\mathrm{EF}<40$, highly enriched; $\mathrm{EF}>40$, extremely enriched.

In addition to AS, an internal sample population mean (SPM) from the WDXRF dataset was derived by calculating the elemental averages of all 87 mudrock samples. Since TOC varies within samples, degrees of enrichment/depletion relative to the SPM allows visualization of the relative enrichment/depletion of elements as TOC varies.

Table 4-3. Average shale values as defined by Wedepohl $(1971,1991)$.

\begin{tabular}{cc|cc|cc} 
& \multicolumn{5}{c}{ Average Shale } \\
\cline { 2 - 6 } Element & wt. \% & Element & ppm & Element & ppm \\
\hline $\mathrm{Si}$ & 27.53 & $\mathrm{As}$ & 0.2 & $\mathrm{Ni}$ & 68 \\
$\mathrm{Ti}$ & 0.47 & $\mathrm{Ag}$ & 0.07 & $\mathrm{~Pb}$ & 22 \\
$\mathrm{Al}$ & 8.84 & $\mathrm{As}$ & 10 & $\mathrm{Rb}$ & 140 \\
$\mathrm{Fe}$ & 4.83 & $\mathrm{Ba}$ & 580 & $\mathrm{Re}$ & 0.01 \\
$\mathrm{Mg}$ & 1.57 & $\mathrm{Bi}$ & 0.1 & $\mathrm{Sb}$ & 1.5 \\
$\mathrm{Ca}$ & 1.57 & $\mathrm{Cd}$ & 0.13 & $\mathrm{Sr}$ & 300 \\
$\mathrm{Na}$ & 1.19 & $\mathrm{Co}$ & 19 & $\mathrm{Tl}$ & 0.68 \\
$\mathrm{~K}$ & 2.99 & $\mathrm{Cr}$ & 90 & $\mathrm{U}$ & 3.7 \\
$\mathrm{P}$ & 0.07 & $\mathrm{Cu}$ & 45 & $\mathrm{~V}$ & 130 \\
& & $\mathrm{Mn}$ & 850 & $\mathrm{Zn}$ & 95 \\
& & $\mathrm{Mo}$ & 2.0 & $\mathrm{Zr}$ & 160
\end{tabular}




\subsubsection{Al Normalization}

The traditional approach in calculating enrichment factors relative to AS uses the following equation;

$\mathrm{EF}=$ Element $_{(\text {sample })} / \mathrm{Al}_{(\text {sample) }} / \operatorname{Element}_{(\mathrm{AS})} / \mathrm{Al}_{(\mathrm{AS})}$.

Though popular, Al normalization has significant pitfalls, which can impact conclusions drawn from the data. Weijden (2001) found uncorrelated variables can acquire erroneous correlations when normalized by a common divisor such as Al. Moreover, normalization by a common divisor can also increase, decrease, invert, or distort correlations between elements (Weijden, 2001). Issues with Al normalization have been documented within Marcellus Shale studies specifically, where it has been found that in certain cases, enrichment can largely reflect anomalously low Al concentration rather than an enrichment of the element interest. This phenomenon of $\mathrm{Al}$ normalization in zones enriched in carbonate was documented in the Marcellus Shale (Lash and Blood, 2014). It is also discussed in detail in Weijden (2001).

In the following sections, correlation-based analyses, such as linear regression and hierarchical cluster analyses, are used to understand covariation between elements and elements and TOC. Thus, it is important to retain the structure of the data and avoid ratio correlations derived from Al-normalized variables. A modified enrichment factor, referred to herein as "bulk enrichment factor" $\left(\mathrm{EF}_{\mathrm{b}}\right)$ is utilized;

$\mathrm{EF}_{\mathrm{b}}=$ Element $_{(\text {sample })} /$ Element $_{(\mathrm{AS})}$.

This calculation derives a degree of enrichment/depletion relative to background, in this case AS, without $\mathrm{Al}$ normalization. This is a common approach in environmental sciences when measuring 
the enrichment of a contaminate relative to background, often referred to as "contamination factor" (Likuku et al., 2013; Remeikaite-Nikienè et al., 2018). A downside to this calculation is that it measures "bulk" enrichment and does not differentiate phases. As stated by Weijden (2001), most problems arise when assessing ratio correlations (Al-normalized elements), thus it is advisable to inspect correlation between elements prior to normalization. In the following sections $\mathrm{Al}$ normalization in some cases is utilized following correlational analyses to differentiate phases, such as assessing enrichment of specific trace metals by non-detrital components.

\subsection{Results and Discussion}

\subsubsection{Establishment of Proxy Elements and Elemental Groups}

A large amount of literature has defined associations between depositional conditions and individual elements and elemental groups, referred to as "proxy elements" (Hallberg, 1974; Emerson, 1991; Pilipchuk and Volkov, 1974; Francois, 1988; Emerson, 1991; Tribovillard et al.,2006). To validate proxy elements and elemental groups derived from numerous published works, two-way cluster via HCA was utilized to assess covariation of column variables (elements) and row variables (samples) measured from the WDXRF. For a proxy elemental group, the associated elements should have positive covariation, typically stronger than that of other elements and elemental groups. Based on cluster analysis on 87 samples, five internal proxy elements and elemental groups were defined; 1) detrital proxy elements ( $\mathrm{Si}, \mathrm{Cr}, \mathrm{K}, \mathrm{Al}, \mathrm{Ti}, \mathrm{Th}$, and $\mathrm{Zr}$ ), 2) chalcophile proxy elements $(\mathrm{Fe}, \mathrm{Pb}, \mathrm{S}), 3)$ productivity proxy elements $(\mathrm{Ni}, \mathrm{Cu}, \mathrm{Zn})$ and anoxia proxy elements (Mo, $\mathrm{V}, \mathrm{U})$, and 4) carbonate proxy elements (Ca, Mn) (figure 4-8). 


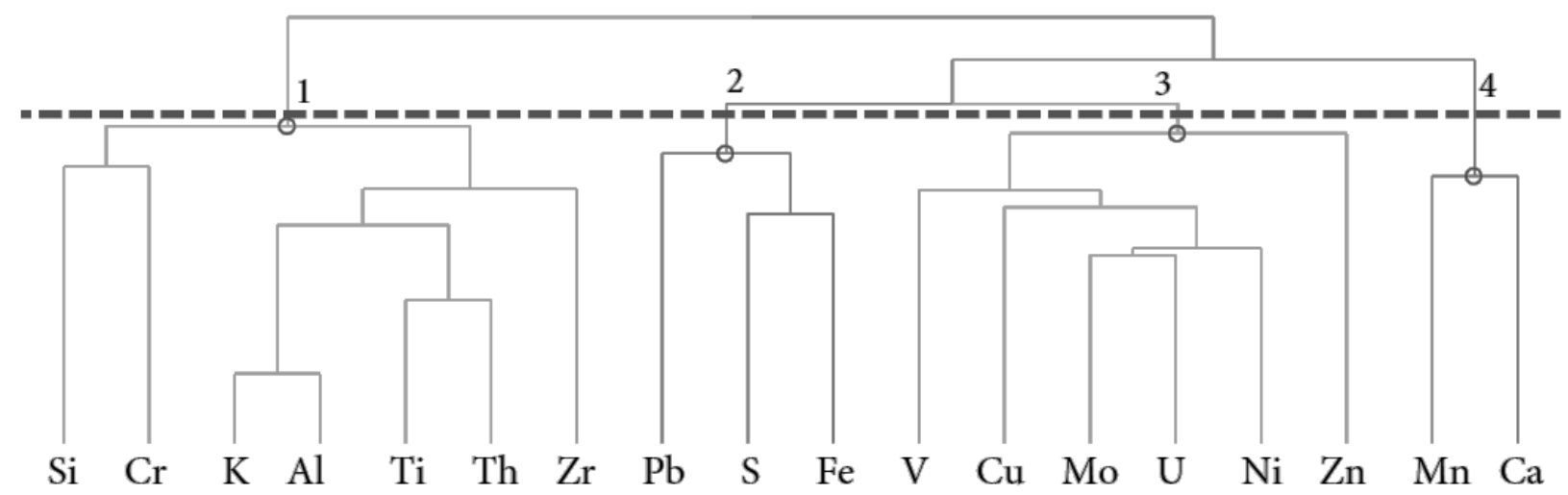

Figure 4-8. Variable clustering displaying column variables (elements) clustering. Dashed line represents pruning line.

\subsubsection{Paleo-depositional Conditions}

Paleo-depositional conditions, divided into redox/degree of oxygenation, productivity/nutrient supply, and dilution, are first approximated with the WDXRF dataset. To reinforce and augment findings from the WDXRF dataset, the high-resolution calibrated hhEDXRF dataset is utilized, which provides continuous elemental profiles. Table 4-4 represents bulk enrichment factors, as well as modelled TOC (wt. \%), for each study element as measured by the hhEDXRF, corresponding to specific study wells and formations. This table summarizes relative enrichment and depletions within the intervals for each corresponding well. 
Table 4-4. Cross table of elements $\left(\mathrm{EF}_{\mathrm{b}}\right)$ relative to formation and study well. Color gradients represent maximum (darkest) to minimum (lightest) $\mathrm{EF}_{\mathrm{b}}$ values.

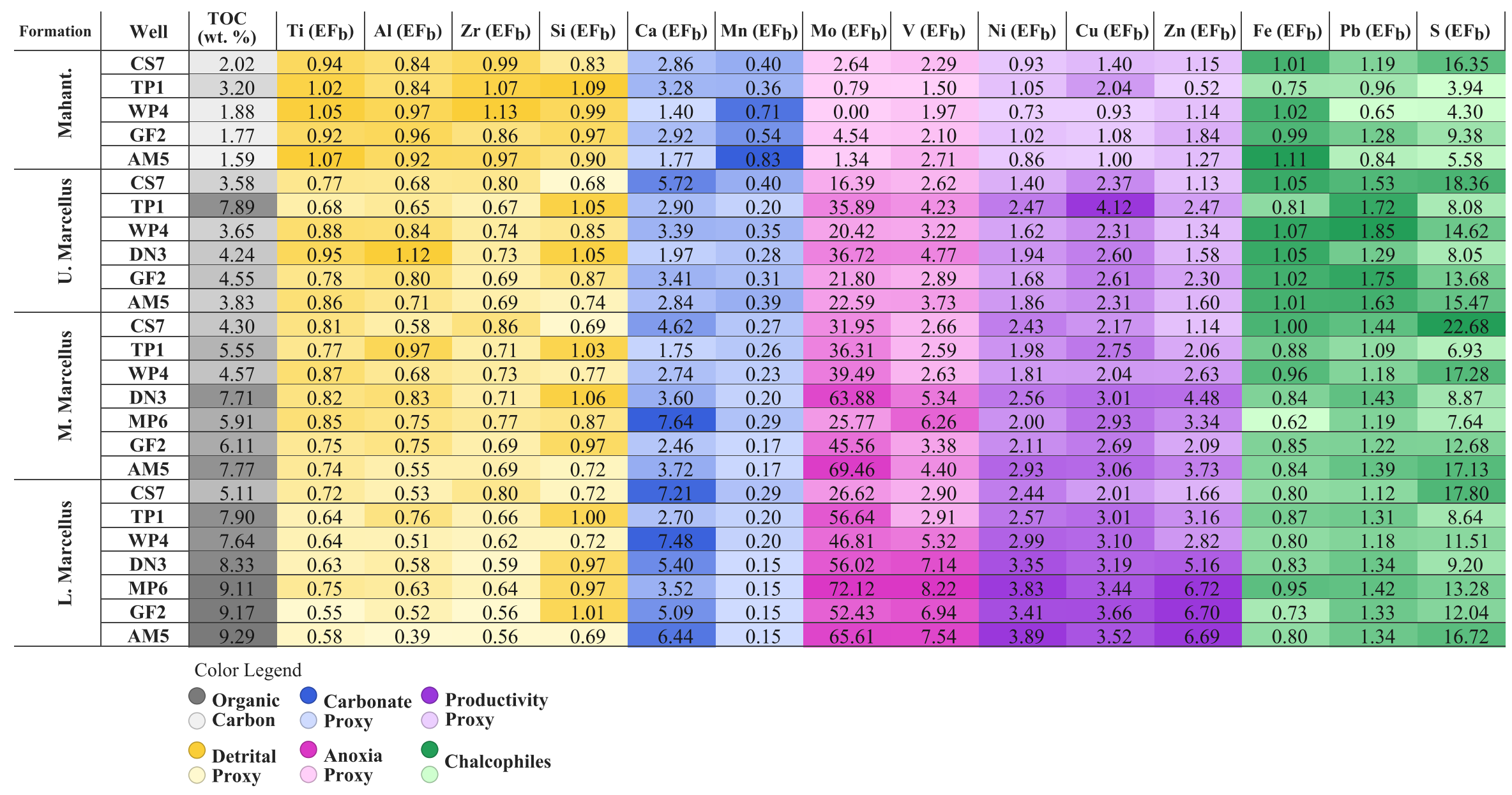




\section{Redox/Degree of Oxygenation}

Redox conditions for the study intervals were estimated using WDXRF elemental values and TOC measured by EA. During the Devonian, marine-sourced organic matter carbon isotopic values of organic carbon $\left(\delta 13 \mathrm{C}_{\mathrm{org}}\right)$ are observed to have lighter $\delta 13 \mathrm{C}_{\text {org }}$ values $(\sim-30.5 \%)$ while terrestrial-

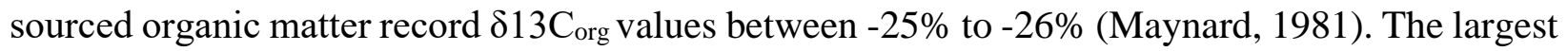
statistical $\delta 13 C_{\text {org }}$ outliers exist within the Mahantango, with three samples recording $\delta 13 C_{\text {org }}$ values of $-28.1 \%,-27.4 \%$, and $-26.6 \%$, indicating potential terrigenous influence. Excluding such samples, the overwhelming majority of $\delta 13 \mathrm{C}_{\text {org }}$ values range between $-29 \%$ to $-31 \%$, and largely represent marine-source organic matter (table 4-5).

Table 4-5. Total organic carbon and $\delta 13 \mathrm{C}_{\text {org }}$ average and standard deviation per formation.

\begin{tabular}{ccccccc} 
& \multicolumn{2}{c}{ TOC $($ wt. \%) } & & \multicolumn{2}{c}{$\delta 13 \mathrm{C}_{\text {org }}$} \\
\cline { 2 - 3 } \cline { 5 - 6 } Formation & Mean & Std. Dev. & & Average & Std. Dev \\
\hline Mahantango & 3.29 & 2.08 & & -28.72 & 0.96 \\
Upper Marcellus & 5.38 & 2.03 & & -29.51 & 0.27 \\
Middle Marcellus & 6.17 & 2.68 & & -29.99 & 0.58 \\
Lower Marcellus & 9.97 & 3.54 & & -30.28 & 0.62
\end{tabular}

Redox facies, which includes suboxic to oxic, anoxic, and euxinic, were assigned by assessing covariations between Mo, TOC, and stoichiometric pyrite $(\mathrm{S} / \mathrm{Fe})$. Estimates of oxygen content of modern benthic environments for oxic, suboxic, anoxic, are greater than 2.0, 2.0-0.2, and less than $0.2 \mathrm{ml} \mathrm{O}_{2} 1^{-1} \mathrm{H}_{2} \mathrm{O}$ respectively, and for euxinic conditions, $0 \mathrm{ml} \mathrm{O}_{2} 1^{-1} \mathrm{H}_{2} \mathrm{O}$ and the presence of free $\mathrm{H}_{2} \mathrm{~S}$ in the water column (Edwards, 1985; Tyson and Pearson, 1991; Algeo and Maynard, 2004). Following Algeo and Maynard (2004), a crossplot between Mo/Al and TOC (wt. \%) was used, in part, to define redox facies (figure 4-9). Additionally, S/Fe ratio was used for defining redox facies, where larger values of the ratio represents higher concentrations of iron sulfide. 
Euxinic Facies was defined for any sample with values of Mo/Al $>20(\mathrm{EF}>70)$, TOC (wt. \%) $>8$, and $\mathrm{S} / \mathrm{Fe}>0.5$. Anoxic Facies was defined for any sample with $\mathrm{Mo} / \mathrm{Al}$ ratios ranging from 4-19 $(\mathrm{EF}=30-65)$, TOC $($ wt. \%) $>4$, and $\mathrm{S} / \mathrm{Fe}$ between 0.35 and 0.5 . Suboxic Facies was defined as any sample with $\mathrm{Mo} / \mathrm{Al}$ ratios between 3-9 (EF=9-25), TOC (wt. \%) between 2-3.5, and S/Fe between 0.25 and 0.35 . Dysoxic to Oxic Facies was defined for any sample with values of Mo/Al between 0-1 ( $\mathrm{EF}=0-3$ ), TOC (wt. \%) between 0-2, and S/Fe between 0-0.25. In addition to Mo/Al, other proxy elements for bottom water anoxia, U/Al and V/Al display very similar trends with the redox facies (Figure4-9B,C). Lastly, Mn, an element that requires at least suboxic bottom water conditions to become strongly depleted, is plotted against TOC and the redox facies, and behaves accordingly with a clear negative relationship (Figure 4-9D) (Brumsack, 2006). The percentage of redox facies observed in each study interval is displayed in table 4-6.

Table 4-6. Percent of redox facies samples (n) for each study interval.

\begin{tabular}{ccccc} 
Redox Facies & Mahantango & $\begin{array}{c}\text { Upper } \\
\text { Marcellus }\end{array}$ & $\begin{array}{c}\text { Middle } \\
\text { Marcellus }\end{array}$ & $\begin{array}{c}\text { Lower } \\
\text { Marcellus }\end{array}$ \\
\hline Dysoxic to Oxic & $27 \%$ & - & - & - \\
Suboxic & $27 \%$ & $14 \%$ & $5 \%$ & - \\
Anoxic & $45 \%$ & $72 \%$ & $70 \%$ & $19 \%$ \\
Euxinic & - & $14 \%$ & $25 \%$ & $81 \%$
\end{tabular}

High-resolution hhEDXRF dataset indicate that TOC concentrations achieve greatest values within the lower Marcellus (table 4-4). A progressive decrease in TOC enrichment from the lower Marcellus to the overlying Mahantango is observed. Coinciding with this relationship is Mn, which progressively increases from the lower Marcellus to the overly Mahantango, reaching a bulk enrichment factor comparable to slightly below AS ( $\left.\mathrm{EF}_{b} \sim 1\right)$. Overall, such relationships indicate strong anoxic to euxinic within the lower Marcellus. Euxinic conditions diminished in the middle Marcellus, although anoxia continued to be pervasive, with Mo and V remaining extremely 
enriched and $\mathrm{V}$ significantly enriched, respectively. The upper Marcellus continues to be dominated by anoxic conditions, but it is the first interval with observed suboxic redox state. Finally, the Mahantango Formation represents the interval deposited under the most oxic conditions, which is dominated by the suboxic to oxic facies. It is important to note that while the Mahantango was deposited under the most oxic conditions relative to the other study intervals, anoxia proxy elements within the Mahantango are still enriched $\left(\mathrm{EF}_{b}=2-5\right)$ relative to AS.
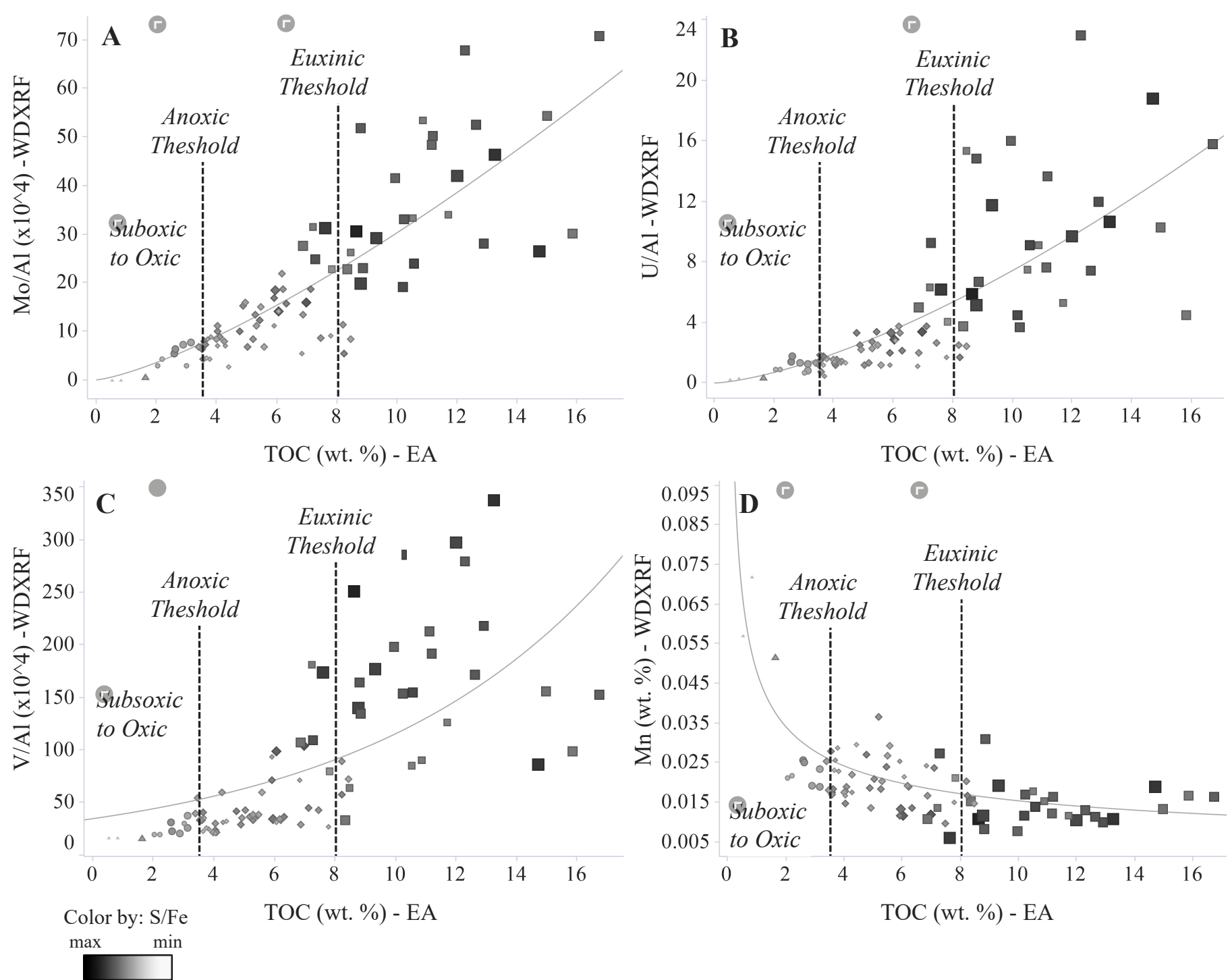

Figure 4-9 (A-D). Cross plot of Mo/Al, U/Al, V/Al, and Mn versus TOC (wt. \%), with the defined euxinic, anoxic, and suboxic to oxic thresholds. 


\section{Productivity}

Enrichment of productivity proxy elements indicates an elevated level of marine productivity within the lower, middle, and upper Marcellus. Productivity proxy elements correlate strongly with anoxia proxy elements, and generally follow the redox facies trends, where the highest concentrations of $\mathrm{Ni}, \mathrm{Cu}$, and for the most part $\mathrm{Zn}$, exist in the lower Marcellus and decrease move up the study interval into the Mahantango. Within the lower Marcellus, both $\mathrm{Ni}$ and $\mathrm{Cu}$ record $\mathrm{EF}_{\mathrm{b}}=7$, and progressively become less enriched into the Mahantango, where the enrichments show slight enrichment $\left(\mathrm{EF}_{b}=2\right) . \mathrm{Zn}$ is enriched up to $19 \mathrm{x}$ in the lower Marcellus and significantly decreases and stays a constant enrichment of $\mathrm{EF}_{\mathrm{b}}=1.5$ within the middle and upper Marcellus, and Mahantango. Productivity proxy elements record a strong correlation with anoxia proxy elements. Following the redox facies defined above, $\mathrm{Ni}, \mathrm{Cu}, \mathrm{Zn}$ all record their highest concentrations under euxinic conditions and display a continued decrease from the anoxia to the most oxic conditions. The high-resolution hhEDXRF data indicate productivity proxy elements display similar trends to anoxia proxy elements, with the lower Marcellus representing the greatest enrichment $\left(\mathrm{EF}_{\mathrm{b}}=3-7\right)$ and progressively decreasing up into the Mahantango (table 4-4).

\section{Dilution - Detrital and Carbonate Influence}

From two-way HCA, the column (element) clusters show that detrital proxy elements fractionate into two groupings, $\mathrm{Si}$ and $\mathrm{Cr}$, and $\mathrm{Al}, \mathrm{K}$, Th, and Ti. Strong correlations exist between the

elements K, Al, Ti, and Th $\left(r^{2}=0.7-0.9\right)\left(\right.$ table 4-7). Moderate $\left(r^{2}=0.5-0.7\right)$ correlation between the elements $\mathrm{Zr}$, Th and $\mathrm{Ti}$ and a very weak correlation with $\mathrm{Si}$ and $\mathrm{Cr}$ all other detrital proxy elements are observed (table 4-7). 
Table 4-7. Correlation table of detrital proxy elements.

\begin{tabular}{cccccccc} 
Elements & $\mathrm{Al}$ & $\mathrm{Cr}$ & $\mathrm{K}$ & $\mathrm{Si}$ & $\mathrm{Th}$ & $\mathrm{Ti}$ & $\mathrm{Zr}$ \\
\hline $\mathrm{Al}$ & - & 0.37 & 0.96 & 0.27 & 0.83 & 0.80 & 0.47 \\
$\mathrm{Cr}$ & 0.37 & - & 0.43 & 0.39 & 0.33 & 0.30 & 0.37 \\
$\mathrm{~K}$ & 0.96 & 0.43 & - & 0.32 & 0.78 & 0.73 & 0.46 \\
$\mathrm{Si}$ & 0.27 & 0.39 & 0.32 & - & 0.26 & 0.25 & 0.34 \\
$\mathrm{Th}$ & 0.83 & 0.33 & 0.78 & 0.26 & - & 0.89 & 0.65 \\
$\mathrm{Ti}$ & 0.80 & 0.30 & 0.73 & 0.25 & 0.89 & - & 0.74 \\
$\mathrm{Zr}$ & 0.47 & 0.37 & 0.46 & 0.34 & 0.65 & 0.74 & -
\end{tabular}

As pointed out by Tribovillard et al. (2006) and others, Cr has a detrital component, but under anoxic conditions can be exported to sediments and become enriched. Al, a detrital proxy element that is largely immobile during diagenesis and represents only detrital influence, normalization is used to determine autogenic influences on elemental concentrations. Generally, if the element/Al ratio increases, this indicates that autogenic enrichment has taken place. Chromium $(\mathrm{Cr})$ and $\mathrm{U}$, and $\mathrm{Cr} / \mathrm{Al}$ and $\mathrm{U}$ record $\mathrm{r}^{2}$ values of 0.03 and 0.22 respectively, indicating autogenic enrichment under increasingly anoxic conditions as approximated by U. Numerous studies have documented problems with utilizing $\mathrm{Si}$ as a detrital proxy, largely because changes in $\mathrm{Si}$ concentrations are affected by both clastic flux and from biogenic controls (Schieber, 1996; Schieber et al., 2000; Tribovillard, 2006). Autogenic silica enrichment takes place when dissolved silica is taken from the water column by diatoms and radiolarians to produce their siliceous skeletal frame (Prothero and Schwab, 1996). Opaline quartz is unstable and commonly undergoes a phase transition during diagenesis into a more stable form and often becomes associated with organic matter (Blood et al., 2013). Within the Oatka Creek Formation (upper Marcellus) one study found majority of quartz was of detrital origin (Werne et al., 2002) while another study found evidence of biogenic influences within the lower Marcellus (Blood and Lash, 2014). Silicon (Si) and U, and Si/Al, and $\mathrm{U}$ record $\mathrm{r}^{2}$ values of 0.03 and 0.27 , respectively. For these reasons, $\mathrm{Si}$ and $\mathrm{Cr}$ have a more limited 
utility as detrital proxy elements relative to $\mathrm{Al}, \mathrm{K}, \mathrm{Ti}$, and $\mathrm{Th}$, and do not distinguish between autogenic and authigenic enrichment.

Numerous elements (K, Al, Ti, Th, and $\mathrm{Zr}$ ) indicate maximum detrital starvation within the lower Marcellus, and detrital input appears to progressively increase moving up the study intervals into the Mahantango. The lowest concentrations of detrital proxies are found in the lower Marcellus and progressively increase in the overlying stratigraphy, with the highest concentrations of detrital proxies located in the Mahantango (table 4-4). For Ti, Al, and Zr, bulk enrichment calculations approached $\mathrm{AS}\left(\mathrm{EF}_{\mathrm{b}} \sim 1\right)$ within the Mahantango, indicating similar quantities of detrital influx with that of average shale. For $\mathrm{Ti}, \mathrm{Al}$, and $\mathrm{Zr}$, strong bulk depletions $\left(\mathrm{EF}_{\mathrm{b}} \sim 0.6\right)$ are found in the lower Marcellus, and progressively increase until bulk enrichments approach average shale values in the Mahantango (table 4-4). With the Euxinic Facies samples, Al, K, Ti, and Th, record bulk depletions of roughly $0.62,0.76,0.58$, and 0.58 . On the other hand, for bulk enrichments greater than in the Euxinic Facies, significant overlap between for Anoxic, Suboxic, and Dysoxic to Oxic Facies exist, although Suboxic and Dysoxic to Oxic Facies generally dominate the highest concentrations for $\mathrm{Al}, \mathrm{K}, \mathrm{Zr}, \mathrm{Ti}$, and $\mathrm{Th}$. Calcium records highest concentrations within the Euxinic Facies, 7.40 wt. \%, with the remaining concentrations recording 1.7 wt. $\%, 4.1$ wt. \%, and 2.15 wt. \% for the Anoxic Facies, Suboxic Facies, and Dysoxic to Oxic Facies respectively. Opposed to detrital dilution, Ca displays no correlation with degree of oxygen in the water column (redox facies), with highest values being in both the Euxinic and Suboxic Facies. As stated previously, Mn records weight percent values of 0.0152 (Euxinic Facies), 0.0179 (Anoxic Facies), 0.0254 (Suboxic Facies), and 0.060 (Dysoxic to Oxic Facies). From the highresolution hhEDXRF dataset, we find $\mathrm{Ti}, \mathrm{Al}$, and $\mathrm{Zr}$ record bulk enrichment factors upwards of 35\% lower than AS within the lower Marcellus and progressively approach concentrations similar 
to AS (EF 1) (table 4-4). These detrital proxy element concentrations increase upward from the lower Marcellus to the overlying Mahantango formation, where they approach comparable concentrations to that of average shale $\left(\mathrm{EF}_{\mathrm{b}} \sim 1\right)$. The progressive increase in detrital proxy elements within the study intervals may reflect the step-out and progradation of the Catskills Delta (Sageman et al., 2003; Ver Straeten et al., 2011). Lash and Blood (2014) hypothesized that disruptions in the progressive increase in detrital proxy elements resulting in a step pattern from the lower Marcellus to the Mahantango, represents tectonic pulses or eustatic fluctuations.

\subsubsection{Covariation of Elements and Elemental Proxy Groups with TOC}

From the two-way clustering within the HCA, column variables (elements) were grouped based on their degree of similarity in hyper-dimensional space (figure 4-8). The second clustering represents the row variables (samples). Utilizing WDXRF and TOC data, the following variables were input into the HCA: Si, Ti, Al, Fe, Mn, Ca, K, Ni, Cr, V, Cu, Zn, Mo, Th, U, Pb, and TOC. The hierarchical nature of the HCA allows for assessment of first order and second order elemental relationships, which are used to assess covariation of TOC relative to elements. In hyperdimensional space, clusters that are closer together have a more similar composition than clusters which are further apart. Euclidian distances are recorded between clusters, and using these distances, first order and second order groupings are defined. Starting with the first order grouping, we divide the data into six clusters. Six clusters were chosen as the first order cutoff based on distances between clusters. In the constellation plot that there are six main distinct branches (blue circles) (figure 4-10). The distances between Cluster 1 and 2, 2 and 3, 3 and 4, 4 and 5, and 5 and 6 were $4.93,6.54,1.32,0.74$, and 0.36 respectively. The distance from cluster 6 to 7 drops significantly to 0.014 . This indicates that six clusters are a useful cutoff point for the first order grouping. A second order grouping incorporated a total of sixteen clusters (figure 4-10). This 
cutoff was chosen based off the distance to the next cluster. For example, after the $15^{\text {th }}$ cluster, the distance between the subsequent clusters diminishes significantly relative to the first fifteen clusters, indicating distances of the clusters are becoming smaller and the clusters themselves are more similar to each other. The Euclidian distances between each set of clusters starting from the first cluster to the sixteenth cluster ranges from 3.7 to 21.7 . The Euclidian distance from the $17^{\text {th }}$ cluster to the $87^{\text {th }}$, where each sample is its own cluster, range only from 0.4 to 3.7 . The first order/second order groupings are shown via a constellation plot (figure 4-10). The 6-cluster grouping (first order) is represented by blue circles, and the 16-cluster grouping (second order) is represented by colored shapes. Based on composition, the 6 clusters have been categorized into 6 chemofacies based on their relative enrichment/depletion of elements; 1) Detrital Enriched, 2) Slightly Enriched Detrital, 3) Enriched Anoxia and Productivity, 4) Extremely Elevated Productivity, 5) Extremely Enriched Anoxia and Productivity, Sulfur (S) Enriched, and 6) Extremely Carbonate Enriched. Each of the 6 clusters, excluding the Extremely Carbonate Enriched Chemofacies, fractionate into numerous second order sub-clusters whose composition is most similar to the first order or "parent" cluster. This relationship is denoted by the numbering scheme, where, for example, Cluster 1 is a parent cluster and its three sub clusters are thus labeled sub-cluster 1.1, 1.2, and 1.3. First, elemental and TOC averages are derived for each chemofacies. Elemental and TOC averages are then derived for the sub-clusters, and the change of elemental concentrations relative to TOC allows inferences to be made regarding controls on TOC accumulation and preservation. First deriving chemofacies and then assessing covariations subcluster internal to that chemofacies, allows resolution of TOC variation of rocks with the most similar composition. To assess the enrichment or depletion of all elements simultaneously, both the SPM and $\mathrm{EF}_{b}$ were both calculated. For both the SPM and EFb, color-coded cross tables were 
created with and organized based on chemofacies and their respective sub clusters, and were sorted by degree or enrichment in ascending order (figure 4-11; figure 4-12). Any value above 1.0 represents an enrichment relative to either $\mathrm{SPM}$ or $\mathrm{EF}_{\mathrm{b}}$ and below 1.0 represents a depletion.

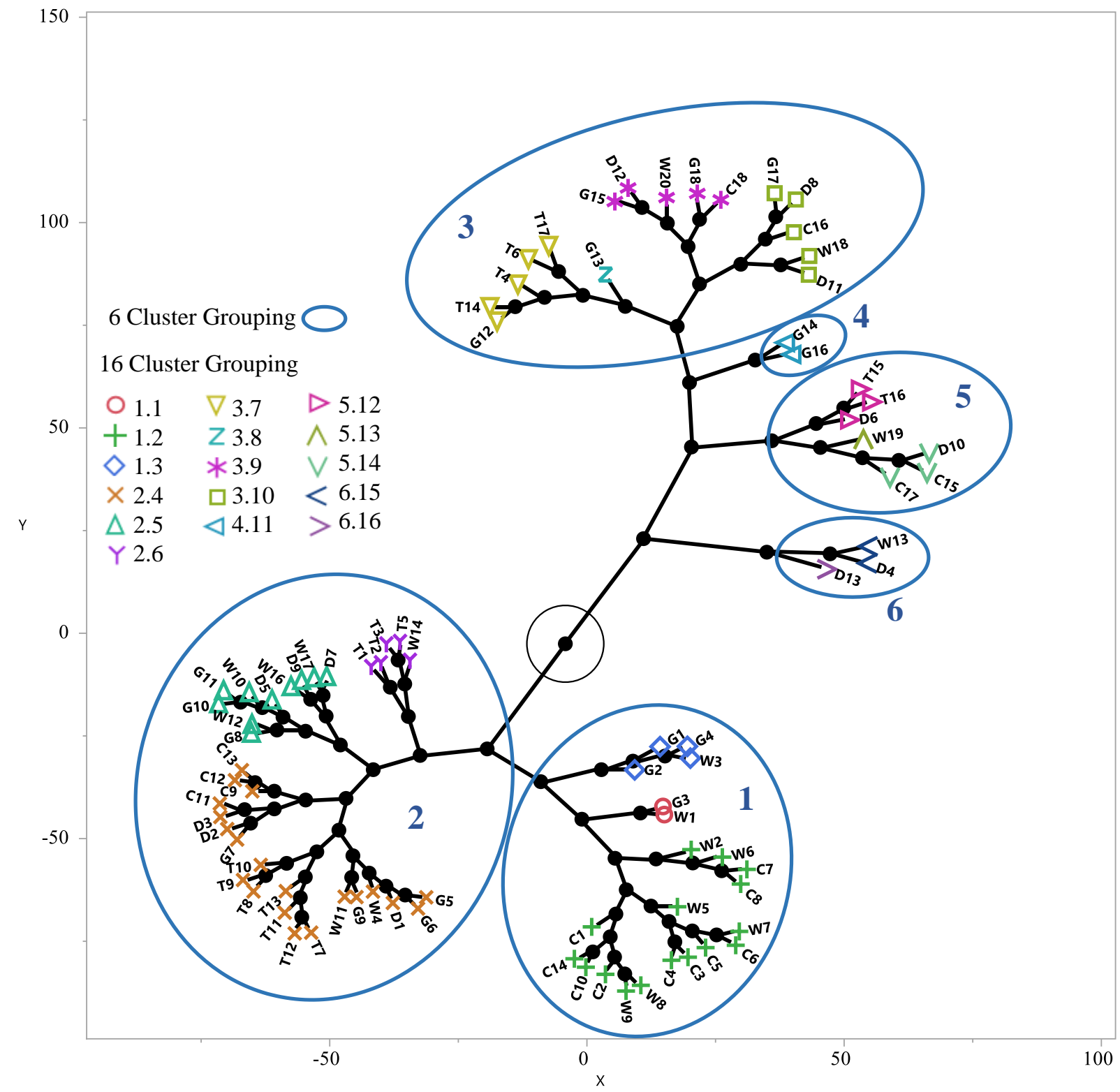

Figure 4-10. Constellation plots illustrating the relationship between the 6-cluster grouping (first order) and the 16-cluster grouping (second order). 


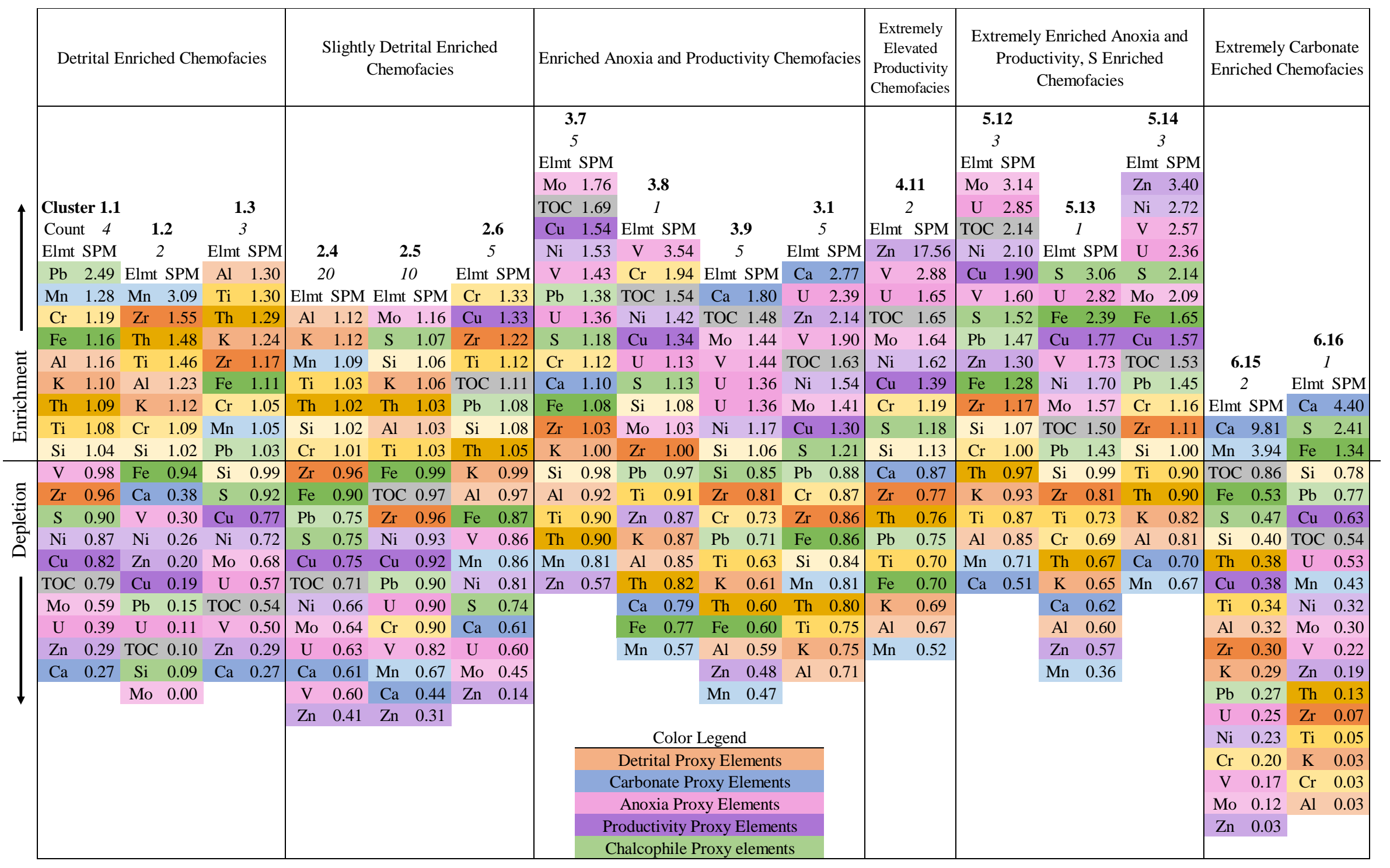

Figure 4-11. Table displaying the relative enrichment/depletion (SPM) of elements per cluster. Values greater than one represent an enrichment and are marked by the black horizontal line. 


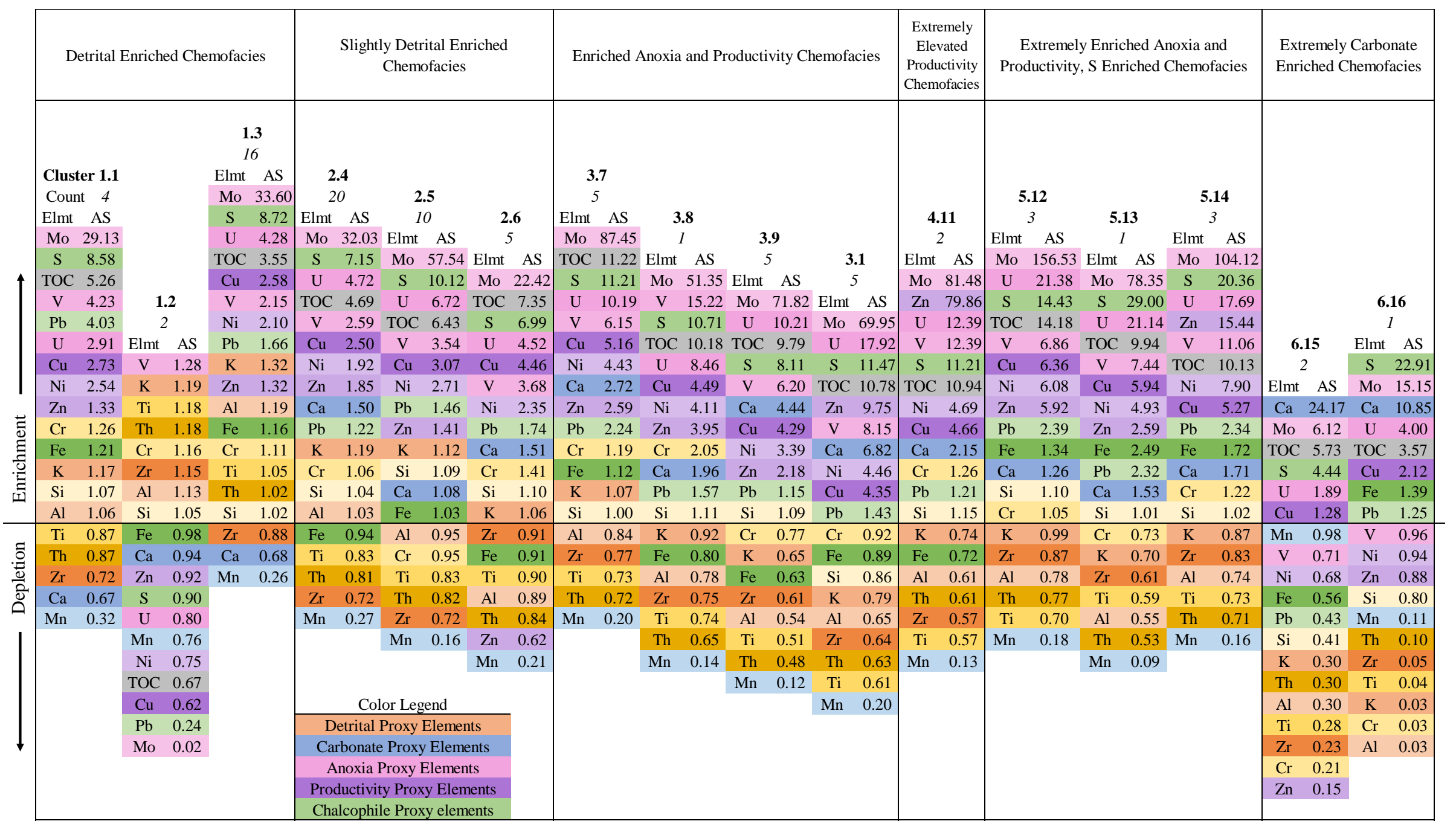

Figure 4-12. Table displaying the enrichment/depletion of elements per cluster relative to AS. Values greater than one represent an enrichment and are marked by the black horizontal line. 


\subsubsection{HCA (WDXRF) Results}

\section{Cluster 1 - Detrital Enriched Chemofacies}

Relative to SPM (figure 4-11), the Detrital Enriched Chemofacies is the facies that is most relatively enriched in detrital proxy elements. For $\mathrm{Ti}$, Th, $\mathrm{Al}$, and $\mathrm{K}$, an average enrichment of $27 \%$ is observed, and $\mathrm{Si}$ and $\mathrm{Cr}$ have an average enrichment of $4 \%$ relative to SPM. Significant depletion of $-43 \%$ relative SPM is observed for productivity proxy elements, as well as $-45 \%$ depletion for anoxia proxy elements. Chalcophile proxy elements split into two groups, with an average enrichment for $\mathrm{Pb}$ and $\mathrm{Fe}$ of $14 \%$ and average depletion of $-16 \%$ for $\mathrm{S}$. For carbonate proxy elements, a significant depletion of $72 \%$ for $\mathrm{Ca}$ and an enrichment of $28 \%$ for $\mathrm{Mn}$ is observed.

Relative to AS (figure 4-12), notable variations in elemental concentrations include depleted to strongly depleted carbonate proxy elements, moderately enriched productivity proxy elements and $\mathrm{U}$, and significantly and highly enriched values for $\mathrm{S}$ and Mo respectively. Most detrital proxy elements as well as $\mathrm{Pb}$ and $\mathrm{Fe}$ are consistent with values of average shale, while $\mathrm{S}$ is significantly enriched. Moving down the hierarchy from the first order to the second order groupings, Cluster 1 can be divided into three sub-clusters, which are denoted as sub-clusters 1.1, 1.2, and 1.3. The sub-clusters element concentrations are compared to Cluster 1 concentrations to analyze the relationships with TOC. Cluster 1 contains 22 samples and is the most organic lean cluster, with an average TOC concentration of $3.6 \mathrm{wt} . \%$. Of the 22 samples, from redox facies previously defined, 9 are classified as the Dysoxic to Oxic Facies and Suboxic facies and 13 are classified as an Anoxic Facies. 


\section{Sub-cluster 1.1}

Of the three sub-clusters, sub-cluster 1.1 records the highest TOC value of 5.3 wt. \%. Ti, Th, Al, and K, record depletions of $-14 \%$ on average, while Si and $\mathrm{Cr}$ enrich slightly up to an average of $7 \%$. Additionally, $\mathrm{Pb}$ records a strong enrichment of $105 \%$ and $\mathrm{S}$ is enriched $7 \%$. Both Mo and $\mathrm{U}$ are depleted an average of $-12 \%$, while productivity proxy elements and $\mathrm{V}$ are enrichment $13 \%$ on average and $72 \%$ respectively. $\mathrm{Mn}$ and $\mathrm{Ca}$ have values comparable to sub-cluster 1. For samples in sub-cluster 1.1, 3 are classified as Anoxic Facies and 1 is Suboxic facies.

\section{Sub-cluster 1.2}

Sub-cluster 1.2 records the lowest TOC (0.7 wt. \%) of the sub-clusters. Si and Cr record values comparable to Cluster 1 . The positive relationship of $\mathrm{Ti}, \mathrm{Th}, \mathrm{Al}$, and $\mathrm{K}$ is disturbed within sub-cluster 1.2. Ti and $\mathrm{Th}$ record an average enrichment of $15 \%$ while $\mathrm{Al}$ and $\mathrm{K}$ record a slight average depletion of $-4 \%$. All chalcophile proxy elements record depletion, with the strong being $\mathrm{Pb}$ and $\mathrm{S}$, which record depletions up to $89 \%$. Strong depletions, an average of $-68 \%$, are observed for anoxia and productivity proxy elements, and strong enrichment of Mn (141\%) and Ca (35\%). Both samples were categorized as Dysoxic to Oxic Facies.

\section{Sub-cluster 1.3}

Average TOC within sub-cluster 1.3 is 3.56 wt. \%. All detrital proxy elements have values comparable to Cluster 1. Notable enrichments and depletions include Mo (13\%), U (15\%) 
and $\mathrm{S}(9 \%)$ and $\mathrm{Pb}(-15 \%)$ and $\mathrm{V}(-12 \%)$. Additionally, Mn recorded a depletion of $-19 \%$.

Of the 16 samples within subcluster1.3, ten were categorized within Anoxic Facies, five as Suboxic Facies and one as Dysoxic Facies.

\section{Cluster 2 - Slightly Enriched Detrital Chemofacies}

Cluster 1 and 2 have the shortest Euclidian distance pair out of all 6 clusters, which indicates they are the most similar to each other in hyper-dimensional space. From figure 4-11 we find Cluster 2 records the $3^{\text {rd }}$ highest average TOC concentration of 5.57 wt. \%. Si, Cr, Ti, Th, Zr record values comparable to SPM and $\mathrm{Al}$ and $\mathrm{K}$ are slightly enriched $8 \%$. Depletion of $-34 \%$ relative SPM is observed for productivity proxy elements, as well as a $-28 \%$ depletion for anoxia proxy elements. Chalcophile proxy elements record an average depletion of $-13 \%$. For carbonate proxy elements, a depletion of $-44 \%$ and $-10 \%$ for $\mathrm{Ca}$ and $\mathrm{Mn}$ respectively is observed.

Relative to AS (figure 4-12), notable enriched/depleted elements include depleted to strongly depleted $\mathrm{Mn}$ and moderately enriched $\mathrm{Ca}$, moderately enriched productivity proxy elements and $\mathrm{U}$, and significantly and highly enriched values for S and Mo respectively. Detrital proxy elements are comparable to average shale, with slightly depletions of $\mathrm{Ti}, \mathrm{Th}$, and $\mathrm{Zr}$.

\section{Sub-cluster 2.4}

Sub-cluster 2.4 records the lowest TOC value, 4.7 wt. \%, within the Slightly Enriched Detrital Cluster. Relative to Cluster 2, detrital proxy elements are comparable. Chalcophile proxy elements are depleted an average of $-8 \%$ and anoxic proxy elements are depleted $13 \%$. $\mathrm{Ni}$ and $\mathrm{Cu}$ are depleted at average of $-14 \%$, and $\mathrm{Zn}$ is uniquely enriched $19 \%$. $\mathrm{Mn}$ and $\mathrm{Ca}$ record enrichments of $21 \%$ and $8 \%$ respectively. Of the 20 samples within sub- 
cluster 2.4, 1 sample is categorized as Suboxic Facies and 19 samples are categorized as Anoxic Facies.

\section{Sub-cluster 2.5}

Average TOC within sub-cluster 2.5 is 6.4 wt. $\%$. All detrital proxy elements have values comparable to Cluster 2, excluding $\mathrm{Cr}$, which is depleted $-12 \%$ relative to Cluster 2. Relative to Cluster 2, chalcophile proxy elements are enriched $7 \%$, with the strong enrichment of $27 \%$ recorded for S. Anoxia and productivity proxy elements record an average enrichment of $32 \%$ and $6 \%$ respectively. Relative to Cluster 2, average depletion of carbonate proxy elements was $-24 \%$. Of the 10 samples within subcluster $2.5,8$ samples are classified as Anoxic Facies and 2 are Classified as Euxinic Facies.

\section{Sub-cluster 2.6}

Average TOC within sub-cluster 2.6 is 7.4 wt. \%. Al and $\mathrm{K}$ record depletions of $-10 \%$, and $\mathrm{Ti}$ and Th record slight average enrichment of 5\%. Cr and $\mathrm{Zr}$ record enrichments of $31 \%$ and $22 \%$ respectively. Anoxia proxy elements, Mo and U, record an average depletion of $-27 \%$, and an average enrichment of $\mathrm{V}$ at $22 \%$. Of the 5 samples within sub-cluster 2.6, all are classified as Anoxic Facies.

\section{Cluster 3 - Enriched Anoxia and Productivity Chemofacies}

Cluster 3 is extremely enriched in TOC, with an average value of 10.6 wt. \%. Three clear characteristics are present; a total depletion of all detrital proxies (-16\%) and enrichment of anoxia $(63 \%)$ and productivity proxy elements (28\%), and an $82 \%$ enrichment of Ca relative to SPM 
(figure 4-12). Relative to AS (figure 4-12), most detrital proxy elements are depleted to strongly depleted, and $\mathrm{Si}$ and $\mathrm{Cr}$ are comparable to AS concentrations. Mo is extremely enriched, accompanied by significant enrichment of U, S, and V. Moderately enriched elements in $\mathrm{Zn}, \mathrm{Cu}$, $\mathrm{Ca}$, and $\mathrm{Ni}$.

\section{Sub-cluster 3.7}

Average TOC concentration within sub-cluster 3.7 reaches up to $11.2 \mathrm{wt}$. \% and is the most organic-rich sub-cluster within Cluster 3. Relative to Cluster 3, most detrital proxy elements record average enrichment of $20 \%$, while $\mathrm{Si}$ is comparable to Cluster 3. Chalcophile proxy elements are enriched up to $26 \%$, with $\mathrm{S}$ recording the lowest enrichment of 9\%. Proxy elemental groups for productivity and anoxia do not increase or decrease in unison. $\mathrm{Ni}, \mathrm{Mo}$, and $\mathrm{Cu}$ record an average enrichment of $12 \%$ and $\mathrm{U}, \mathrm{V}$, and $\mathrm{Zn}$ are on average depleted $-27 \%$. For carbonate proxy elements, $\mathrm{Mn}$ is enriched $13 \%$ and $\mathrm{Ca}$ is depleted $-40 \%$. Of the 5 samples within sub-cluster 3.7, all are classified as Euxinic Facies.

Sub-cluster 3.8

Sub-cluster 3.8 records an average TOC concentration of $10.2 \mathrm{wt}$ \% $\%$. Relative to Cluster 3, Si and $\mathrm{Cr}$ are enriched $19 \%$ and 55\% respectively, and other detrital proxy elements are enriched on an average of $12 \%$. Productivity and anoxia proxy elements are depleted $-6 \%$ and $-14 \%$ respectively, excluding $\mathrm{V}$ which is $107 \%$ enriched. For chalcophile proxy elements, $\mathrm{Fe}$ and $\mathrm{Pb}$ record a slight average depletion of $-4 \%$ and $\mathrm{S}$ is enriched $4 \%$. Both 
Mn and Ca are depleted $-20 \%$ and $-56 \%$ respectively relative to Cluster 3 . This sample is categorized as Euxinic Facies.

\section{Sub-cluster 3.9}

Sub-cluster 3.9 records the lowest TOC concentration, 9.8 wt. \%, within Cluster 3. This cluster is characterized by a total depletion of detrital proxy elements, with an average depletion of $-19 \%$. Additionally, chalcophile, productivity, and anoxia proxy elements record average depletions of $-26 \%,-26 \%$, and $-13 \%$ respectively. $\mathrm{Mn}$ is depleted $-34 \%$ and Ca is comparable to Cluster 3 average. Of the 5 samples within sub-cluster 3.9, all are classified as Euxinic Facies.

Sub-cluster 3.10

Sub-cluster 3.10 records an average TOC concentration of 10.8 wt. \%. For Si and Cr, average depletion of $-12 \%$ relative to Cluster 3 are found. All other detrital proxy elements record an average depletion of $-3 \%$. Fe and $\mathrm{S}$ record an average enrichment of $5 \%$ and $\mathrm{Pb}$ is depleted $-11 \%$. Proxy elemental groups for productivity and anoxia do not increase or decrease in unison. Enrichments of Ni (9\%), U (43\%), V (11\%), and Zn (104\%) were found, as well as depletions for $\mathrm{Mo}(-7 \%)$ and $\mathrm{Cu}(-5 \%)$. Mn and $\mathrm{Ca}$ record enrichments of $13 \%$ and $52 \%$ respectively. Of the 5 samples within sub-cluster 3.10 , all are classified as Euxinic Facies. 
Cluster 4 and sub-cluster 4.11 - Extremely Elevated Productivity Chemofacies

Cluster 4 is extremely enriched in TOC, recording an average concentration of 10.9 wt.\%. This cluster is characterized by an extreme enrichment $(1,656 \%)$ of $\mathrm{Zn}$ and a strong enrichment of V (188\%) relative to SPM (figure 4-11). Si and Cr record average enrichment of $15 \%$ and all other detrital proxy elements record an average depletion of $-28 \%$. Both $\mathrm{Pb}$ and $\mathrm{Fe}$ are depleted $-28 \%$, and $\mathrm{S}$ is enriched $18 \%$. Excluding $\mathrm{Zn}$ and $\mathrm{V}$, while are extremely enriched relative to SPM, productivity and anoxia proxy elements record average enrichments of 50\% and $65 \%$ respectively. Mn and Ca are depleted $-48 \%$ and $-13 \%$ respectively. Cluster 4 does not fractionate into subclusters within the high-resolution 16 cluster cutoff. Of the 2 samples within sub-cluster 4.11 , both are classified as Euxinic Facies.

Cluster 5 - Extremely Enriched Anoxia and Productivity, S Enriched Chemofacies

Cluster 5 is the most enriched cluster in the study, with an average concentration of 11.8 wt. \%. Relative to SPM (figure 4-11), this cluster is characterized by slight average enrichment of $\mathrm{Si}, \mathrm{Cr}$, and $\mathrm{Zr}$ of $5 \%$, and a depletion of all other detrital proxy elements averaging $-15 \%$. Chalcophile, productivity, and anoxia proxy elements record average enrichments of $69 \%, 105 \%$, and $138 \%$ respectively relative to SPM. Carbonate proxy elements record average depletion of $-38 \%$.

Relative to AS (figure 13, detrital proxy elements are comparable to AS to depleted. Productivity proxy elements, $\mathrm{V}$, and $\mathrm{U}$ are significantly enriched. Both $\mathrm{Pb}$ and $\mathrm{Fe}$ are moderately enriched, and S is significantly enriched. $\mathrm{Mn}$ is strongly depleted, and $\mathrm{Ca}$ is moderately enriched. 


\section{Sub-cluster 5.12}

Sub-cluster 5.12 record the highest TOC concentration (14.2 wt. \%) out of all sub-clusters. Relative to Cluster 5 averages, $\mathrm{Si}$ and $\mathrm{Cr}$ record an average concentration comparable to Cluster 5, and all other detrital proxy elements record an average enrichment of $7 \%$. Chalcophiles display an average depletion of $-14 \%$. Proxy elemental groups for productivity and anoxia do not increase or decrease in unison. A depletion of $\mathrm{Ni}(-9 \%), \mathrm{V}$ $(-21 \%)$, and $\mathrm{Zn}(-38 \%)$ and an enrichment of $\mathrm{Mo}(27 \%), \mathrm{U}(8 \%)$, and $\mathrm{Cu}(9 \%)$ is observed. $\mathrm{Mn}$ is enriched $15 \%$ and $\mathrm{Ca}$ is depleted $-16 \%$. Of the 3 samples within sub-cluster 5.12 , all are classified as Euxinic Facies.

\section{Sub-cluster 5.13}

Sub-cluster 5.13 records an average TOC concentration of 9.9 wt.\%. Relative to Cluster 5, Si and $\mathrm{Cr}$ record depletions of $-4 \%$ and $-32 \%$, and all other detrital proxy element record an average depletion of $-23 \%$. Fe and S record enrichments of $50 \%$ and $52 \%$, respectfully. Proxy elemental groups for productivity and anoxia do not increase or decrease in unison. A depletion of $\mathrm{Ni}(-26 \%)$, Mo (-36\%), V (-15\%), and Zn (-73\%), and an enrichment of U (7\%) and $\mathrm{Cu}(2 \%)$ is observed. $\mathrm{Mn}$ is depleted $-41 \%$ and $\mathrm{Ca}$ is enriched $3 \%$. The sample within subcluster5.13 is categorized as Euxinic Facies.

\section{Sub-cluster 5.14}

Sub-cluster 5.14 records a TOC concentration of 10.1 wt. \%. Cr is enriched $13 \%$ and all other detrital proxy elements have comparable concentrations within Cluster 5 averages. $\mathrm{Fe}$ and $\mathrm{Pb}$ are comparable to concentrations within Cluster 5 averages, and $\mathrm{S}$ is enriched 
7\%. Proxy elemental groups for productivity and anoxia do not increase or decrease in unison. A depletion of $\mathrm{Mo}(-15 \%), \mathrm{U}(-10 \%)$, and $\mathrm{Cu}(-10 \%)$ and an enrichment of $\mathrm{Ni}$ (18\%), V (26\%), and $\mathrm{Zn}(62 \%)$ is observed. Mn and $\mathrm{Ca}$ are enriched $8 \%$ and $15 \%$ respectively. Of the 3 samples within sub-cluster 5.14, all are classified as Euxinic Facies.

Cluster 6 - Extremely Carbonate Enriched Chemofacies

Cluster 6 records an average TOC concentration of 5.0 wt. \%. Relative to SPM (figure 4-11), detrital, chalcophile, productivity, and anoxia proxy elements are extremely depleted an average of $-73 \%,-22 \%,-73 \%$, and $-76 \%$ respectively. $\mathrm{Ca}$ and $\mathrm{Mn}$ are enriched $176 \%$ and $701 \%$ respectively.

\section{Sub-cluster 6.15}

Sub-cluster 6.15 records an average TOC concentration of 5.7 wt. \%. Relative to Cluster 6, Si is depleted $-24 \%$, and all other detrital proxy elements are enriched an average of $38 \%$. Chalcophile, productivity, and anoxia proxy elements record average depletions of $43 \%,-31 \%$, and $-23 \%$ respectively. Mn and Ca record average enrichment of $43 \%$ and $23 \%$ respectively. Of the 2 samples within subcluster6.15, both fall within the Suboxic Facies and Euxinic Facies categorization.

\section{Sub-cluster 6.16}

Sub-cluster 6.16 records a TOC concentration of 3.6 wt. \%. Relative to Cluster $6, \mathrm{Si}$ is enriched $48 \%$ and all other detrital proxy elements are depleted an average of $-76 \%$. Chalcophile, productivity, and anoxia proxy elements record average enrichments of $87 \%$, 
$61 \%$, and $47 \%$ respectively. Mn and Ca record average enrichment of $-85 \%$ and $-45 \%$ respectively. The sample within sub-cluster 6.16 is categorized as Euxinic Facies.

\subsubsection{Control on Organic Carbon Enrichment/Depletion}

Dilution, productivity, and degree of bottom water oxygenation have been at the forefront in understanding the key controls on organic carbon enrichment and depletion. Investigators have historically emphasized the overarching importance of a single control on accumulation of organic-rich mudrock to the exclusion of others (Demaison and Moore, 1979; Pederson and Calvert, 1990; Canfield, 1994). Within studies on Devonian mudrock of the Appalachian basin specifically, more recent investigators emphasized an interplay between dilution, productivity, and degree of bottom water oxygenation, but nonetheless determine a chief control on organic carbon enrichment, such as changes in base level or regeneration of nutrients via upward mixing (Sageman et al., 2003; Chen and Sharma; Lash and Blood, 2014). The source of the recent disparate explanations and emphasis on specific controls in Appalachian basin studies may be explained by the fact that the studies focus on a single study well and core. With this limitation, local variation in the depositional system can impact observations and conclusions. The data presented are collected from seven cored intervals distributed throughout dispersed locals within the basin, allowing for consistencies and contrasts to be documented across the basin. The HCA analysis allows for interrelationships between elements and elemental proxies and TOC to be assessed in simultaneously. 


\section{Cluster 1, 2 - Detrital Enriched Chemofacies, Slightly Enriched Detrital Chemofacies}

The Detrital Enriched Chemofacies and Slightly Enriched Detrital Chemofacies record the highest concentrations of detrital proxy elements and the lowest TOC concentration out of all clusters. Along with this enrichment of detrital proxy elements, Mn records its highest concentrations, especially within the Detrital Enriched Chemofacies. Excluding samples extremely enriched in carbonate, these chemofacies also record the most depleted anoxia and productivity proxy elements. Relative to AS, $\mathrm{S}$ is significantly enriched, $\mathrm{Pb}$ is equivalent, and $\mathrm{Fe}$ is depleted to equivalent.

The Detrital Enriched Chemofacies fractionates into three sub-clusters. Investigating the two end members in regard to TOC concentration, sub-cluster 1.1 (TOC $=5.3$ wt. \%) and subcluster $1.2(\mathrm{TOC}=0.7 \mathrm{wt} . \%)$, we find that subcluster 1.1 is more depleted in detrital proxy elements and more enriched in anoxia and productivity proxy elements. Sub-cluster 1.2 displays $\mathrm{Mn}$ concentrations twice that of sub-cluster 1.1, is more enriched in $\mathrm{Ca}$, and records the highest total concentration of detrital proxy elements out of all clusters and sub-clusters. When compared to AS, sub-cluster 1.2's detrital proxy element concentrations are similar to AS to moderately enriched, while productivity and anoxia proxy elements are depleted to strongly depleted. For subcluster 1.1, most detrital proxy elements are at concentrations equivalent to AS or slightly depleted, and productivity and anoxia concentrations moderately enriched to significantly enriched. From the investigation of the sub-cluster end members in regard to TOC, the following tended to associate with more limited organic carbon enrichment; 1) a combination of relatively limited surface productivity and subsequent export production, 2) a more oxygenated water column (evidenced by anoxic proxy element depletion and Mn enrichment), and 3) elevated dilution into the basin. Although, sub-cluster 1.1 demonstrates that, accompanied by moderately enriched to 
highly enriched anoxia and productivity proxy elements relative to AS, samples with bulk enrichments of detrital proxy elements comparable to AS can accumulate significant amount of organic carbon $(\mathrm{TOC}=5.3 \mathrm{wt}$. \%). Comparisons between sub-cluster 1.2 and sub-cluster 1.3 both contain detrital proxy elements that are comparable to AS to slightly enriched, while their enrichment/depletion of anoxia and productivity proxy elements differ. Sub-cluster 1.2 and subcluster1.3 are characterized as Dysoxic to Oxic Facies and a mixed Suboxic to mostly Anoxic Facies, respectively. While holding detrital proxy elements relatively constant, the enrichment of anoxia and productivity proxy elements in sub-cluster 1.3 is accompanied by a five-fold enrichment of TOC relative to subcluster1.2. Sageman et al. (2003) found the master control on excessive organic carbon burial was relative sea level. Relative sea level, in this study, was inferred by Al-normalized ratios of detrital proxy elements, namely Ti. In contrast, the relationship between subcluster1.2 and sub-cluster 1.3 may indicate an independence between the degree of detrital influx (approximated by detrital proxy elements) and TOC enrichment, if accompanied by enrichment of proxy elements indicative of anoxia and and enhanced productivity.

\section{Cluster 3 - Enriched Anoxia and Productivity Chemofacies}

The Enriched Anoxia and Productivity Chemofacies is especially enriched in TOC, with an average value of 10.6 wt. \%. Characteristics of the Enriched Anoxia and Productivity Chemofacies include a total depletion of all detrital proxy elements, enrichment of anoxia and productivity proxy elements, and enrichment of Ca relative to the mean of the samples in this study (SPM). Cluster 3 is fractionated into four sub-clusters. In regard to TOC, the endmember clusters, sub-cluster 3.9 $(\mathrm{TOC}=9.8$ wt. $\%)$ and sub-cluster $3.7(\mathrm{TOC}=11.2 \mathrm{wt} . \%)$, differ largely in the magnitude of enrichment of anoxia and productivity proxy elements, with sub-cluster 3.7 having $11 \%$ higher 
enrichments on average relative to AS. In regard to detrital proxy element enrichment, sub-cluster 3.9 has $35 \%$ higher enrichment on average relative to sub-cluster 3.7 , indicating that a total increase in productivity and anoxia proxy elements leading to increasing TOC concentrations. It is observed that detrital proxy elements do not reflect a linear relationship with TOC as found with productivity and anoxia proxy. That is, within the Cluster 3 sub-clusters, enriching detrital proxy elements do not correlate with a corresponding decrease in TOC. As noted previously, when assessing the entire sample population, the negative relationship between detrital proxy elements, $\mathrm{Al}, \mathrm{K}, \mathrm{Ti}$, and Th, and TOC are strong, with an average $\mathrm{r}^{2}$ value of 0.5 . When segregated into two categories, low to high TOC (0-8 wt. \%) and very high TOC (8-16 wt. \%), we find within low to high TOC category, Al, K, Ti, and Th retain positive correlations when plotted against TOC, with an average $r^{2}$ value of 0.34 . Within the very high TOC sample population, the correlation between $\mathrm{Al}, \mathrm{K}, \mathrm{Ti}$, and Th when plotted against TOC records an average $\mathrm{r}^{2}$ value of 0.0 . This demonstrates that for very high TOC concentrations, detrital proxy elements on average are depleted to strongly depleted- to AS, but the degree of depletion or enrichment does not impact TOC concentrations.

Cluster 4, 5 - Extremely Elevated Productivity Chemofacies, Extremely Enriched Anoxia and Productivity, S Enriched Chemofacies

The Extremely Elevated Productivity Chemofacies has an average TOC concentration of 10.9 wt. $\%$ and is characterized by anomalously high $\mathrm{Zn}$ concentration, reaching $\mathrm{EF}_{\mathrm{b}}=79$. In addition to $\mathrm{Zn}$, $\mathrm{V}$ reaches its highest concentration out of all samples, reaching up to $\mathrm{EF}_{\mathrm{b}}=12$. Other productivity proxy elements, $\mathrm{Ni}$ and $\mathrm{Cu}$, are moderately enriched, and anoxia proxy elements are significantly enriched to extremely enriched relative to AS. Detrital proxy elements are depleted to strongly depleted. Fe and $\mathrm{Pb}$ moderately enriched, and $\mathrm{S}$ is highly enriched. Relationships defined with 
Cluster 3 and its sub-clusters are retained within the Extremely Elevated Productivity and the Extremely Enriched Anoxia and Productivity S Enriched chemofacies. The Extremely Enriched Anoxia and Productivity, S Enriched Chemofacies records the highest TOC concentration, 11.8 wt. \%, out of all chemofacies. This chemofacies fractionates into three sub-clusters. In regard to TOC, the endmember clusters, sub-cluster $5.13(\mathrm{TOC}=9.9$ wt. $\%)$ and sub-cluster $5.12($ TOC = 14.2 wt. \%), differ largely in the magnitude of enrichment of anoxia and productivity proxy elements, with sub-cluster 5.12 having $14 \%$ higher enrichments on average relative to AS. This indicates as anoxia and productivity proxy elements become more enriched relative to AS, TOC will also become more enriched.

Strong covariation between anoxia and productivity proxy elements are observed. Variable (element) clustering from the HCA also clustered anoxia and productivity proxy elements, as displayed under the clade labelled "3" (figure 4-8). Additionally, the variable clustering from the HCA displayed commingling of anoxia and productivity proxy elements, with the order from most to least similar being Mo-U-Ni-Cu-V-Zn. Such strong covariation between anoxia and productivity proxy elements, strong positive correlation with TOC, and commingling within HCAderived cluster complicates decoupling. This may support an interrelationship between anoxia and productivity via the mechanism of "productivity-anoxia feedback" (Ingall et al., 1993; Piper and Calvert, 2009). This feedback refers to the idea that export production to bottom waters can accelerate the rate of benthic bacterial respiration, and if the rate of consumption exceeds the rate of $\mathrm{O}_{2}$ replenishment, the bottom waters will become more anoxic. The first assumption of this mechanism is the manifestation of high primary productivity, which calls for the presence of biolimiting nutrients. Bio-limiting nutrients are sourced both externally (fluvial and/or eolian) and internally (vertical mixing and/or upwelling), with internal nutrient sources accounting the nutrient 
volume (Piper and Calvert, 2009). Chen and Sharma (2016) concluded through relationships between $\mathrm{C} / \mathrm{N} / \mathrm{P}$ ratios that primary productivity was maintained and augmented by regeneration of bio-limiting nutrients through mixing of bottom currents and water column mixing during deposition of organic-rich intervals. In contrast, Sageman et al. (2003) inferred at maximum water depth during the deposition of the Marcellus, seasonal mixing rarely penetrated the bottom waters which in turn allows for anoxic and/or euxinic conditions to prevail. This infers, at least during Marcellus deposition within basin, a "stagnant basin" model as the mode of organic carbon enrichment. Hotinski et al (2001) raised concern in regard to the hypothesis that pervasive anoxic bottom waters result from stagnate oceanic circulation, stating that such stagnation would severely reduce the upwelling and/or mixing supply of nutrients, which would have deleterious effects on primary surface productivity. In this study, positive covariation between anoxia and productivity proxy elements, strong positive correlation with TOC, significant evidence of elevated to extremely elevated primary productivity, and commingling within HCA-derived cluster indicate productivity-anoxia feedback is a better explanation for TOC enrichment.

\section{Cluster 6-Extremely Carbonate Enriched}

The Extremely Carbonate Enriched Chemofacies has an average TOC concentration of 5.0 wt. \% and contains the highest concentrations of $\mathrm{Ca}$ and $\mathrm{Mn}$ out of all clusters. Cluster 6 is significantly depleted in detrital proxy elements. Cluster 6 fractionations into two clusters, subcluster6.15 and sub-cluster 6.16, and record TOC (wt. \%) concentrations of 5.7 and 3.6 respectively. The high-resolution hhEDXRF data show that for Ca concentrations of $20 \mathrm{wt} . \%$ and greater, $91 \%$ of samples record less than 6 wt. $\%$ of TOC, $72 \%$ of samples record less than 4 wt. $\%$ of TOC, with an average TOC of 3.31 wt. \%. For Ca concentrations of 15 wt.\% and greater, $89 \%$ 
of samples record less than $6 \mathrm{wt}$. $\%$ of TOC, $66 \%$ of samples record less than $4 \mathrm{wt} . \%$ of TOC, with an average TOC of 3.56 wt. \%. When significant Ca-enriched samples are removed to assess the effect of background levels of $\mathrm{Ca}$, we find that $\mathrm{Ca}$ and TOC record an $\mathrm{r} 2$ value of 0.001 . In total, these findings indicate Ca concentrations of $<15$ wt. \%, a bulk enrichment up to seven times that of AS, do not impact TOC enrichment.

\subsection{Conclusions}

Dilution, productivity, and degree of bottom water oxygenation have been at the forefront of understanding controls on organic carbon enrichment/depletion in mudrock. Investigators have historically emphasized in organic-rich mudrock the importance of a single control to the exclusion of others (Demaison and Moore, 1979; Pederson and Calvert, 1990; Canfield, 1994). Within studies on Devonian mudrock of the Appalachian basin specifically, more recent investigators emphasize an interplay between dilution, productivity, and degree of bottom water oxygenation, but nonetheless determine a chief control on organic carbon enrichment, such as changes in base level or regeneration of nutrients via upward mixing (Sageman et al., 2003; Chen and Sharma; Lash and Blood, 2014). The source of the recent disparate explanations/emphases on specific controls in Appalachian basin studies organic-rich mudrock may be explained by studies that are limited to a single well or core. With this limitation, local variation in the depositional system can profoundly impact conclusions. However, using a combination of wave-dispersive XRF technology (WDXRF) and energy-dispersive handheld XRF (hhEDXRF) the data base can be significantly expanded to multiple samples from seven cored intervals distributed across the basin. Using hierarchical cluster analysis (HCA) analysis permits better understanding of interrelationships between elements and elemental proxies and TOC to be assessed in unison to 
improve understanding controls on organic carbon enrichment/depletion in organic-rich mudrock. From the analyses herein, the following specific conclusions are highlighted:

1) During the deposition of the upper, middle, and lower Marcellus, overall the detrital influx was limited, comparable to (AS) in few intervals and largely depleted relative to AS in most intervals. The most detrital enriched chemofacies, the Detrital Enriched Chemofacies, demonstrates that detrital proxy values comparable to slightly enriched relative to AS can still coincide with elevated levels of TOC, upwards of $5 \mathrm{wt} . \%$, if anoxia and productivity proxies are significantly enriched relative to AS, as evidenced in sub-cluster 1.1. Additionally, sub-cluster 1.2 has slightly more enriched anoxia and productivity proxy elements, but is accompanied by a near-total enrichment of detrital proxy elements, resulting in a slightly lower TOC of $3.6 \mathrm{wt}$. \%. These relationships indicate an interplay between dilution, productivity, and anoxia, where increased levels of dilution directly impact enrichment of TOC. This observation is reinforced through assessing sub-cluster 1.2, which records a total enrichment of detrital proxy elements relative to AS in addition to a total depletion of detrital proxy elements, resulting in the lowest measured TOC value of 0.67 wt. \%.

2) Extreme enrichments of Ca represent short-lived oxygenation events. High concentration of Ca hinders TOC enrichment, but elevated TOC values are still recorded in such zone. Specifically, for Ca concentrations $>20$ wt. $\%, 72 \%$ of samples record less than 4 wt. $\%$ of TOC and an average of 3.3 wt. \%. At Ca concentrations $<15 \%$, we find that $\mathrm{Ca}$ does not impact TOC enrichment, recoding an $\mathrm{r}^{2}=0.0$. 
3) The negative correlation observed between detrital proxy elements and TOC becomes uncorrelated at very high levels of TOC. Titanium, Th, Al, and $\mathrm{K}$ record an average $\mathrm{r}^{2}$ value with TOC of 0.3 . When restricted to TOC of $<8$ wt. $\%$ and $>8$ wt. $\%$, the average $\mathrm{r}^{2}$ value between $\mathrm{Ti}$, Th, $\mathrm{Al}$, and $\mathrm{K}$ and $\mathrm{TOC}$ is 0.16 and 0.0 , respectively. If the detrital proxy elements on average are depleted between -10- $-30 \%$ relative to AS, significant enrichment is observed (>9.8 wt. \%). Within this very organic rich group, samples most detrital depleted are not necessarily the most enriched in TOC.

4) Relative to AS, anoxia and productivity proxy elements for the Marcellus formation and Mahantango formation were moderately enriched to extremely enriched. Throughout the study interval, oxic conditions were absent during deposition. Anoxia and productivity proxy elements recorded the strong correlations with TOC. These proxy elements, unlike the detrital proxy elements, retain their positive correlation regardless of TOC values. Generally, the more enriched anoxic and productivity proxy elements are, the more enriched TOC will be as well. The strong relationship ( $\mathrm{r} 2>0.65)$ between anoxia and productivity proxy elements reinforce the "productivity - anoxia feedback" mechanism, which undoubtable played a significant role the extreme enrichment of TOC within the lower and middle Marcellus. 


\subsection{References Cited}

Algeo, T.J., 2004. Can marine anoxic events draw down the trace element inventory of seawater? Geology 32, 1057-1060.

Algeo, T.J., Maynard, J.B., 2004. Trace-element behavior and redox facies in core shales of Upper Pennsylvanian Kansas-type cyclothems. Chem. Geol. 206 (3-4), 289-318.

Arístegui, J., Agustí, S., Middelburg, J.J. and Duarte, C.M., 2005. Respiration in the mesopelagic and bathypelagic zones of the oceans. Respiration in Aquatic Ecosystems, 181.

Berner, R. A., 1980, Early diagenesis: a theoretical approach: Princeton, New Jersey, Princeton University Press, 241 p.

Blatt, H. Middleton, G. and Murray, R. (1972): Origin of sedimentary rocks. Englewood Cliffs, New Jersey, Prentice-Hall, 374 pp.

Boyce, M.L., Carr, T.R., 2010. Lithostratigraphy and petrophysics of the Devonian Marcellus interval in West Virginia and southwestern Pennsylvania. In: Carr, T.R., Rosen, N.C. (Eds.), Unconventional Resources: Making the Unconventional Conventional, Gulf Coast Section SEPM, Publication That is the Product of the 29th Bob F. Perkins Research Conference, December 6-8, 2009 in Houston, Texas, USA, pp. 254-281. 
Brumsack, H.J., 1989. Geochemistry of recent TOC-rich sediments from the Gulf of California and the Black Sea. Geol. Rundsch. 78, 851-882.

Brumsack, H.J., 2006. The trace metal content of recent organic carbon-rich sediments: implications for Cretaceous black shale formation. Palaeogeography, Palaeoclimatology, Palaeoecology, 232(2-4), pp.344-361.

Canfield, D.E., 1994. Factors influencing organic carbon preservation in marine sediments. Chem. Geol. 114, 315- 329.

Caplan, M.L., Bustin, R.M., 1999. Devonian-Carboniferous Hangenberg mass extinction event, widespread organic-rich mudrocks and anoxia: causes and consequences. Palaeogeogr. Palaeoclimatol. Palaeoecol. 149, 187-207.

Chen, R. and Sharma, S., 2016. Role of alternating redox conditions in the formation of organicrich interval in the Middle Devonian Marcellus Shale, Appalachian Basin, USA. Palaeogeography, palaeoclimatology, palaeoecology, 446, pp.85-97.

Conrey, R. (Ed.). (2018). Instrumentation. Retrieved February 13, 2019, from https://www.hamilton.edu/academics/analytical-lab/instrumentation

Costech Analytical Tecnologies Inc. (2005). Elemental Combustion System CHNS-O [Brochure]. Valencia, CA, USA 
Crump, B.C., Peranteau, C., Beckingham, B., and Cornwell, J.C. (2007) Respiratory succession and community succession of bacterioplankton in seasonally anoxic estuarine waters. Appl Environ Microbiol 73: 6802-6810.

Demaison, G.J., Moore, G.T., 1980. Anoxic environments and oil source bed genesis. Am. Assoc. Pet. Geol. Bull. 64, 1179- 1209.

Edwards, B.D., 1985. Bioturbation in a dysaerobic, bathyal basin: California borderland. In: Curran, H.A. (Ed.), Biogenic Structures: Their Use in Interpreting Depositional Environments.

Emerson, S.R., Huested, S.S., 1991. Ocean anoxia and the concentration of molybdenum and vanadium in seawater. Mar. Chem. 34, 177-196.

Erickson B. E. and Helz G. R. (2000) Molybdenum(VI) speciation in sulfidic waters: stability and lability of thiomolybdates. Geochim. Cosmochim. Acta 64, 1149-1158.

Flugel, E. and Flügel, E., 2004. Microfacies of carbonate rocks: analysis, interpretation and application. Springer Science \& Business Media.

François, R., 1988. A study on the regulation of the concentrations of some trace metals $(\mathrm{Rb}, \mathrm{Sr}$, $\mathrm{Zn}, \mathrm{Pb}, \mathrm{Cu}, \mathrm{V}, \mathrm{Cr}, \mathrm{Ni}, \mathrm{Mn}$ and $\mathrm{Mo}$ ) in Saanich Inlet sediments, British Columbia, Canada. Mar. Geol. 83, 285-308. 
Froelich, P. N., G. P. Klinkhammer, M. L. Bender, N. A. Luedtke, G. R. Heath, D. Cullen, P. Dauphin, D. Hammond, and B. Hartman, 1979, Early oxi-dation of organic matter in pelagic sediments of the eastern equatorial Atlantic: suboxic diagenesis: Geochimica et Cosmochimica Acta, v. 43, p. J075-1090.

Gamero-Diaz, H., Miller, C. and Lewis, R., 2012. sCore: A classification scheme for organic mudstones based on bulk mineralogy. AAPG Search and Discovery article, 40951.

Gamero-Diaz, H; Miller, C. and Richard Lewis, 2012, Core: A classification scheme for organic mudstones based on bulk mineralogy, Search and Discovery article \# 40951.

Gilleaudeau, G.J., R. Frei, A.J. Kaufman, L.C. Kah, K. Azmy, J.K. Bartley, P. Chernyavskiy, and A.H. Knoll. 2016. "Oxygenation of the Mid-Proterozoic Atmosphere: Clues from Chromium Isotopes in Carbonates.” Geochemical Perspectives Letters: 178-187. doi:10.7185/geochemlet.1618

Goldhaber, M. B., and I. R. Kaplan, 1974, The sulfur cycle, in E. D. Goldberg, ed., The sea, v. 5: New York, John Wiley, p. 569-655.

Hallberg, R.O., 1974. Paleoredox conditions in the eastern Gotland basin during the recent centuries. Merentutkimuslaitoksen Julk. Havsforskningsinst. Skr., 238: 3-16. 
Henrichs, S.M. and Reeburgh, W.S., 1987. Anaerobic mineralization of marine sediment organic matter: rates and the role of anaerobic processes in the oceanic carbon economy. Geomicrobiol. J., 5: 191-237.

Hetzel, A., Mearz, C., Vogt, C., Brumsack, H.-J., 2011. Geochemical environment of Cenomanian-Turonian black shale deposition at Wunstorf (northern Germany). Cretac. Res. 32, $480 \mathrm{e} 494$.

Hotinski, R.M., Bice, K.L., Kump, L.R., Najjar, R.G. and Arthur, M.A., 2001. Ocean stagnation and end-Permian anoxia. Geology, 29(1), pp.7-10.

Ingall, E.D., Bustin, R.M., Van Cappellen, P., 1993. Influence of water column anoxia on the burial and preservation of carbon and phosphorus in marine shales. Geochim. Cosmochim. Acta57, $303-316$

Ingri, J., Widerlund, A., Suteerasak, T., Bauer, S. and Elming, S.Å., 2014. Changes in trace metal sedimentation during freshening of a coastal basin. Marine Chemistry, 167, pp.2-12.

James, N.P. and Jones, B., 2015. Origin of carbonate rocks. John Wiley \& Sons.

Johnson, J.G., Sandberg, C.A., 1988. Devonian eustatic events in the western United States and their biostratigraphic responses. In: McMillan, N.J., Embry, A.F., Glass, D.J. (Eds.), Devonian of the World, III: Calgary, Alberta. Canadian Society of Petroleum Geologists, Memoir, vol. 14, pp. $171-178$. 
Jones, B. and Manning, D.A., 1994. Comparison of geochemical indices used for the interpretation of palaeoredox conditions in ancient mudstones. Chemical geology, 111(1-4), pp.111-129.

Klump, J., Hebbeln, D., Wefer, G., 2000. The impact of sediment provenance on barium-based productivity estimates. Marine Geology 169, 259-271.

Lash, G.G., Blood, D.R., 2014. Organic matter accumulation, redox, and diagenetic history of the Marcellus formation, southwestern Pennsylvania, Appalachian basin. Mar. Pet. Geol. 57, 244263.

Lash, G.G., Engelder, T., 2011. Thickness trends and sequence stratigraphy of the Middle Devonian Marcellus formation, Appalachian Basin: implications for Acadian foreland basin evolution. Am. Assoc. Pet. Geol. Bull. 95, 61-103

Likuku, A.S., Mmolawa, K.B. and Gaboutloeloe, G.K., 2013. Assessment of heavy metal enrichment and degree of contamination around the copper-nickel mine in the Selebi Phikwe Region, Eastern Botswana. Environment and Ecology Research, 1(2), pp.32-40.

Likuku, A.S., Mmolawa, K.B. and Gaboutloeloe, G.K., 2013. Assessment of heavy metal enrichment and degree of contamination around the copper-nickel mine in the Selebi Phikwe Region, Eastern Botswana. Environment and Ecology Research, 1(2), pp.32-40. 
Luo, Q., Zhong, N., Zhu, L., Wang, Y., Qin, J., Qi, L., Zhang, Y. and Ma, Y., 2013. Correlation of burial organic carbon and paleoproductivity in the Mesoproterozoic Hongshuizhuang Formation, northern North China. Chinese Science Bulletin, 58(11), pp.1299-1309.

Martin, K., Carr, T., Developing a quantitative regression-based mudrock calibration for a handheld energy dispersive X-ray fluorescence spectrometer, under review.

Mackin, J.E., Aller, R.C., 1984. Diagenesis of dissolved aluminum in organic-rich estuarine sediments. Geochimica et Cosmochimica Acta 48, 299-313.

Meyers, S.R., Sageman, B.B., Lyons, T.W., 2005. Organic carbon burial rate and the molybdenum proxy: theoretical framework and application to Cenomanian-Turonian oceanic event 2. Paleoceanography 20, PA2002. doi:10.1029/2004PA001068.

Moore, G. T., 1975, Relationship between biologic productivity in the ocean and accumulation of organic material, Chevron Oil Field Research Company Technical Memorandum No. TM 75000744.

Murray, R.W., Leinen, M., 1996. Scavenged excess aluminum and its relationship to bulk titanium in biogenic sediment from the central equatorial Pacific Ocean. Geochimica et Cosmochimica Acta $60,3869-3878$. 
Okita, P.M., Shanks, W.C., 1992. Origin of stratiform sedimenthosted manganese carbonate ore deposits: examples from Molango, Mexico, and TaoJiang, China. Chem. Geol. 99, 139 - 163.

Pearce, T.J. and Jarvis, I., 1992. Applications of geochemical data to modelling sediment dispersal patterns in distal turbidites: Late Quaternary of the Madeira Abyssal Plain: Journal of Sedimentary Petrology, 62, p. 1112-1129.

Pearce, T.J., Besly, B.M., Wray, D.S., Wright, D.K. (1999) Chemostratigraphy: a method to improve interwell correlation in barren sequences - a case study using onshore Duckmantian/Stephanian sequences (West Midlands, U.K.): Sedimentary Geology, 124, p. 197220.

Pedersen, T.F., Calvert, S.E., 1990. Anoxia vs productivity; what controls the formation of organic-carbon-rich sediments and sedimentary rocks? AAPG Bull. 74 (4), 454-466.

Pedersen, T.F., Calvert, S.E., 1990. Anoxia vs. productivity: what controls the formation of organic- carbon-rich sediments and sedimentary rocks? Am. Assoc. Pet. Geol. Bull. 74, 454e466.

Perkins R. B., Piper D. Z. and Mason C. E., 2008. Trace-element budgets in the Ohio/Sunbury shales of Kentucky: constraints on ocean circulation and primary productivity in the Devonian Mississippian Appalachian Basin. Palaeogeogr. Palaeoclimatol.Palaeoecol. 265, 14-29. 
Pilipchuk, M.F. and Volkov, I.I., 1974. Behavior of molybdenum in processes of sediment formation and diagenesis in Black Sea: geochemistry.

Pilipchuk, M.F. and Volkov, I.I., 1974. Behavior of molybdenum in processes of sediment formation and diagenesis. In: E.T. Degens and D.A. Ross (Editors), The Black Sea: Geology, Chemistry and Biology. Am. Assoc. Petrol. Geol. Mem., 20: 542-552.

Piper, D.Z., Calvert, S.E., 2009. A marine biogeochemical perspective on black shale deposition. Earth-Sci. Rev. 95, 63e96.

Remeikaitè-Nikienė, N., Garnaga-Budrè, G., Lujanienė, G., Jokšas, K., Stankevičius, A., Malejevas, V. and Barisevičiūtè, R., 2018. Distribution of metals and extent of contamination in sediments from the south-eastern Baltic Sea (Lithuanian zone). Oceanologia, 60(2), pp.193-206.

Rimmer, S.M., 2004. Geochemical paleoredox indicators in Devonian- Mississippian black shales, Central Appalachian Basin (USA). Chem. Geol. 206, 373-391.

Santos-Echeandía, J. Prego, R. and Cobelo-García, A., 2005. Copper, nickel, and vanadium in the Western Galician Shelf in early spring after the Prestige catastrophe: is there seawater contamination? Analytical and Bioanalytical Chemistry 382, 360-365.

Sarmiento, J.L. and Gruber, N., 2006. Ocean biogeochemical dynamics. Princeton University Press. 
Schieber, J., 1999. Distribution and deposition of mudstone facies in the Upper Devonian Sonyea Group of New York. J. Sediment. Res. 69, 909-925.

Schieber, J., Krinsley, D., Riciputi, L., 2000. Diagenetic origin of quartz silt in mudstones and implications for silica cycling. Nature 406, 981-985.

Scott C. and Lyons T. W., 2012. Contrasting molybdenum cycling and isotopic properties in euxinic versus non-euxinic sediments and sedimentary rocks: refining the paleoproxies. Chem. Geol. 324-325, 19-27.

Shaw, T.J., Gieskes, J.M. and Jahnke, R.A., 1990. Early diagenesis in differing depositional environments: The response of transition metals in pure water. Geochim. Cosmochim. Acta, 54: 1233-1246.

Stein, R., 1986. Surface-water paleo-productivity as inferred from sediments deposited in oxic and anoxic deep water. SCOPE/UNEP Sonderband, 60:55-70.

Sunda, W.G. Barber, R.T. and Huntsman, S.A., 1981. Phytoplankton growth in nutrient rich seawater-importance of copper-manganese cellular interactions. Journal of Marine Research 39, $567-586$.

Templ, M., Filzmoser, P. and Reimann, C., 2008. Cluster analysis applied to regional geochemical data: problems and possibilities. Applied Geochemistry, 23(8), pp.2198-2213. 
Tribovillard, N., Algeo, T.J., Lyons, T. and Riboulleau, A., 2006. Trace metals as paleoredox and aleoproductivity proxies: an update. Chemical geology, 232(1-2), pp.12-32.

Turekian, K.K. and Wedepohl, K.H., 1961. Distribution of the elements in some major units of the earth's crust. Geological Society of America Bulletin, 72(2), pp.175-192.

Turner, B.W., Tréanton, J.A. and Slatt, R.M., 2016. The use of chemostratigraphy to refine ambiguous sequence stratigraphic correlations in marine mudrocks. An example from the Woodford Shale, Oklahoma, USA. Journal of the Geological Society, 173(5), pp.854-868.

Van der Weijden, C.H., 2002. Pitfalls of normalization of marine geochemical data using a common divisor. Marine Geology, 184(3-4), pp.167-187.

Van der Weijden, C.H., 2002. Pitfalls of normalization of marine geochemical data using a common divisor. Marine Geology, 184(3-4), pp.167-187.

Ver Straeten, C.A., Brett, C.E., 1995. Lower and Middle Devonian foreland basin fill in the Catskill Front: stratigraphic synthesis, sequence stratigraphy, and the Acadian Orogeny. In: Garver, J.I., Smith, J.A. (Eds.), New York State Geological Association, 67th Annual Meeting Field Trip Guidebook, pp. 313-356.

Ward, J.H.,1963. Hierarchical grouping to optimize an objective function: Journal of the American Statistical Association, 69, p. 236-244. 
Wedepohl, K.H., 1971. Environmental influences on the chemical composition of shales and clays. In: Ahrens, L.H., Press, F., Runcorn, S.K., Urey, H.C. (Eds.), Physics and Chemistry of the Earth, vol. 8. Pergamon, Oxford, pp. 305-333.

Werne, J.P., Sageman, B.B., Lyons, T.W., Hollander, D.J., 2002. An integrated assessment of a "type euxinic" deposit: evidence for multiple controls on black shale deposition in the middle Devonian Oatka Creek formation. Am. J. Sci. 302 (2), 110-143.

Whitfield, M., 2002. Interactions between phytoplankton and trace metals in the ocean. Adv. Mar. Biol. 41, 3-120.

Yarincik, K.M., Murray, R.W., Peterson, L.C., 2000. Climatically sensitive eolian and hemipelagic deposition in the Cariaco Basin, Venezuela, over the past 578,000 years: results from Al/Ti and K/Al. Paleoceanography 15 (2), 210-228.

Zabel, M., Schneider, R.R., Wagner, T., Adegbie, A.T., de Vries, U., Kolonic, S., 2001. Late Quaternary climate changes in Central Africa as inferred from terrigenous input to the Niger Fan. Quaternary Research 56 (2), 207-217. 


\section{Appendix}

The following graphics are normalized elemental profiles for each study well. The color code represents proxy elements groups; $\tan =$ detrital proxy elements, blue $=$ carbonate proxy elements, pink $=$ productivity proxy elements, purple $=$ anoxia proxy elements, and green $=$ chalcophile proxy elements. For each log section, TOC (black line) is displayed for purposes of comparison. 


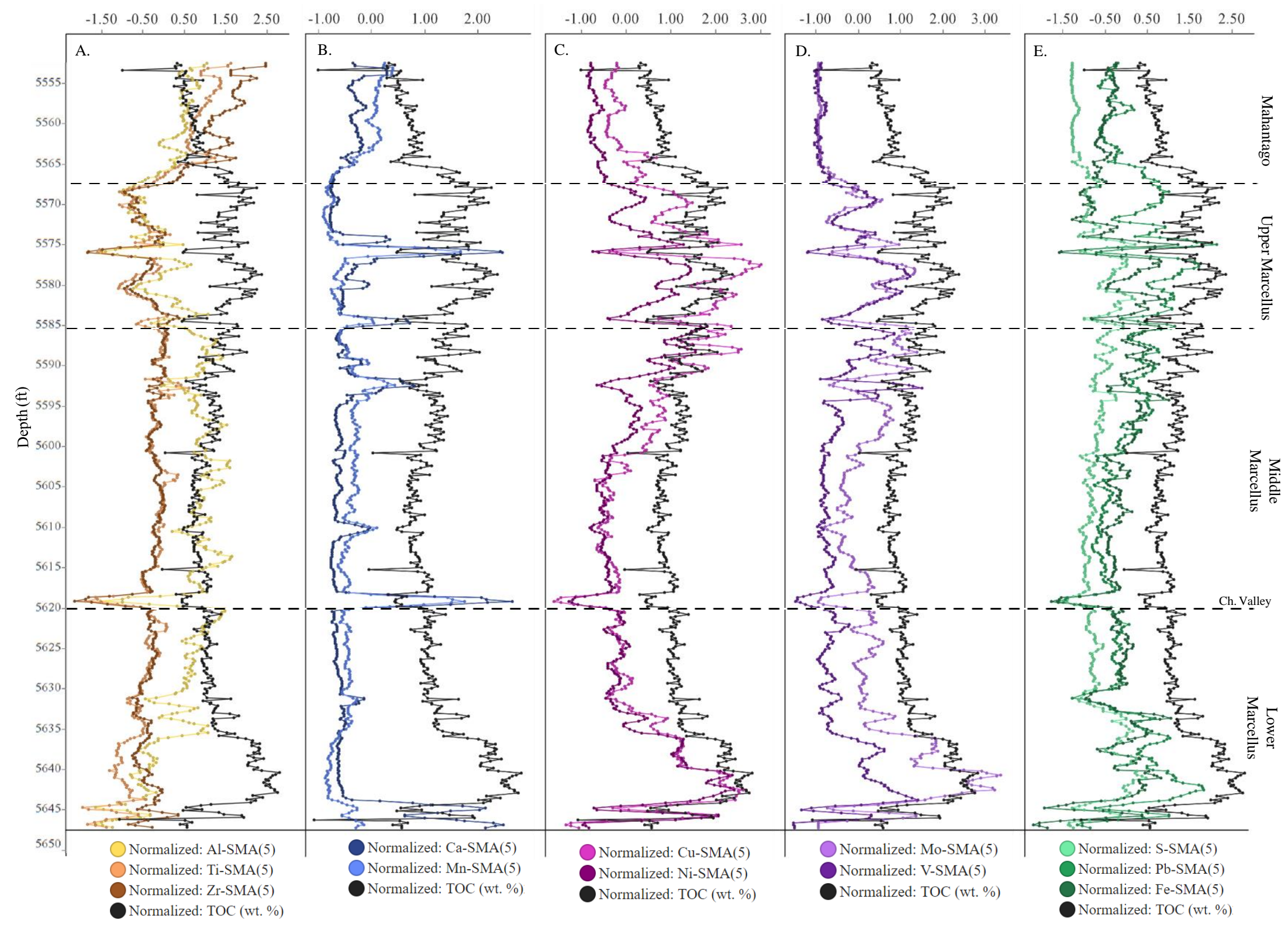

Figure 5-1. Elemental profiles of study well TP1. 


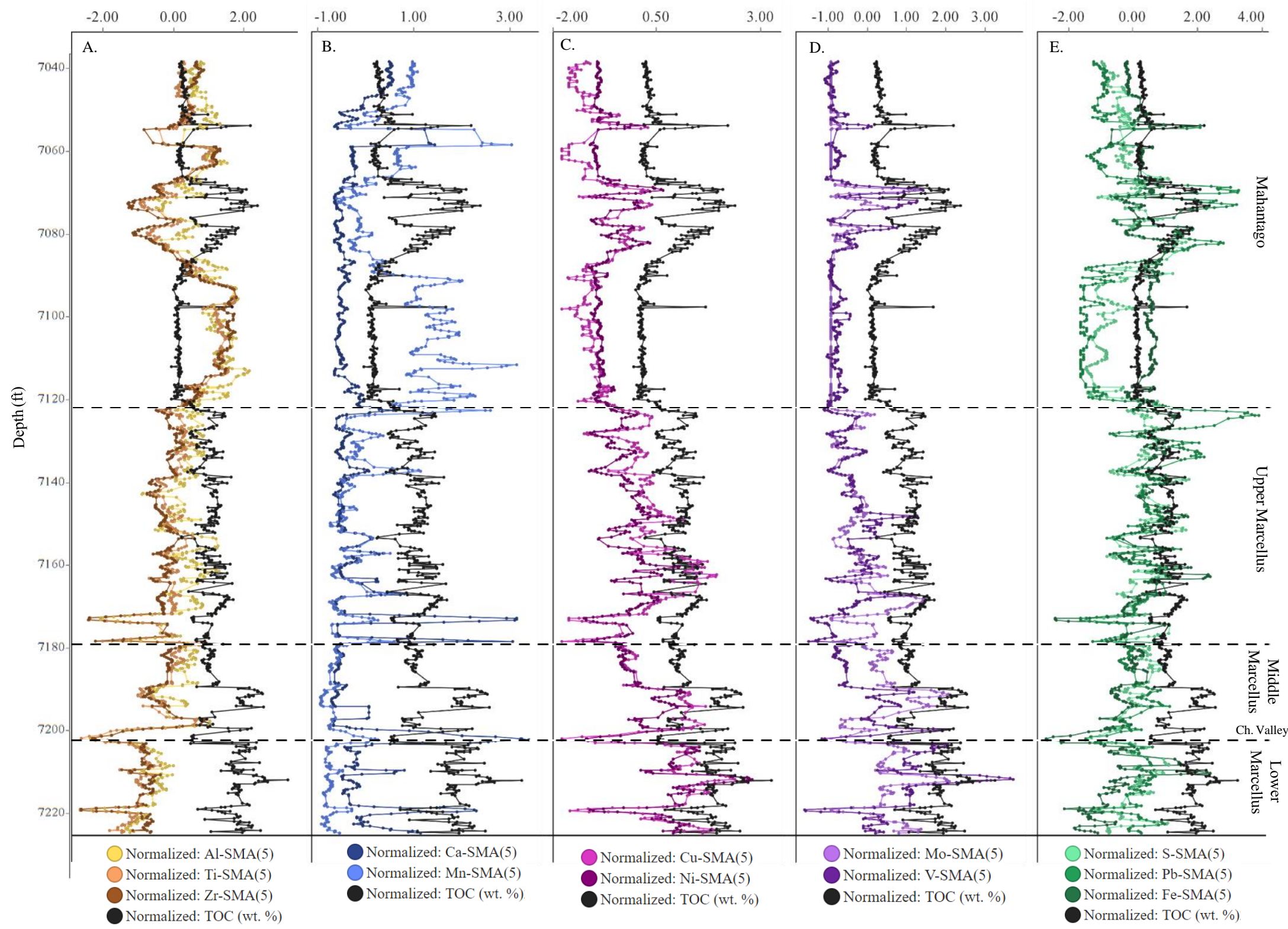

Figure 5-2. Elemental profiles of study well GF2. 


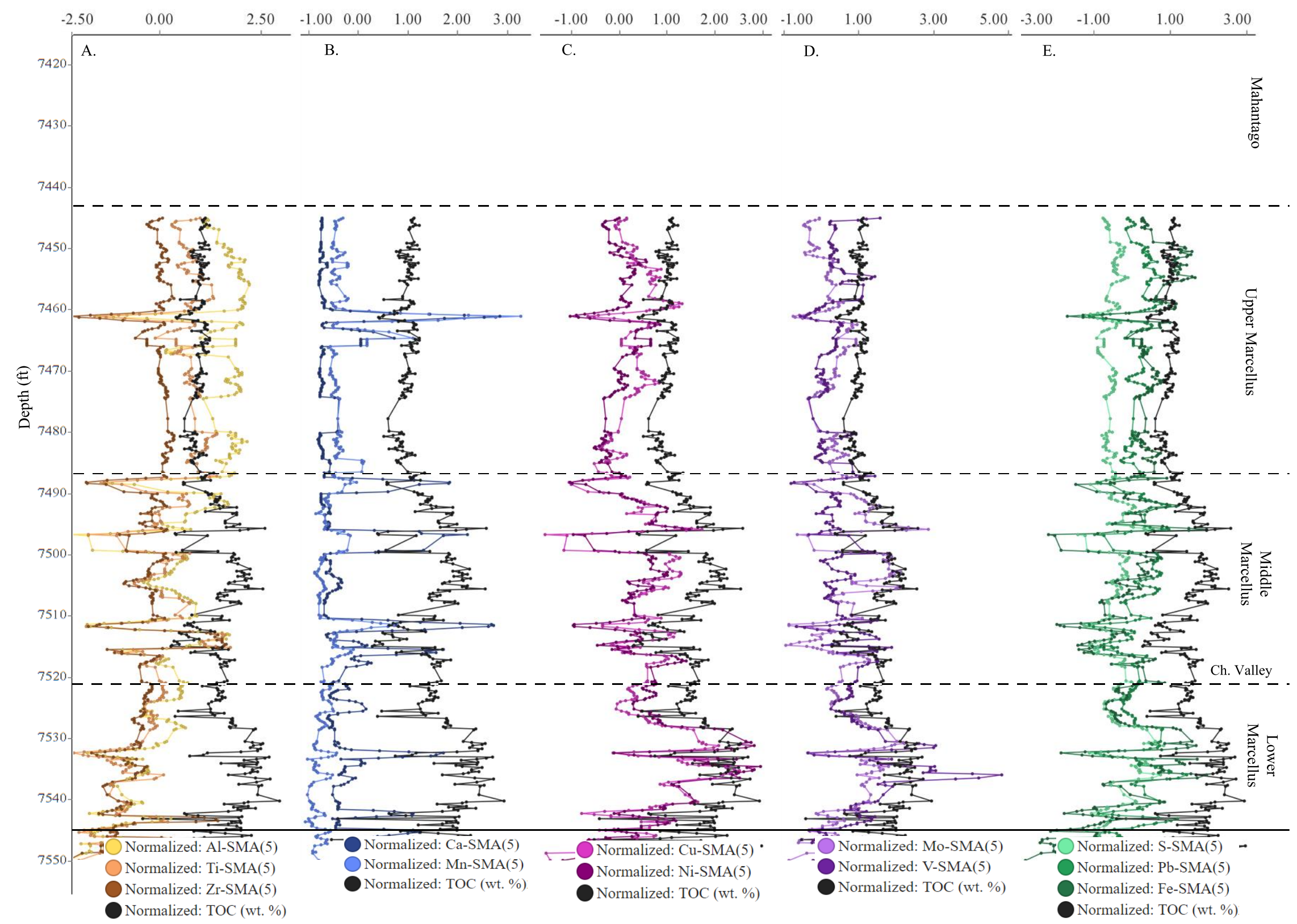

Figure 5-3. Elemental profiles of study well DN3. 


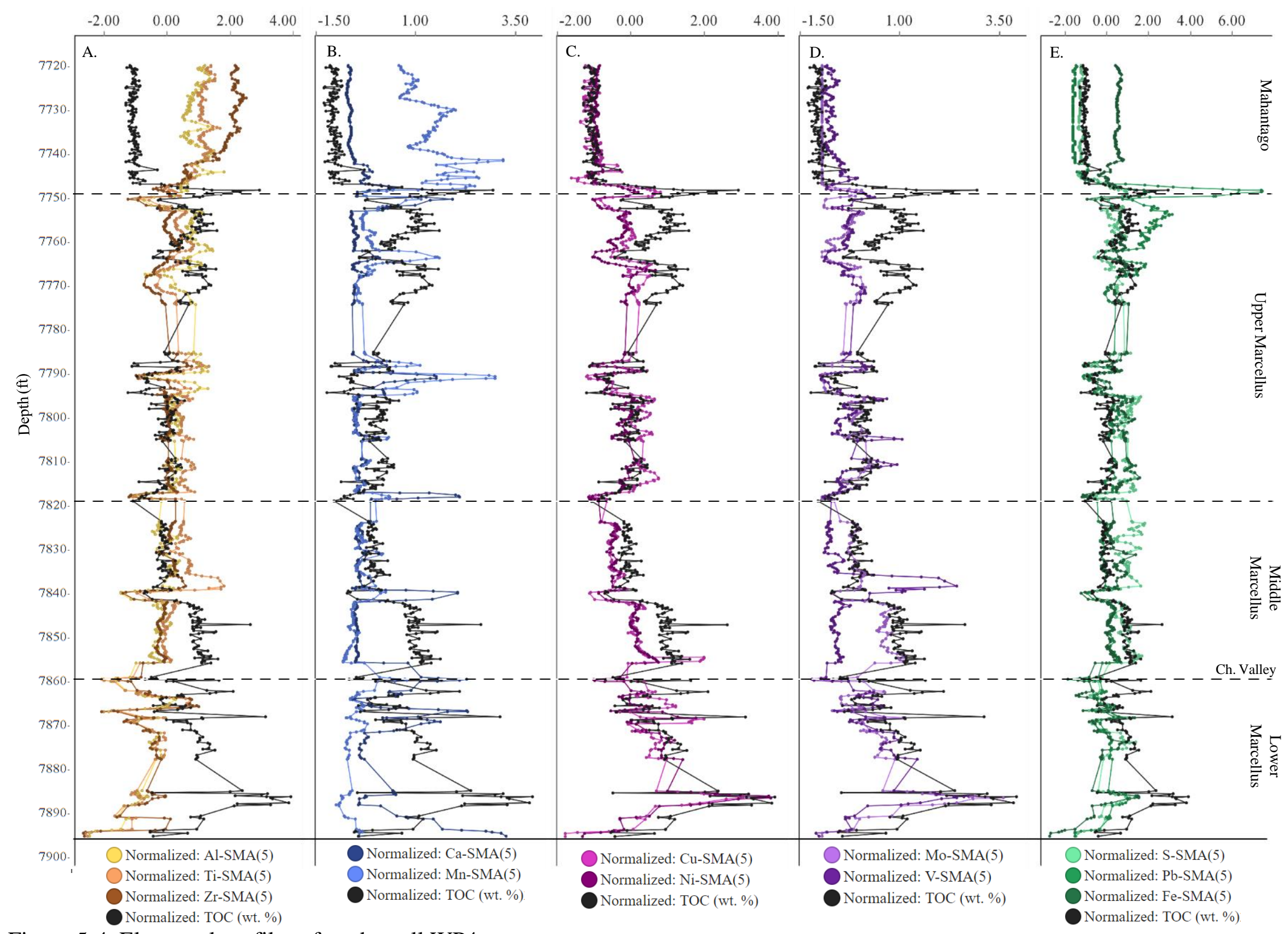

Figure 5-4. Elemental profiles of study well WP4. 


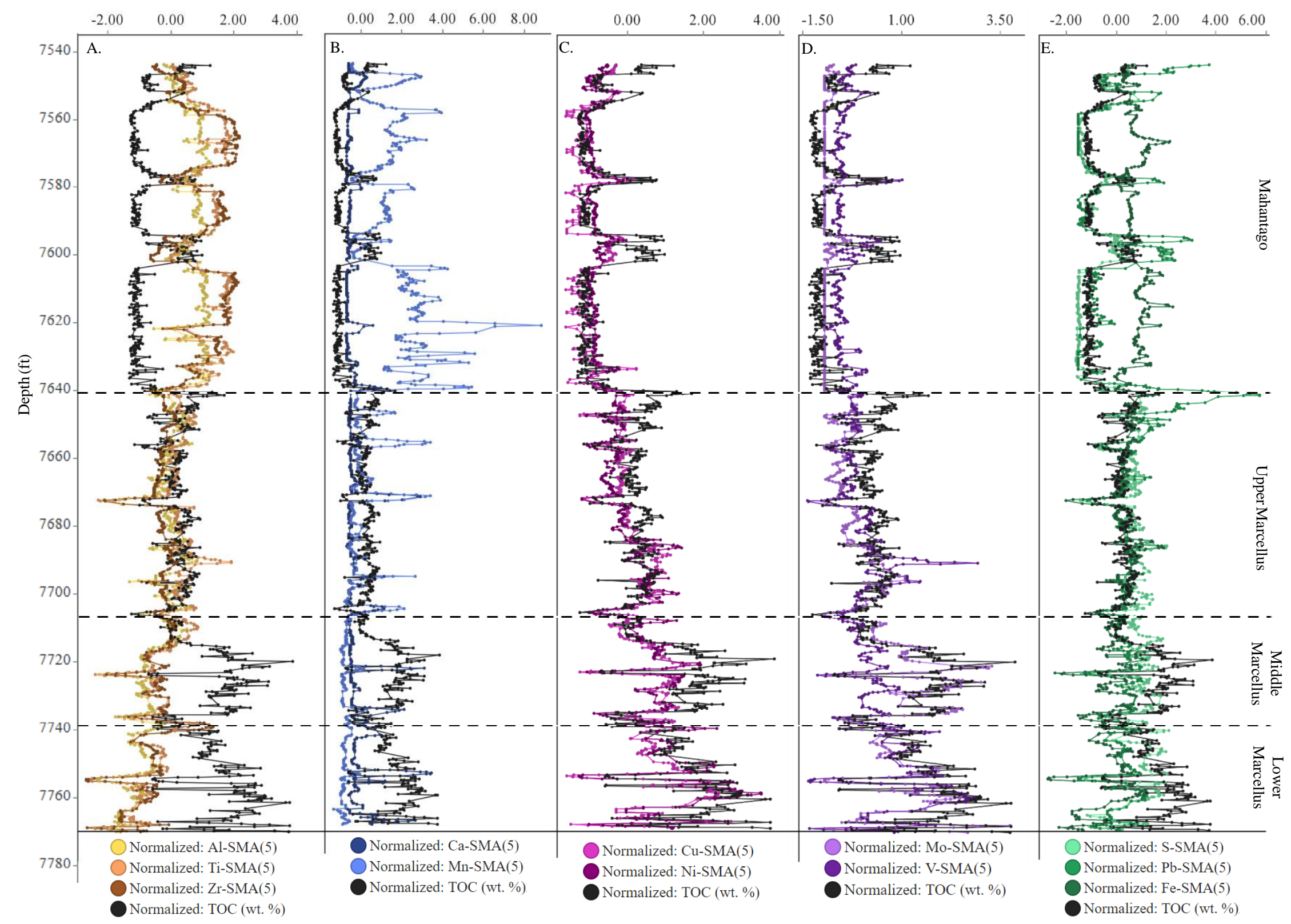

Figure 5-5. Elemental profiles of study well AM5. 


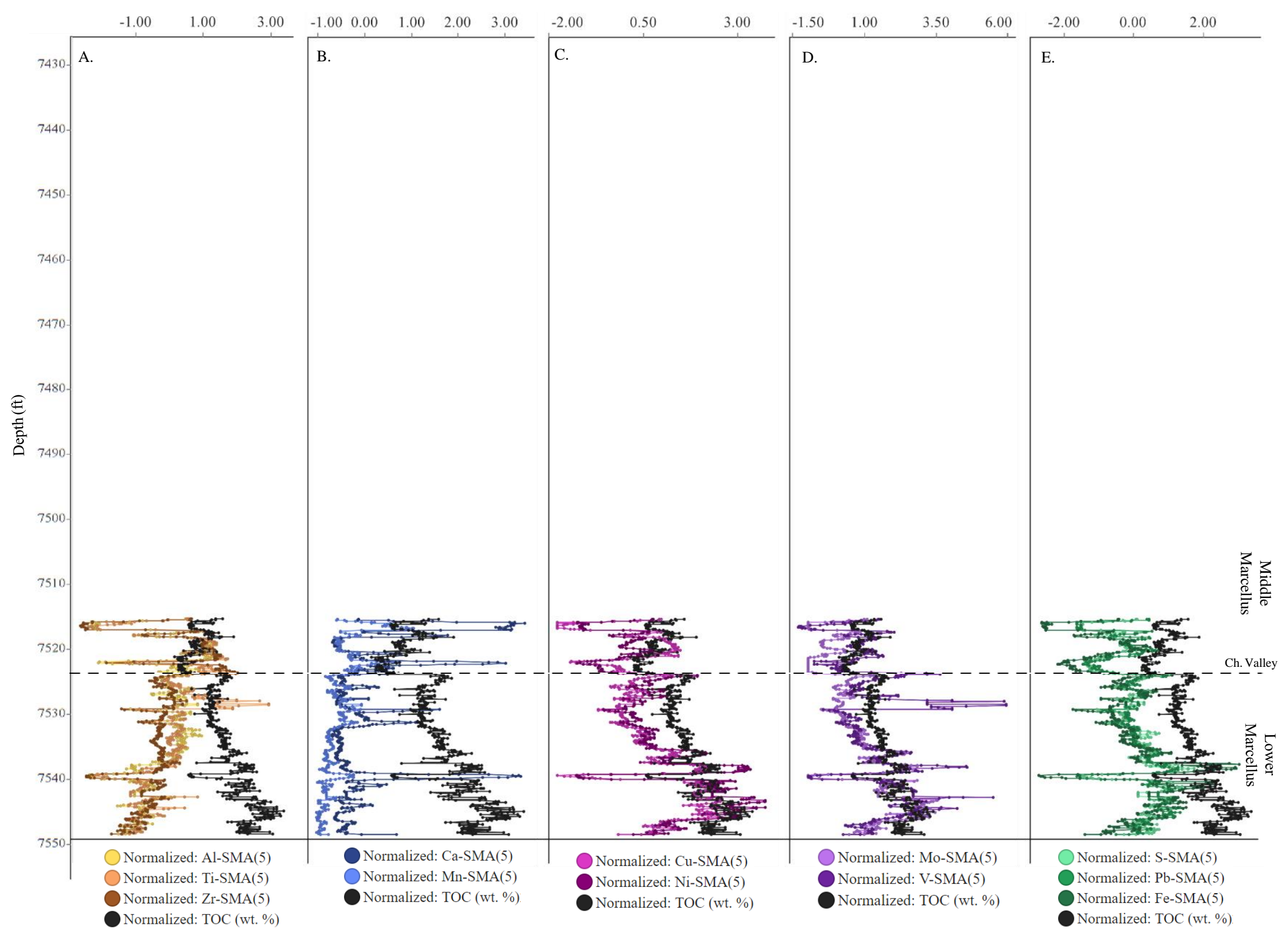

Figure 5-6. Elemental profiles of study well MP6. 


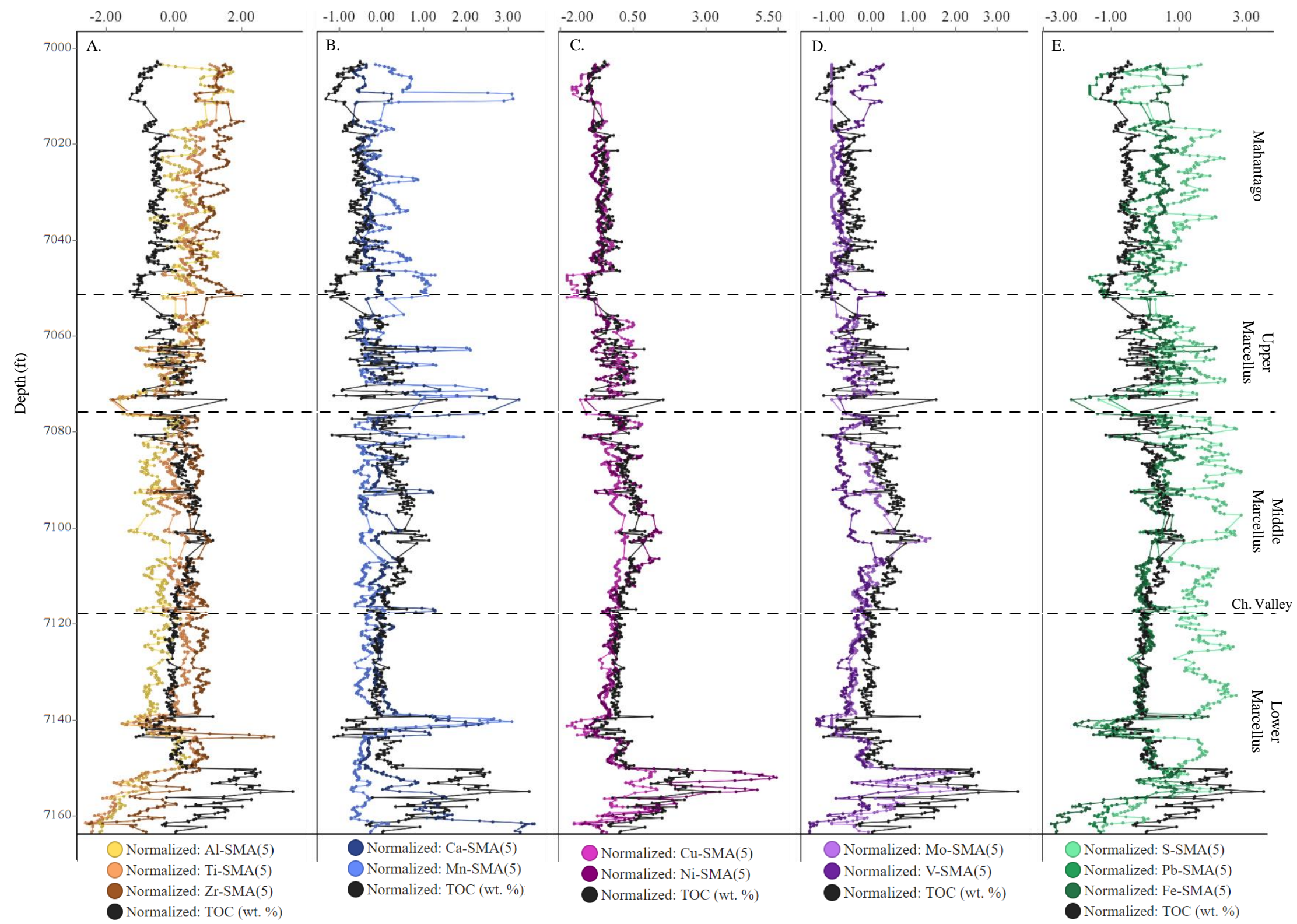

Figure 5-7. Elemental profiles of study well CS7. 


\subsection{Stratigraphic Framework}

The high resolution hhEDXRF dataset is utilized to reinforce elemental relationships discovered from the hierarchical cluster analysis of TOC, measured by EA, and elemental data, measured by WDXRF, as well as contextualize such relationships within a stratigraphic framework. An additional HCA was completed on the hhEDXRF and modelled TOC data, and ultimately 13 clusters were defined. The 13 clusters fit into the chemofacies defined within the HCA conducted on the WDXRF dataset, which are; Detrital Enriched Chemofacies, Slightly Enriched Detrital Che mofacies, Enriched Anoxia and Productivity, Extremely Elevated Productivity, Extremely Enriched Anoxia and Productivity, S Enriched, and Extremely Carbonate Enriched. Enrichment/depletion cross tables, relative to both SPM and AS, are displayed in figure 4-14 and figure 4-15. Chemofacies are plotted against depth within each well to assess relationships in a high-resolution stratigraphic framework. 


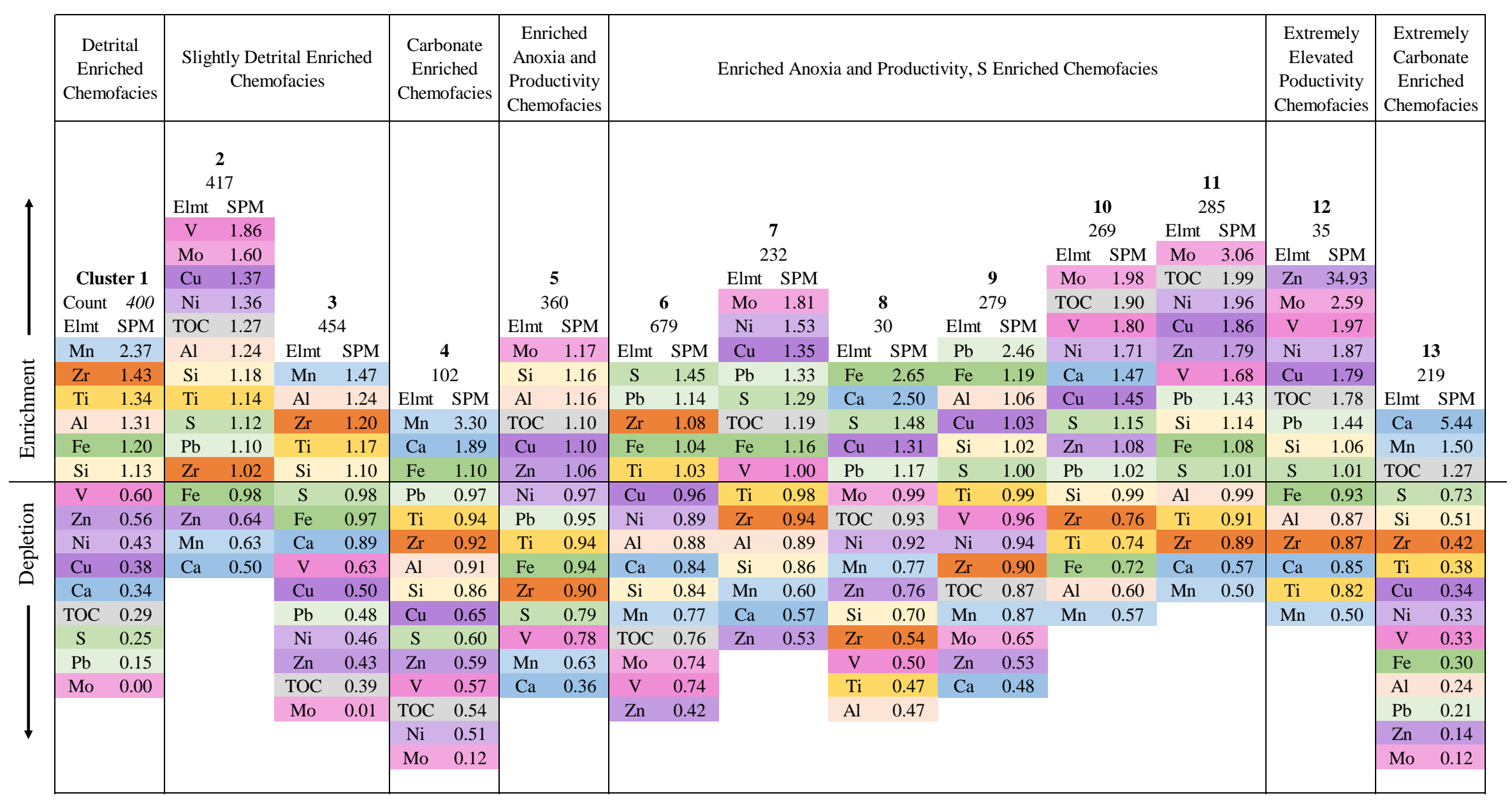

Figure 5-8: Table displaying the relative enrichment/depletion (SPM) of elements per cluster for the hhEDXRF dataset. Values greater than one represent an enrichment and are marked by the black horizontal line. 


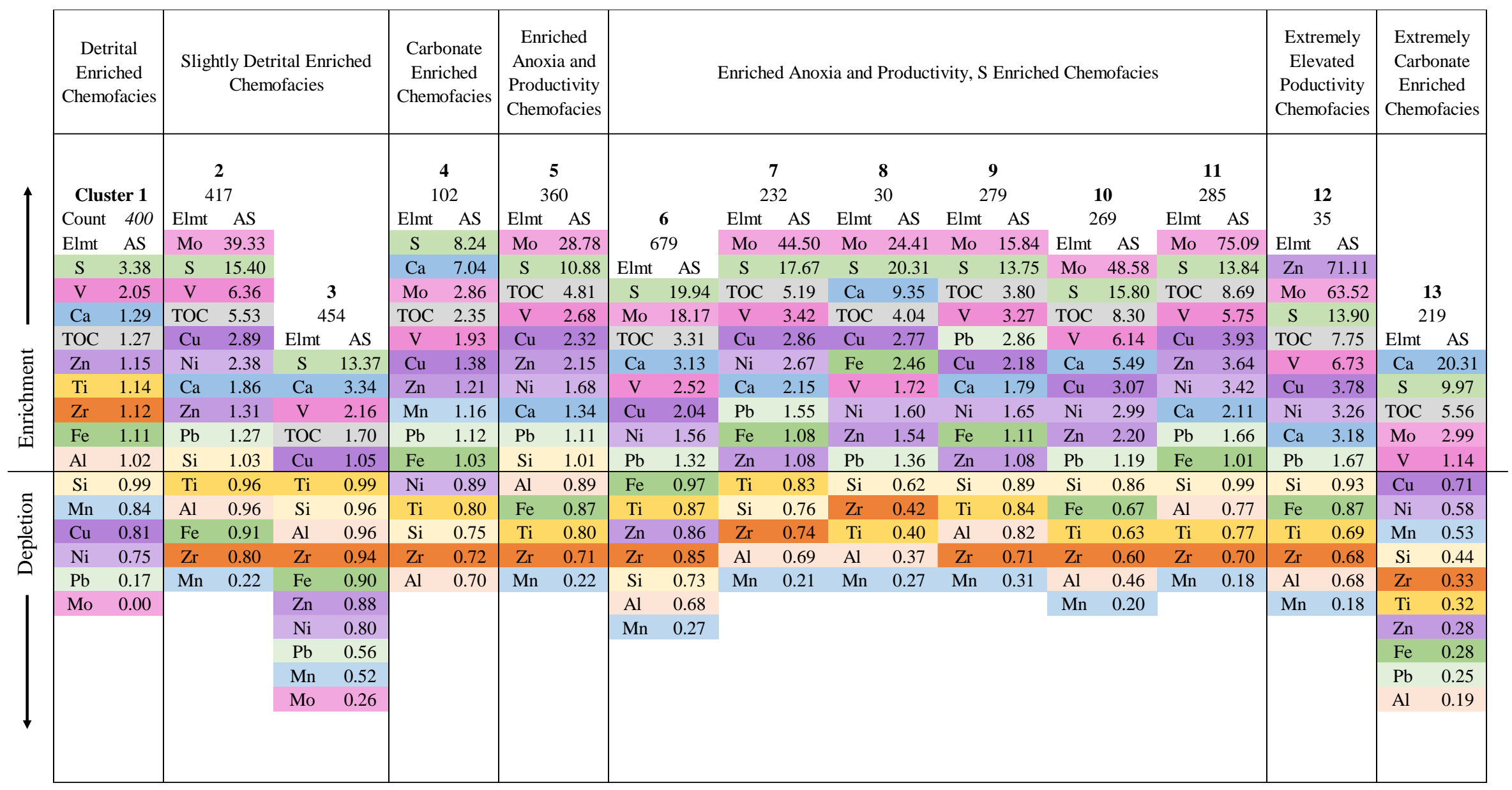

Figure 5-9: Table displaying the relative enrichment/depletion (SPM) of elements per cluster for the hhEDXRF dataset. Values greater than one represent an enrichment and are marked by the black horizontal line. 


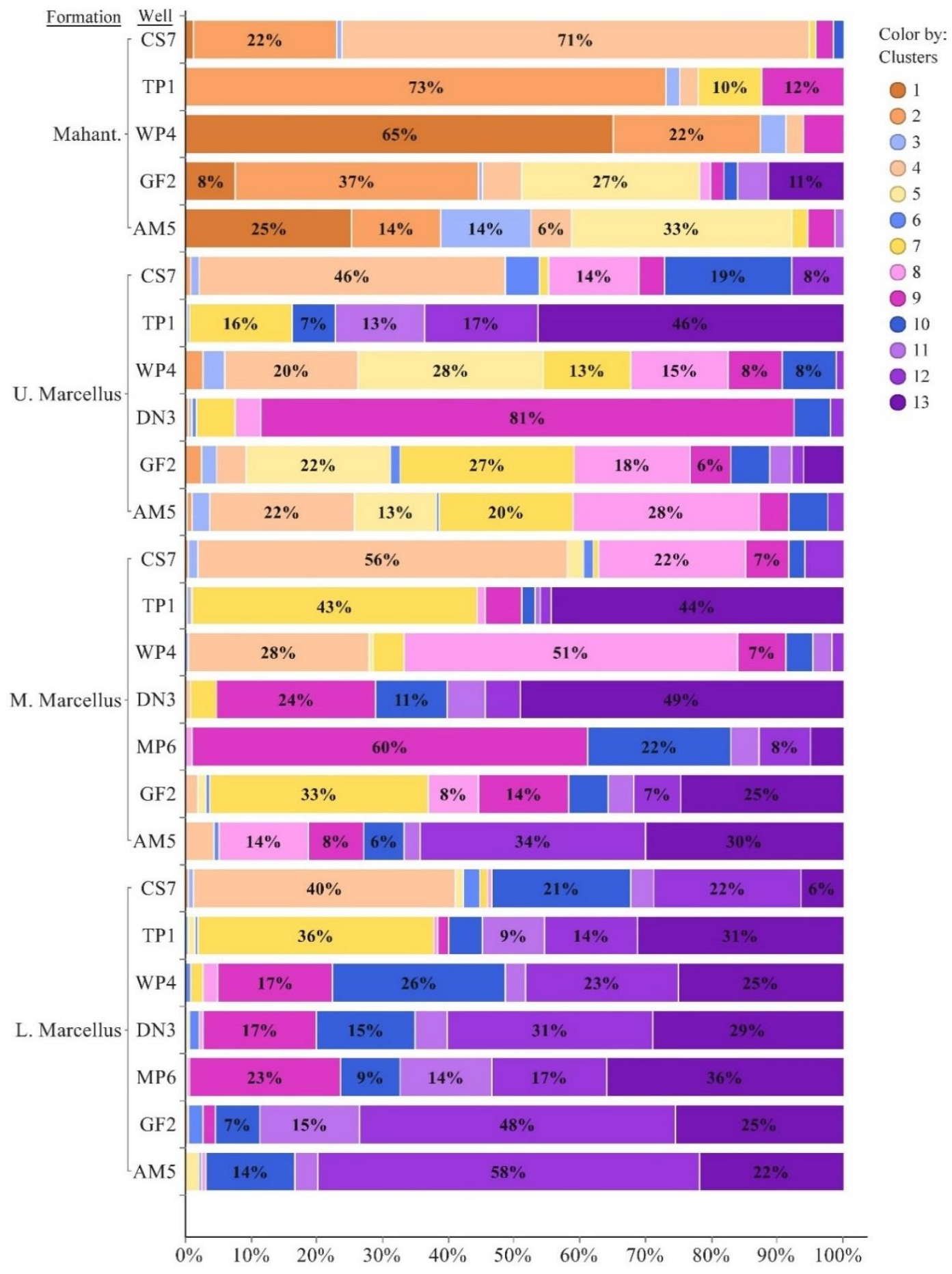

Figure 5-10: 100\% stack bars displaying the percent each cluster makes up within the study intervals for each respective study well. Color-coding; orange/yellow $=$ enriched detrital proxy elements, blue=enriched carbonate proxy elements, pink $=$ enriched anoxia proxy elements, purple $=$ enriched productivity proxy elements. 


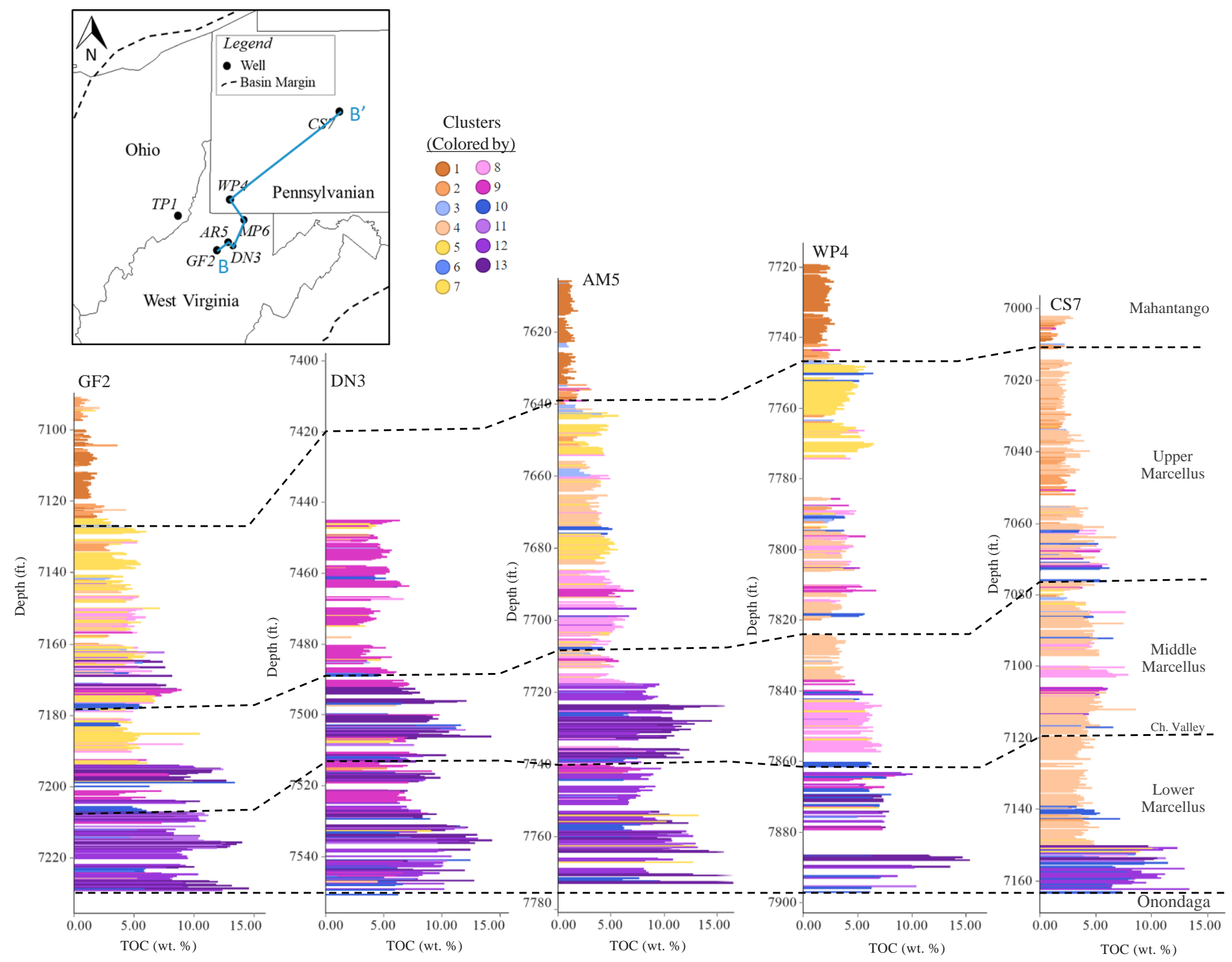

Figure 5-11: Northwest-southeast cross section of study wells GF2, DN3, AM5, WP4, and CS7 displaying cluster presence per depth. 


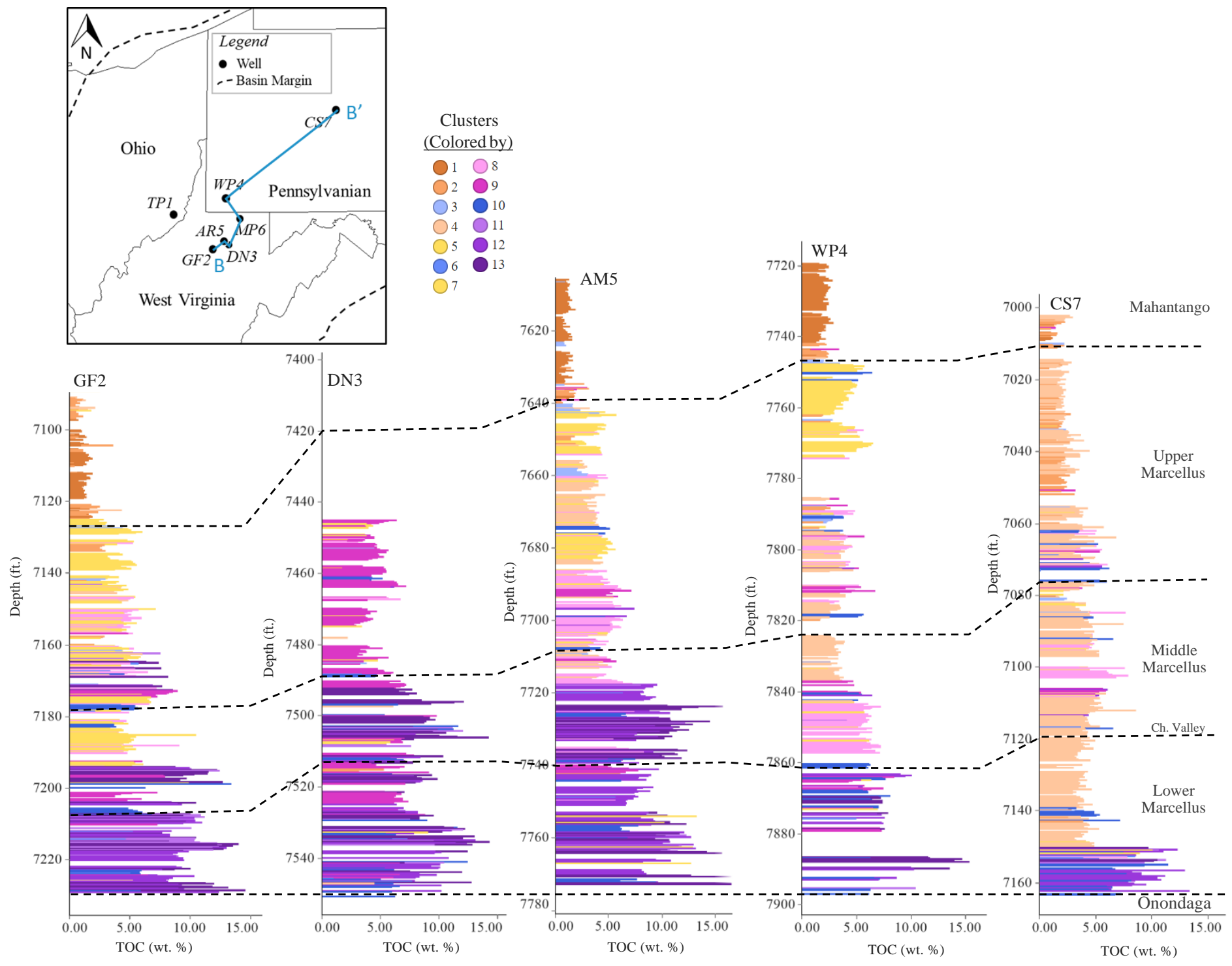

Figure 5-12: East-west cross section of study wells TP1, WP4, and MP6. Color-coding; orange/yellow = enriched detrital proxy elements, blue=enriched carbonate proxy elements, pink = enriched anoxia proxy elements, purple = enriched productivity proxy elements. Display cluster presence per depth. 